\title{
IONIC ALKALI HALIDE XUV LASER FEASIBILITY STUDY
}

\author{
FINAL REPORT \\ 29 SEPTEMBER 1987 through 10 NOVEMBER 1989
}

(This Document is Unclassified)

\author{
Date: 10 NOVEMBER 1989 \\ Contract: DE-AC03-87SF17121 \\ CDRL 11 \\ Prepared for \\ U. S. Department of Energy \\ San Francisco Operations Office
}

Prepared by:

T. T. Yang, V. T. Gylys, R. D. Bower, D. G. Harris

J. A. Blauer, C. E. Turner, R. N. Hindy

\author{
Rockwell International \\ Rocketdyne Division \\ 6633 Canoga Avenue \\ Canoga Park, California $9 / 303$
}

\section{DISCLAIMER}

\begin{abstract}
This report was prepared as an account of work sponsored by an agency of the United States Government. Neither the United States Government nor any agency thereof, nor any of their employees, makes any warranty, express or implied, or assumes any legal liability or responsibility for the accuracy, completeness, or usefulness of any information, apparatus, product, or process disclosed, or represents that its use would not infringe privately owned rights. Reference herein to any specific commercial product, process, or service by trade name, trademark, manufacturer, or otherwise does not necessarily constitute or imply its endorsement, recommendation, or favoring by the United States Government or any agency thereof. The views and opinions of authors expressed herein do not necessarily state or reflect those of the United States Government or any agency thereof.
\end{abstract}




\section{NOTICE}

This report was prepared as an account of work sponsored by an agency of the United States Government. Neither the United States nor any agency thereof, nor any of their employees, makes any legal warranty, expressed or implied, or assumes any liability or responsibility for any third party's use of the results or such use of any information, apparatus, product, or process disclosed in this report, or represents that its use by such third party would not infringe privately owned rights.

This report has been reproduced directly from the best available copy.

Available from the National Technical Information Service, U. S. Department of Commerce, Springfield, Virginia 22161 
TABIE OF CONTENTS

Page

1.0 Project Summary. .................... 1

1.1 Prcject Objectives .................. 1

1.2 Concept Description .................. 1

1.3 Accomplishments ................. 2

1.4 Future VUV/XUV Laser Research . . . . . . . . . 3

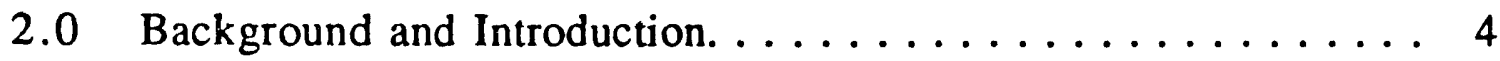

3.0 Experimental Method $\ldots \ldots \ldots \ldots \ldots \ldots \ldots \ldots \ldots \ldots$

$3.1 \quad$ Laser Plasma Facility $\ldots \ldots \ldots \ldots \ldots \ldots \ldots \ldots 11$

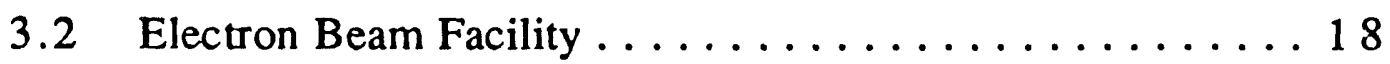

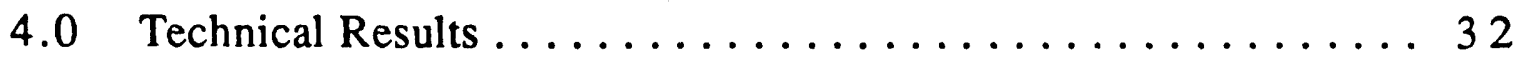

4.1 Reference Plasma Check ............... 33

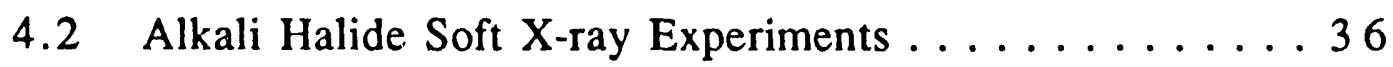

4.2.1 Soft X-ray Excitation of $\mathrm{RbF} \ldots \ldots \ldots \ldots \ldots$

4.2.2 Soft X-ray Excitation of $\mathrm{RbBr} \ldots \ldots \ldots \ldots \ldots 1$ 
4.3 Alkali Halide Electron Beam Experiments . . . . . . 54

4.3.1 Electron-beam Excited Helium . . . . . . . . 54

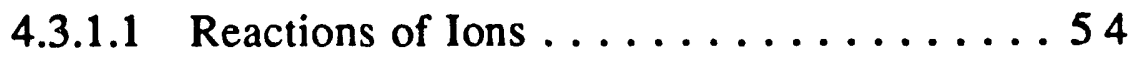

4.3.1.2 Reactions of Metastables ....... 55

4.3.2 Electron-beam Excitation of $\mathrm{CsF} \ldots \ldots \ldots \ldots 7$

4.3.3 Electron-beam Excitation of RbF ....... 69

4.3.4 Electron-beam Excitation of Three Component

Mixtures.................. 70

5.0 Future VUV/XUV Laser Research Recommendations . . . . 76

5.1 Ionic Rare-gas Alkaline Excimers . . . . . . 76

5.2 XUV Lasers by Quartet to Doublet Energy Transfer in Alkali Atoms . ................... 80

6.0 References $\ldots \ldots \ldots \ldots \ldots \ldots \ldots \ldots \ldots \ldots \ldots \ldots$

7.0 Distribution List $\ldots \ldots \ldots \ldots \ldots \ldots \ldots \ldots \ldots \ldots \ldots \ldots$ 


\subsection{Project Summary}

\subsection{Project Objectives}

The objective of this work is to assess the feasibility of a select set of ionic alkali halide XUV (extreme-ultraviolet) laser concepts by obtaining the relevant kinetic and spectroscopic parameters required for a proof-of-principle and conceptual design. The proposed lasers operate in the $80-200 \mathrm{~nm}$ spectral region and do not require input from outside radiation sources for their operation. Frequency upconversion and frequency mixing techniques are therefore not considered in the work to be described.

An efficient XUV laser will have many applications including microelectronics, laser chemistry, laser materials processing, plasma diagnostics, medicine, and communications. One program in particular which requires an XUV source is the Discrimination by Electrons with Laser Photo Ionization (DELPHI) Program at Sandia National Laboratory. A short wavelength laser is required to photoionize oxygen atoms in the upper atmospher creating a channel of ions. The channel then guides an electron beam.

\subsection{Concept Description}

An experimental and theoretical study of a new type of laser operating in the extreme ultraviolet wavelength region has been conducted. The lasing species are singly ionized alkali halide molecules such as $\mathrm{Rb}^{2}+\mathrm{F}^{-}, \mathrm{Rb}^{2}+\mathrm{Br}^{-}$and $\mathrm{Cs}^{2}+\mathrm{F}^{-}$. These species are similar in electronic structure to the rare gas halide excimers, such as $\mathrm{XeF}$ and $\mathrm{KrF}$, except that the ionic molecules emit at wavelengths of $80-200 \mathrm{~nm}$, much shorter than the conventional rare-gas halide excimer lasers. The radiative lifetime of these molecules are typically near $1 \mathrm{~ns}$, which is about an order of magnitude shorter than that for rare-gas halide systems. The values of the cross section for stimulated emission are on the order of $1 \times 10^{-16} \mathrm{~cm}^{2}$. Because of the fundamental similarity to existing UV lasers, these systems show promise as a high power, efficient XUV lasers. 


\subsection{Accomplishments}

Two approaches for demonstrating fluorescence of ionic alkali-halide molecules such as RbF, RbBr and CsF have been selected. The first produces the ionic excited states of the alkali halide by incoherent soft $x$-rays emitted from a laser produced plasma. In the second approach, the excited states are pumped by means of an electron beam. The first technique was selected for demonstrating some of the basic principles and for making preliminary spectroscopic measurements, such as transition wavelength location, lineshape, linewidth and fluorescence decay time. The use of electron beam excitation is intended for the investigati on of scaling feasibility for these systems.

In the first study using soft $x$-ray pumping, the i onic excimer transition $R^{2} b^{2} F^{-} \rightarrow R b^{+} F$ was investigated. Emi sion peaks were observed at 130 and $150 \mathrm{~nm}$. The peak at $130 \mathrm{~nm}$ is attributed to the $\mathrm{B} \rightarrow \mathrm{X}$ transition, as it is in good agreement with the theoretically estimated range of $115-130 \mathrm{~nm}$. The broadband emission centered around $155 \mathrm{~nm}$ has been tentatively assigned to the $\mathrm{C} \rightarrow \mathrm{A}$ transition of this molecule. Since $\mathrm{Rb}^{2}+\mathrm{F}^{-}$is likely to have a similar molecularsiate structure and spectrum to $\mathrm{Kr}^{+} \mathrm{F}^{-}$, the assignment of the observed features at 130 and $150 \mathrm{~nm}$ as $B \rightarrow X$ and $C \rightarrow A$ in $R^{2+} F^{-}$is consistent with the known transition of the $\mathrm{Kr}^{+} \mathrm{F}-$ spectrum.

In a second study using soft $x$-ray excitation, the ionic excimer transition of $\mathrm{RbBr}$ was investigated. The anticipated emission near 90 $\mathrm{nm}$ from the $\mathrm{Rb}^{2}+\mathrm{Br}^{-} \rightarrow \mathrm{Rb}^{+} \mathrm{Br}$ transition was not observed instead many atomic bromine transitions were observed. It is presumed that the absence of this emission and the observation of atomic bromine fluorescence line is due to predissociation of the excimer molecule. The $\mathrm{Rb}^{2}+\mathrm{Br}^{-}$curve crosses the $\mathrm{Rb}^{+}+\mathrm{Br}^{+}$and $\mathrm{Rb}^{+}+\mathrm{Br}^{*}$ potential curves at small internuclear separation.

Electron beam excitation of CsF in a high pressure heatpipe has also been investigated. Temporally integrated spectra and time-resolved fluorescence on the ionic excimer transition $\mathrm{Cs}^{2+} \mathrm{F}^{-} \rightarrow \mathrm{Cs}^{+} \mathrm{F}$ were 
observed at $185 \mathrm{~nm}$. The pressure dependence of the fluorescence is influenced by self-absorption in the $\mathrm{CsF}$ vapor.

Due to insufficient energies of atomic and molecular metastables and ions of $\mathrm{He}$, direct electron beam excitation of $\mathrm{RbF}$ was not successful.

Electron beam excitation of three component mixtures such as $\mathrm{He}$ (or $\mathrm{Ne}) / \mathrm{Cs} / \mathrm{BF}_{3}$ (or $\mathrm{SiF}_{4}, \mathrm{CF}_{4}$ ) and $\mathrm{He}\left(\right.$ or $\mathrm{Ne}$ ) $/ \mathrm{Rb} / \mathrm{BF}_{3}$ (or $\mathrm{SiF}_{4}, \mathrm{CF}_{4}$ ) has also been studied. No emission was observed in all cases. Reasons for the lack of observable emission have not been fully established but a brief discussion is given.

\subsection{Future VUV/XUV laser research}

Although the emphasis of this program has been to investigate ionic alkali halides, we have also recognized that several other potential candidate molecules are of a great interest for the construction of XUV lasers. Among them are: (1) ionic rare-gas alkali excimers which are isoelectronic to the rare-gas dimers, (2) and quartet levels of the alkali atoms or ions which retain metastability against autoionization and radiate quite strongly in the XUV. 


\subsection{Introduction and Background}

Although considerable progress has been achieved in the generation of short wavelength radiation by nonlinear optical methods, ${ }^{1-7}$ very little information is available regarding attempts to achieve the goal by means of more-direct approaches.

Excimer lasers have proven their capability to produce high power coherent radiation from the visible to the UV with high efficiency. Recently, Sauerbrey and Langhoff 8 suggested an approach for generation of stimulated emission in the $80-200 \mathrm{~nm}$ region by making use of ionic molecules that are isoelectronic with rare-gas halide excimers. In particular, a scheme based on excited ionic states of alkali halides was proposed.

The estimated spectroscopic properties of ionic alkali halide systems are summarized in table $2-18$. The estimated radiative lifetirnes are typically near $1 \mathrm{nsec}$ or about an order of magnitude shorter than those for rare gas halide systems. Experience with the XeF laser has shown that with lifetimes this short, the development of gain will be dominated by the radiative process $^{9-10}$ and require high pump rates.

Table 2-1

\begin{tabular}{lccc} 
Molecule & Wavelength(nm) & $\begin{array}{l}\text { Radiative } \\
\text { Lifetime(ns) }\end{array}$ & $\begin{array}{l}\text { Stimulated } \\
\text { Emission } \\
(10-16\end{array}$ \\
\hline $\mathrm{K}^{2+} \mathrm{F}^{-}$ & $86-110$ & 0.54 & 0.72 \\
$\mathrm{Rb}^{2+} \mathrm{F}^{-}$ & $115-130$ & 0.67 & 0.95 \\
$\mathrm{Cs}^{2+} \mathrm{F}^{-}$ & $154-195$ & 1.47 & 1.50 \\
$\mathrm{Cs}^{2+} \mathrm{Cl}^{-}$ & $131-205$ & 1.80 & 1.10 \\
$\mathrm{Cs}^{2+} \mathrm{Br}^{-}$ & $117-190$ & 1.92 & 0.77 \\
$\mathrm{Rb}^{2+} \mathrm{Br} r^{-}$ & $80-100$ & 0.91 & 0.50
\end{tabular}

In this work, a concept has been developed for the extension of raregas halide laser technology to shorler wavelength by means of isoelectronic excimer transitions. The similarity of the ionic excimer 
molecules with the rare gas halide excimer molecules should by very helpful in the study of these systems.

By using a Rittner potential ${ }^{11}$ for the upper state and a Born-Mayer potential12 for the repulsive interaction, the range of the emitted wavelengths has been predicted.8.13-15 The potential energy diagrams for these systems are shown in Figures $2-1$ and 2-2. The emission should exhibit structure similar to that observed for rare gas halide excimers. The main intensities are due to the $B \rightarrow X$ and $C \rightarrow A$ transitions.

Since for the rare gas halides no stable ground state molecules exist, only a reactive formation of the upper lasing state is possible. Contrary to rare-gas halides, due to the existence of stable alkali halide molecules, a variety of excitation methods for the ionic alkali halide excimer states are possible. These include direct excitation of the alkali halides by charge transfer using atomic or molecular ions, optical pumping such as soft $\mathrm{x}$-ray excitation, collisional excitation transfer using metastable rare gas states, and the reactive formation after excitation of the molecular constituents.

Figures 2-1 and 2-2 show the relative energy levels between various ionic $\mathrm{RbF}$ and $\mathrm{CsF}$ and the atomic and molecular metastables and ions of He. For CsF, collisional transfer using metastable helium and charge transfer using atomic and molecular He ions appear to be the logical scheme for direct excitation. On the other hand, this scheme is seen to be inadequate for the direct pumping of $\mathrm{RbF}$ vapor.

One pumping scheme for the production of population inversions in ionic alkali halide excimers, $\mathrm{A}^{2+} \mathrm{X}$ - involves e-beam deposition of energy in gas mixtures of $\mathrm{He}$, alkali atoms, $\mathrm{A}$, and a suitable halogen donor, $\mathrm{MX}_{\mathrm{n}}$, such as $\mathrm{BF}_{3}$ or $\mathrm{SiF}_{4}$. The energy is deposited in the gas principally as electronic excitation and ionization of $\mathrm{He}$. The assumed reaction sequence leading to the upper ionic $A^{2+} X^{-}$level is illustrated in Figure 2-3 along with information concerning several alternative processes that are thermochemically possible, among which is the reaction of a halogen donor with an excited state of an alkali metal ion. Two pumping sequences for the formation of $\left(\mathrm{A}^{+}\right)^{*}$ are immediately apparent as follows: 


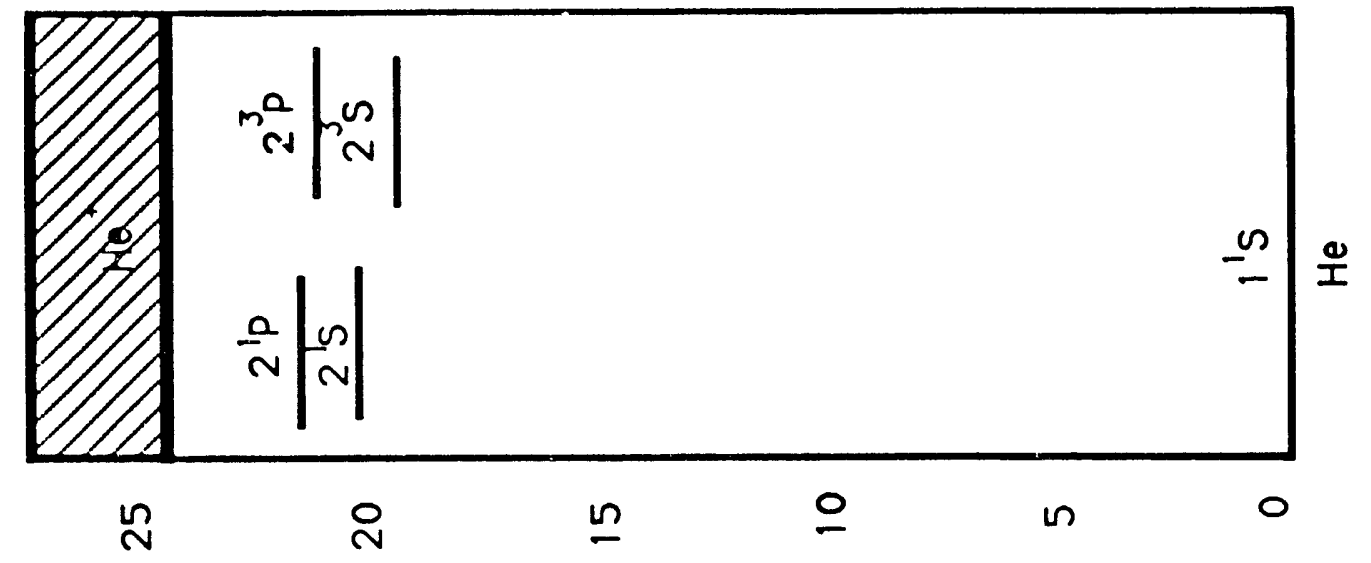

옴
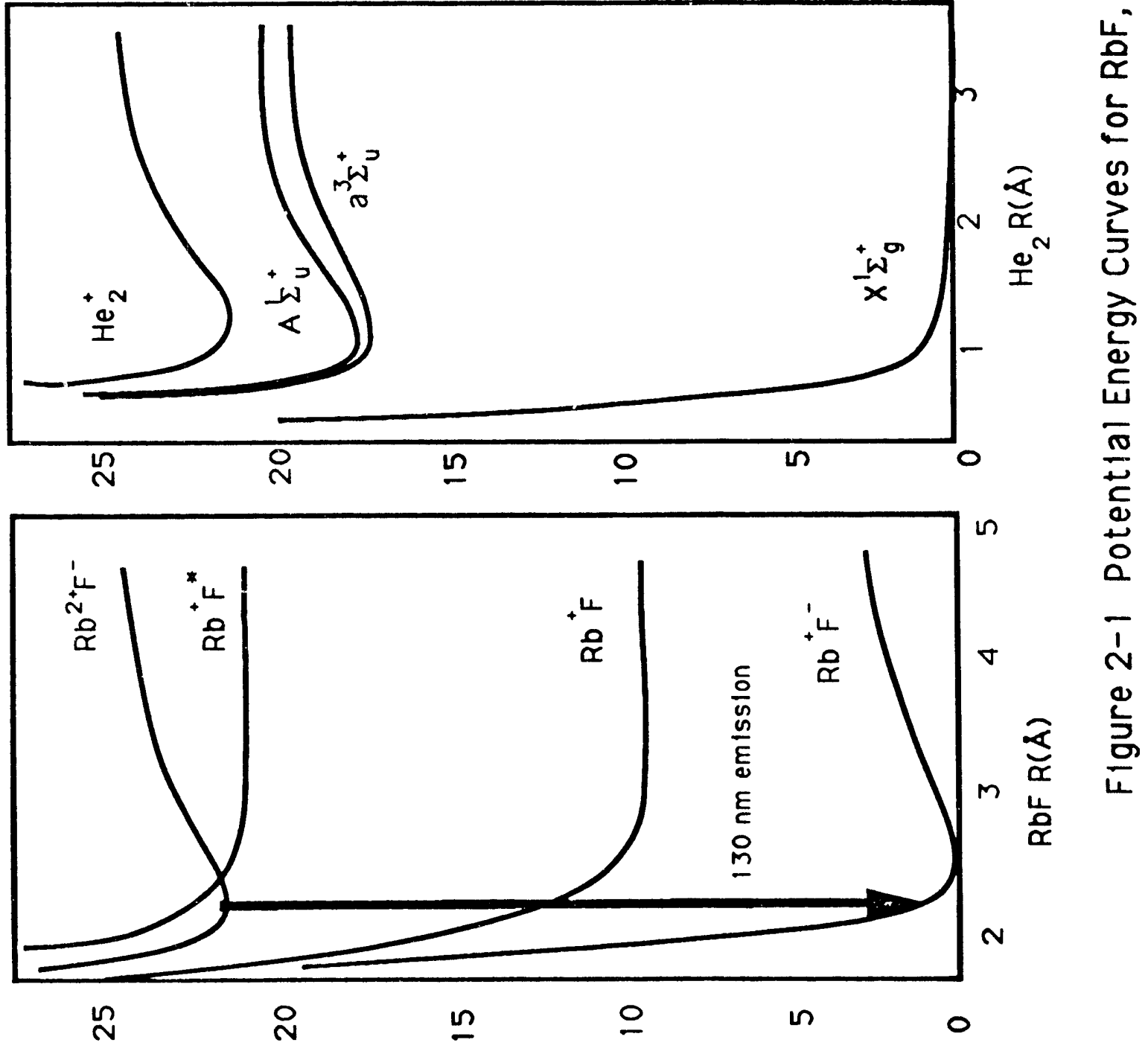

(^ә) KDjaUz lelquazod - 6 - 
Potential Energy (eV)

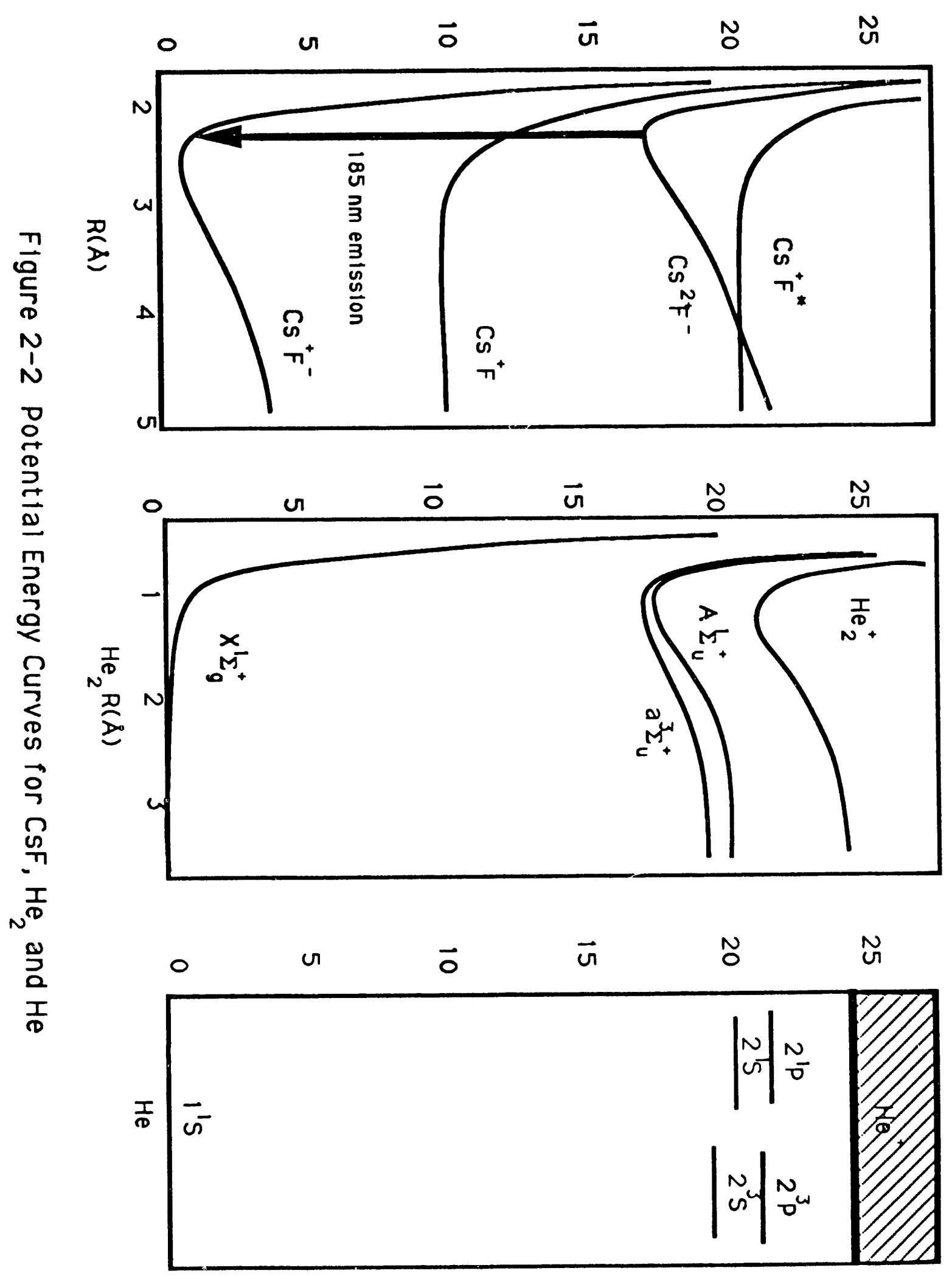




\section{Charge Transfer Sequence}

$$
\begin{aligned}
& \mathrm{He}+\mathrm{e}^{-} \rightarrow \mathrm{He}^{+}+\mathrm{e}^{-}+\mathrm{e}^{-} \\
& \mathrm{He}^{+}+2 \mathrm{He} \rightarrow \mathrm{He}_{2}^{+}+\mathrm{He} \\
& \mathrm{He}^{+}+\mathrm{A} \rightarrow \mathrm{He}+\left(\mathrm{A}^{+}\right)^{*} \\
& \mathrm{He}_{2}^{+}+\mathrm{A} \rightarrow 2 \mathrm{He}+\left(\mathrm{A}^{+}\right)^{*}
\end{aligned}
$$

Penning Ionization Sequence

$$
\begin{gathered}
\mathrm{He}+\mathrm{e}^{-} \rightarrow \mathrm{He}^{*}\left(2^{3} \mathrm{~S}\right)+\mathrm{e}^{-} \\
\rightarrow \mathrm{He}^{*}\left(2^{1} \mathrm{~S}\right)+\mathrm{e}^{-} \\
\mathrm{He}^{*}\left(2^{3} \mathrm{~S}, 2^{1} \mathrm{~S}\right)+2 \mathrm{He} \rightarrow \mathrm{He}^{*}+\mathrm{He} \\
\mathrm{He}^{*}\left(2^{3} \mathrm{~S}\right)+\mathrm{A} \rightarrow \mathrm{He}+\left(\mathrm{A}^{+}\right)^{*} \\
\mathrm{He}^{*}\left(2^{1} \mathrm{~S}\right)+\mathrm{A} \rightarrow \mathrm{He}+\left(\mathrm{A}^{+}\right)^{*} \\
\mathrm{He}^{*}+\mathrm{A} \rightarrow 2 \mathrm{He}+\left(\mathrm{A}^{+}\right)^{*}
\end{gathered}
$$

Once $\left(\mathrm{A}^{+}\right)^{*}$ is formed, it can then react with a halogen donor to form excited excimer molecules though a harpooning reaction.

$$
\left(\mathrm{A}^{+}\right)^{*}+\mathrm{MX}_{\mathrm{n}} \rightarrow \mathrm{A}^{2+\mathrm{X}^{-}}+\mathrm{MX}_{\mathrm{n}-1}
$$

Based upon known and interpolated thermodynamic properties of $\mathrm{A}^{2+} \mathrm{X}^{-}$, we find this process to be exothermic. Harpoon reactions of this type are one of the two key channels for formation of rare-gas halide excimers.9,10,16 Exothermic reactions of this type typically have rate constants in the (1-4) $\times 10^{-10} \mathrm{~cm}^{3} / \mathrm{sec}$ range. Therefore, a mixture containing alkali vapor $(\mathrm{Cs}, \mathrm{Rb})$, inert halogen $\left(\mathrm{BF}_{3}, \mathrm{SiF}_{4}, \mathrm{CF}_{4}\right)$ donor and $\mathrm{He}$ as buffer gas can be excited in a pulsed electron beam or a pulsed discharge. The metastable $\mathrm{He}$ atoms, atomic and molecular $\mathrm{He}$ ions transfer their energy forming excited alkali ions 
which undergo a harpooning reaction with a halogen donor leading to the formation of ionic excimers.

The thermochemical information illustrated in figure 2-3 indicates clearly that apart from reactions involving $\left(A^{+}\right)^{*}$, there is an alternative class of energetically accessible pump reactions which involve direct ionization and excitation of stable ground state alkali inalide molecules. The expected reactions for direct excitation are shown as follows:

$$
\begin{gathered}
\text { Direct Excitation } \\
\mathrm{He}^{+}+\mathrm{AX} \rightarrow \mathrm{He}+\left(\mathrm{A}^{+} \mathrm{X}\right)^{*} \\
\mathrm{He}_{2}^{+}+\mathrm{AX} \rightarrow 2 \mathrm{He}+\left(\mathrm{A}^{+} \mathrm{X}\right)^{*} \\
\mathrm{He}^{+}+\mathrm{He}+\mathrm{AX} \rightarrow 3 \mathrm{He}+\left(\mathrm{A}^{+} \mathrm{X}\right)^{*} \\
\mathrm{He}^{*}\left(2^{3} \mathrm{~S}\right)+\mathrm{AX} \rightarrow \mathrm{He}+\left(\mathrm{A}^{+} \mathrm{X}\right)^{*}+\mathrm{e}^{-} \\
\mathrm{He}^{*}\left(2^{1} \mathrm{~S}\right)+\mathrm{AX} \rightarrow \mathrm{He}+\left(\mathrm{A}^{+} \mathrm{X}\right)^{*}+\mathrm{e}^{-} \\
\mathrm{He}^{*}+\mathrm{AX} \rightarrow 2 \mathrm{He}+\left(\mathrm{A}^{+} \mathrm{X}\right)^{*}+\mathrm{e}^{-}
\end{gathered}
$$

In section 3, the experimental method is described, technical results are presented in section 4 and finally future VUV/XUV research recommendations are provided in section 5 . 


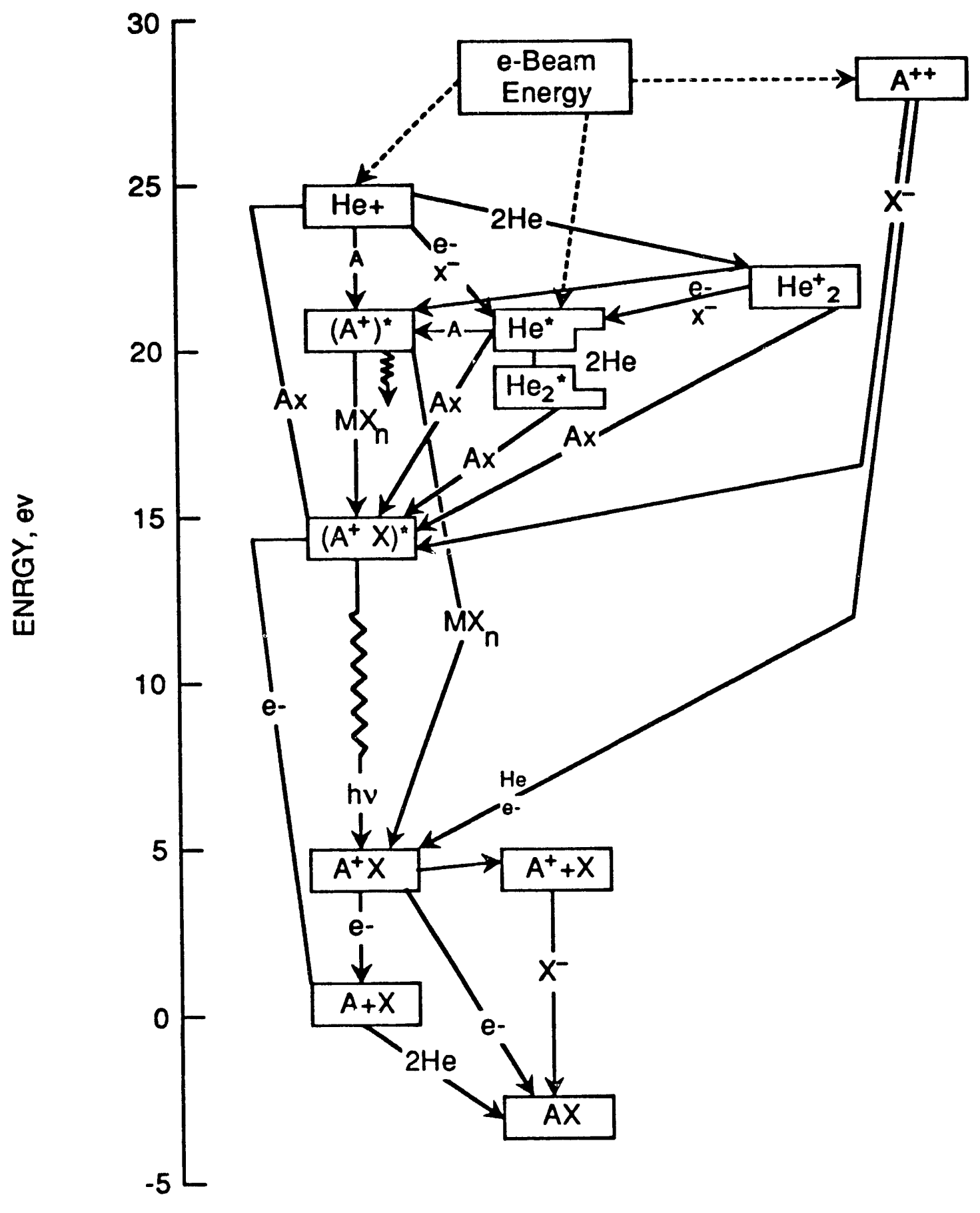

Figure 2-3. Major Energy Channels for e-Beam Pumped $\mathrm{He} / \mathrm{A} / \mathrm{MX}_{\mathrm{n}}$ Mixtures 


\section{0 Experimental Method}

The objective of this program has been the evaluation of the ionic alkali halide as candidate molecules for XUV lasers. The paucity of existing experimental data and theoretical models suggested that the initial effort be a spectroscopic survey of the candidate molecules.

A two-pronged effort was chosen to investigate the spectroscopic properties of the molecules. In the first approach, soft $x$-ray excitation of the molecules was chosen because of its simplicity and ease of use. Radiation from a high power laser is focussed onto a target. The resulting soft $x$-rays emitted from the lasei produced plasma photoionize an inner shell electron from the candidate molecules. The molecule subsequently fluorescences. This fluorescence is detected and identifies the promising transitions in the molecules.

The second approach addresses the feasibility of electron beam excitation of the candidate molecules. As e-beam experiments are more difficult and time consuming, the initial laser produced plasma survey provided a spectroscopic guide which saved time and effort. The candidate molecules were added to a buffer gas ( $\mathrm{He}$ or $\mathrm{Ne}$ ) in a heatpipe. The e-beam excited the buffer gas which transferred its excitation to the ionic alkali halide. Spectroscopic measurements were subsequently carried out.

To support this research, two experimental facilities were established: 1) a laser plasma facility and 2) an electron beam facility. Each facility had heatpipes, a gas handling system and data acquisition equipment.

\subsection{Laser Plasma Facility}

The laser produced plasma facility was established to conduct a spectroscopic surveys of the candidate molecules. A schematic of the overall facility is depicted in Figure 3-1 and a photograph of the 


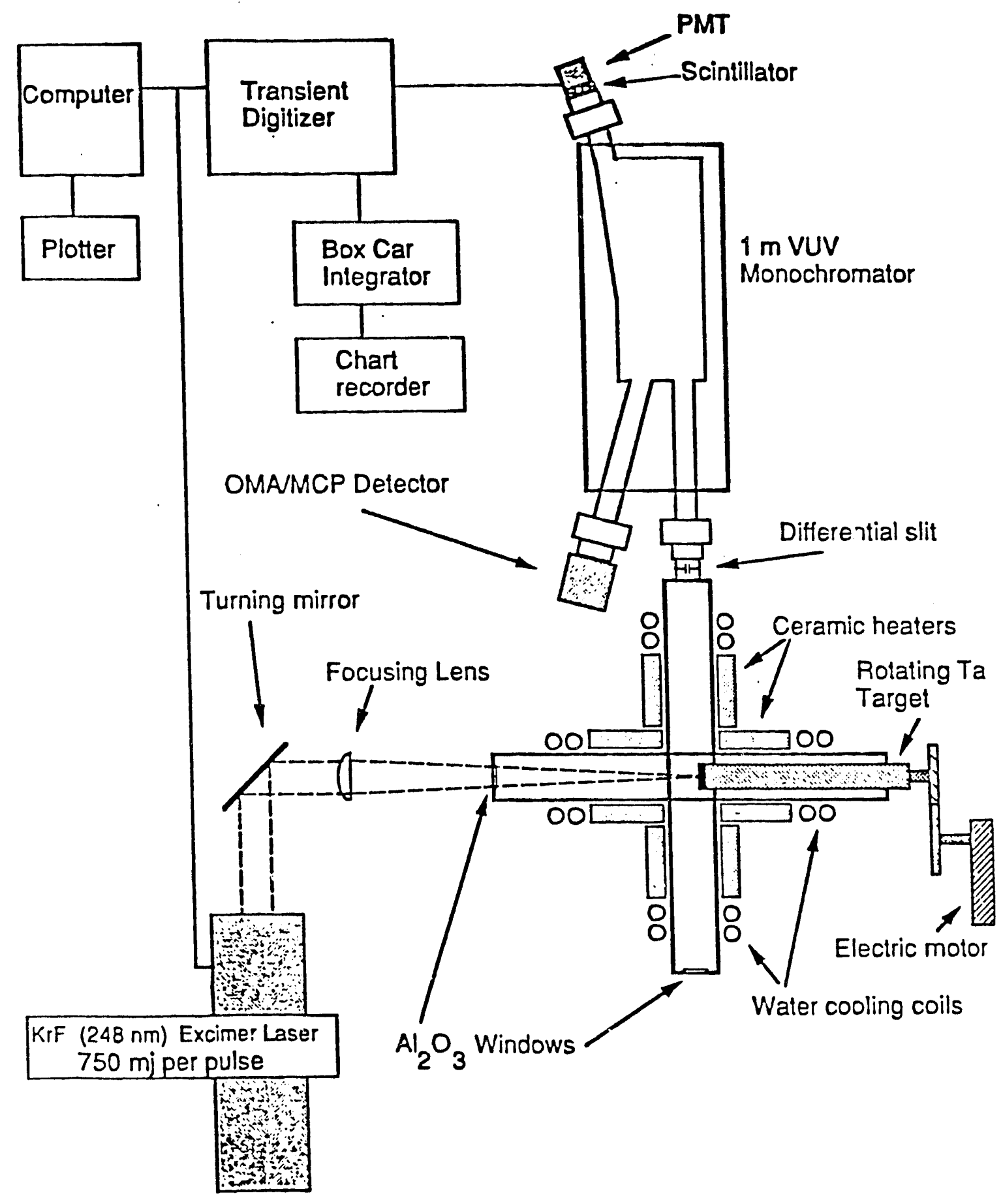

Figure 3-1. Schematic of soft $x$-ray facility. The differential slit was often replaced by a capillary plate. 
actual apparatus is shown in Figure 3-2. The facility may be divided into three distinct areas: the laser which was used as the excitation source of the soft $x$-rays, the heatpipe cell used to contain the atoms and molecules under study, and the monochromator with its associated detection electronics. The excitation laser was a discharge pumped KrF excimer laser. It emitted approximated $700 \mathrm{~mJ}$ of 248 $\mathrm{nm}$ radiation in a $25 \mathrm{~ns}$ pulse. During data acquisition, the laser was generally operated at a $1-3 \mathrm{~Hz}$ repetition rate.

A detailed schematic of the low pressure heatpipe (LHP) is depicted in Figure 3-3 and a photograph of the device is shown in Figure 3-4. A five-arm design was chosen to allow a sufficient number of ports for operation and instumentation. The heatpipe was constructed of inconel to allow operation over $1000^{\circ} \mathrm{C}$, thus producing up to 10 Tori of alkali halide vapor. Each of the arms was $28 \mathrm{~cm}$ in length. One of the arms contained a tantalum target attached to the heatpipe with $a$ ferrofluidic seal to allow rotation of the tube. An electric motor provided the rotation, so that a fresh tantalum target surface was presented to the laser on each shot.

The laser radiation was injected into the heatripe through the window opposite to the tantalum target. The focussed laser spot on the target was estimated to be approximately $100 \mu \mathrm{m}^{2}$, which corresponds to a power density of $10^{11} \mathrm{~W} / \mathrm{cm}^{2}$. It has been well established by Caro et al 17 that focussed laser radiation onto a heavy metal target efficiently produces soft $x$-rays. These soft $x$-rays can efficiently photoionize and excite the surrounding gas. The core excited atoms and molecules subsequently decay; and it is this decay fluorescence which is detected. The fluorescence is collected at right angles to the entering laser radiation.

During operation, a few grams of the alkali halide are inserted, and the heatpipe is brought to the desired operating temperature (vapor pressure). The temperature was monitored with thermocouples attached to the heatpipe. A few Torr of $\mathrm{He}$ gas was also injected into the cell to ensure operation as a heatpipe and to prevent the alkali halide from depositing on the windows. The pressure was monitored with a Baratron pressure transducer. 

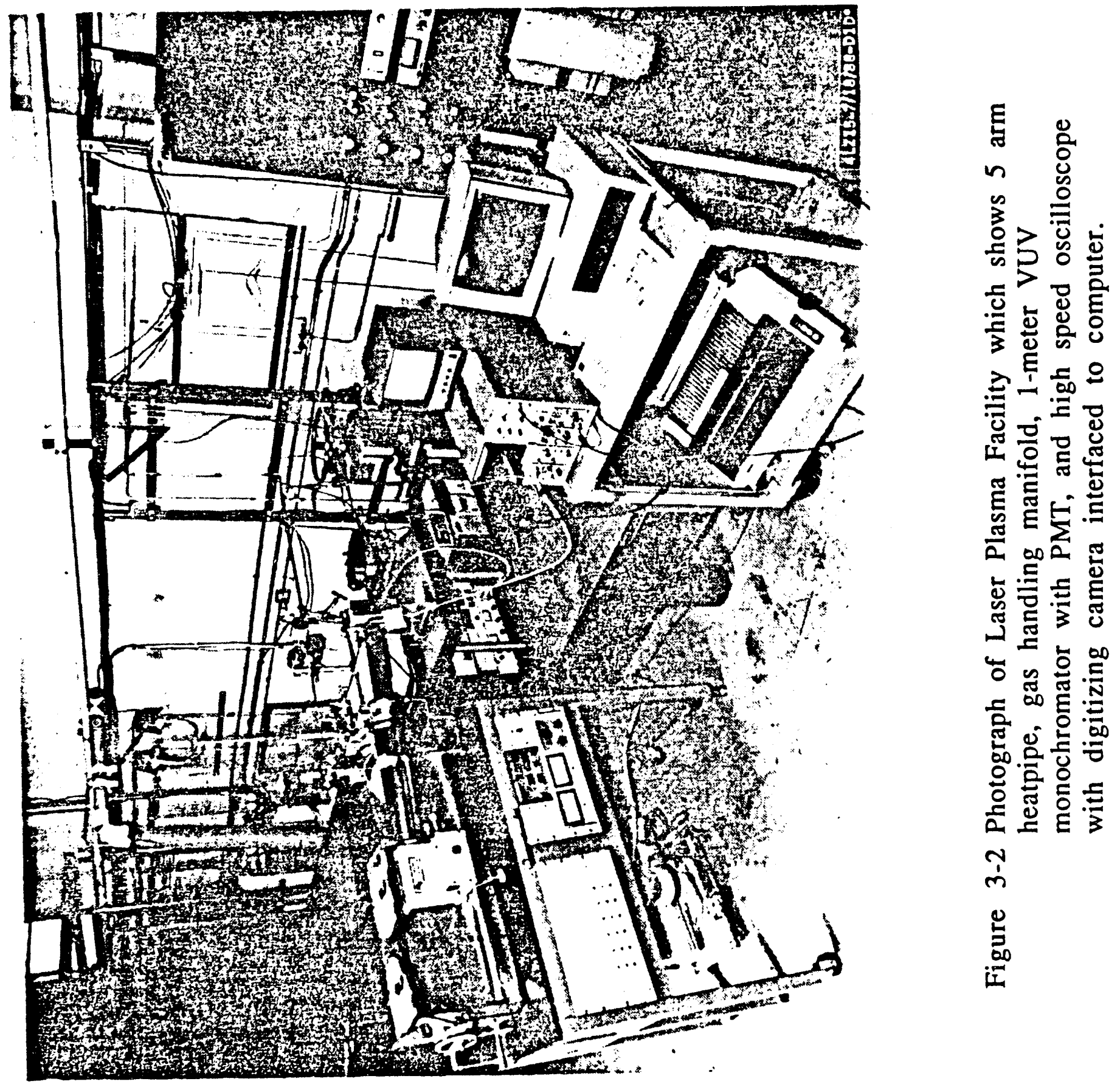


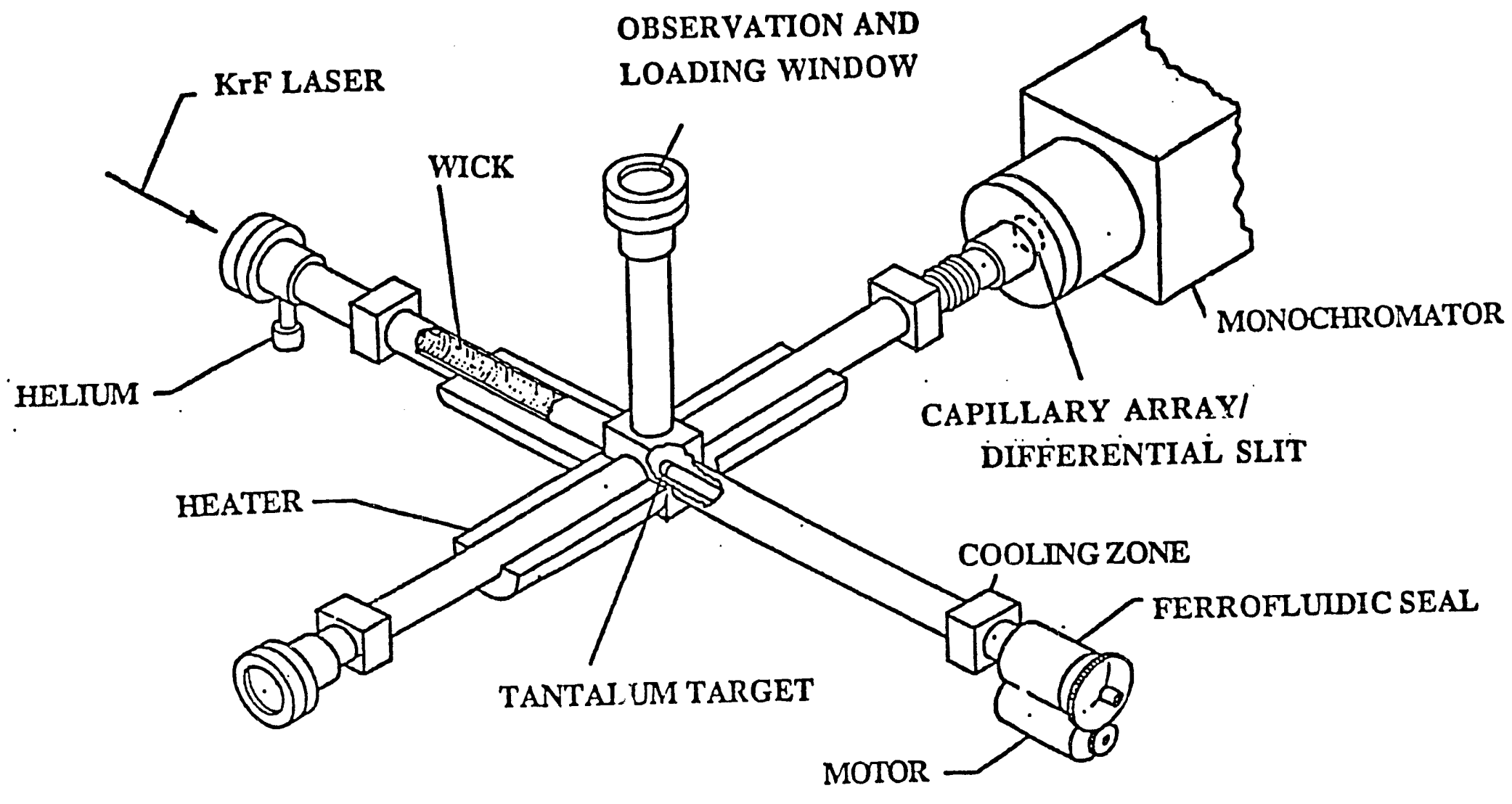

Figure 3-3. Detailed drawing of the low pressure heatpipe (LPH) used in the Laser Plasma facility. 


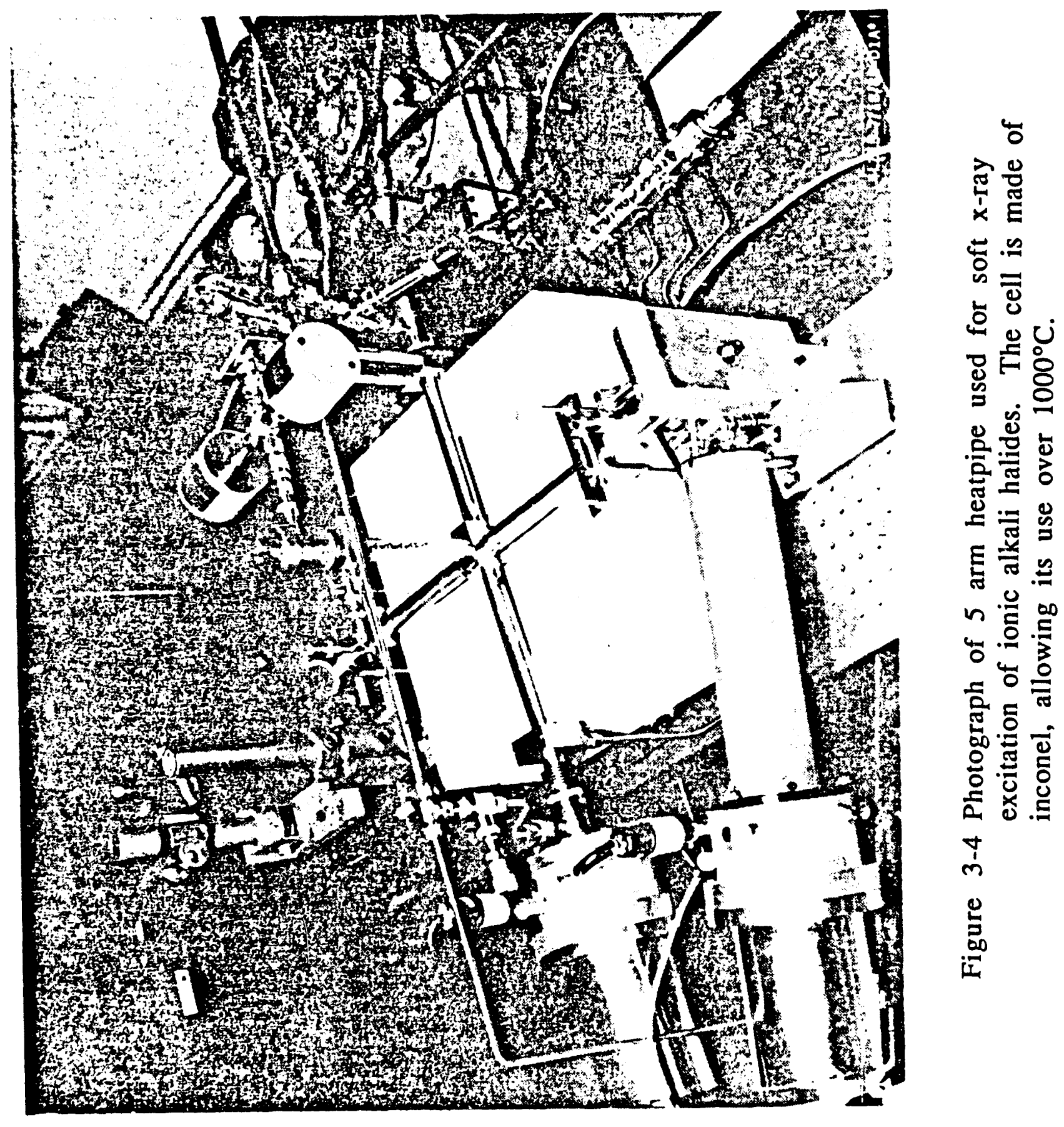


The fluorescence emission was collected with a VUV monochromator attached to a third arm of the heatpipe. Depending on circumstances, several different methods of connecting the monochromator to the heatpipe were used. For detection of radiation above $120 \mathrm{~nm}$, a $\mathrm{MgF}$ window could be used to isolate the monochromator from the heatpipe. At shorter wavelengths, a semi-permeable capillary array or a differential pumping slit system could be used. Frequently, the monochromator was flooded with an inert buffer gas at the same pressure as the heatpipe. This technique permitted a windowless connection between the heatpipe and allowed the radiation to efficiently enter the detection apparatus.

Either of two VUV monochromators were used to collect and disperse the fluorescence. A 1.0 meter monochromator was equipped with a 1200 groove $/ \mathrm{mm}$ and a 300 groove $/ \mathrm{mm}$ grating. Both gratings were Al with a $\mathrm{MgF}$ coating for protection, and could be used efficiently above $100 \mathrm{~nm}$. For operation below $100 \mathrm{~nm}$, an iridium coated 2400 groove $/ \mathrm{mm}$ grating was installed. The second monochromator was a 0.25 meter VUV monochromator with an Al-MgF coated, 1200 groove $/ \mathrm{mm}$ grating.

The fluorescence was detected with either of two detectors systems. Initially a photomultiplier (PMT) with a sodium salicylate scintillator was used. Time-resolved measurements were made by connecting the PMT to a high speed oscilloscope equipped with a digitizing camera. The camera was interfaced to a computer to allow data acquisition and processing to be carried out. The rise-time of this acquisition system was $5 \mathrm{nsec}$.

To obtain a spectrum, the PMT signal was sent into a boxcar integrator. The gate width of the boxcar was set to $30-50 \mathrm{nsec}$ in order to discriminate between the signal and the background fluorescence. The laser was operated at a few $\mathrm{Hz}$ while the monochromator was scanned in wavelength.

A second detector was designed and fabricated. This was a VUV Optical Multchannel Analyzer (OMA) with nearly single photon detection between 30 and $250 \mathrm{~nm}$. This detector consisted of a microchannel plate detector interfaced to a reticon array. The VUV 
photons strike a CsI scintillator, which emits photoelectrons. The photoelectrons are amplified in the microchannel plate, and then converted to visible radiation by a phosphor, which is interfaced through a fiber optic bundle to a reticon array. The array was read out to a computer which allowed signal processing. The resulting instrument, a very sensitive and versatile VUV detector, permits a spectrum to be acquired on a single excitation pulse. It also allows averaging and subtraction of spectra as well as other data processing to be carried out. Examples of this capability are shown in subsequent sections.

\subsection{Electron Beam Facility}

A versatile facility, as shown in Figure 3-5 was assembled to investigate the feasibility of electron beam pumping of the ionic excimers. Two electron beam sources were procured with the specifications listed in Table 3-1.

Table 3-1

\begin{tabular}{|c|c|c|}
\hline & Febetron 706 & HP-43710 A \\
\hline Avg. Energy & $0.6 \mathrm{MeV}$ & $1.0 \mathrm{MeV}$ \\
\hline eak Current & $7000 \mathrm{~A}$ & $2000 \mathrm{~A}$ \\
\hline Pulse Length & $3 \mathrm{nsec}$ & $30 \mathrm{nsec}$ \\
\hline
\end{tabular}

Two heatpipe cells were fabricated. The electron beam generator and heatpipe were enclosed in a lead shielded room to contain the $x$-ray emission. The electron beam passed through a 0.001 " foil and into the heatpipe cell where it excited the gas. Two solenoid magnets confined the beam to the cell. Fluorescence emission from the gas in the heatpipe was again detected with a monochromator and PMT of VUV Optical Multichannel Analyzer. The data acquisition electronics were contained in an EMI shielded room to reduce the electromagnetic noise produced by the e-beam.

Two high pressure heatpipes (HPH-1 and HPH-2) were designed and fabricated. $\mathrm{HPH}-1$ is a concentric design (Figure 3-6) with an outer 


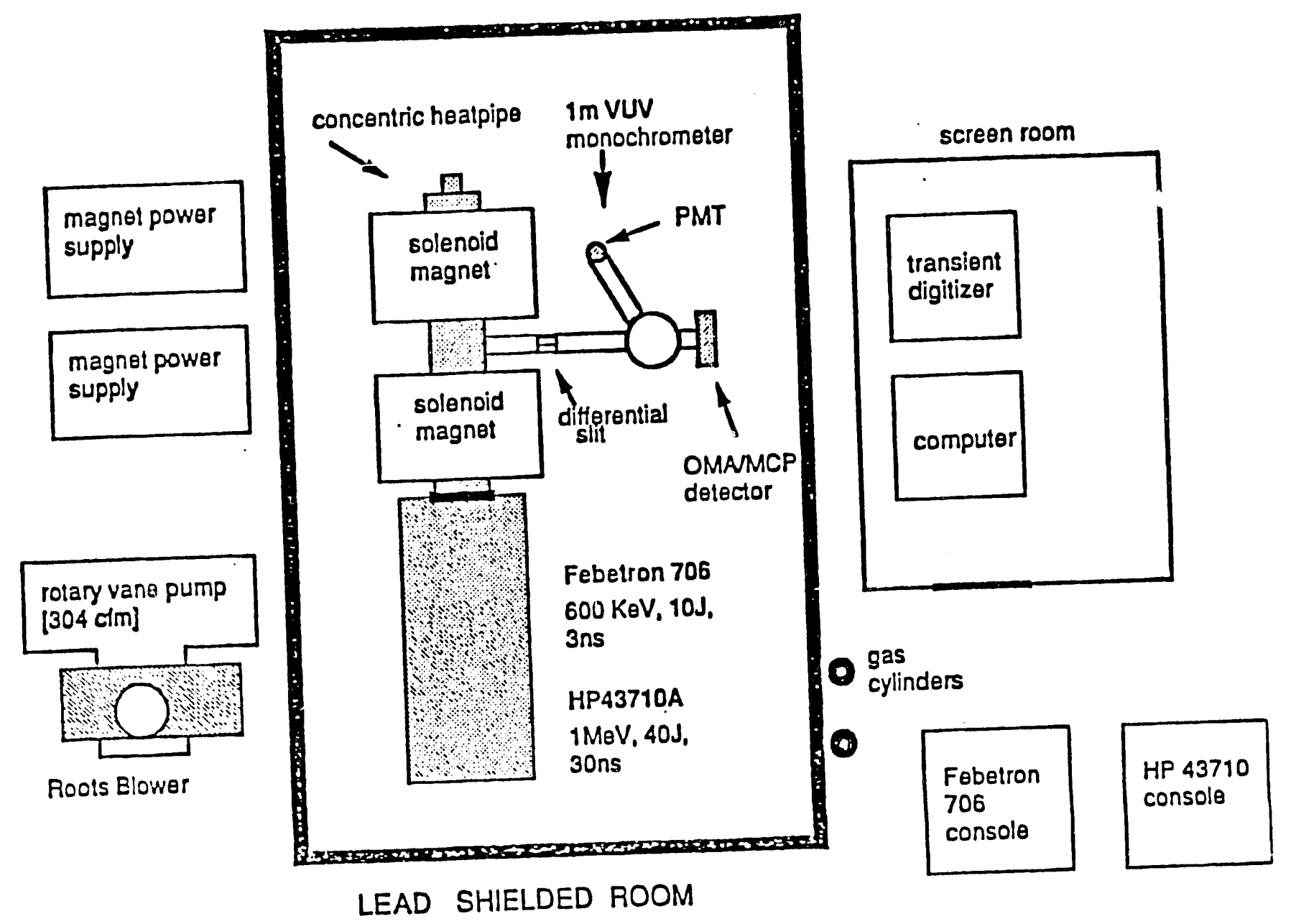

Figure 3-5. Schematic of the electron beam facility. The facility was equipped with both Febetron 706 and HP-43710A electron beam pulsers. The HPH-1 had a transverse arm permitting both longitudual and transverse viewing of the excited gas. 


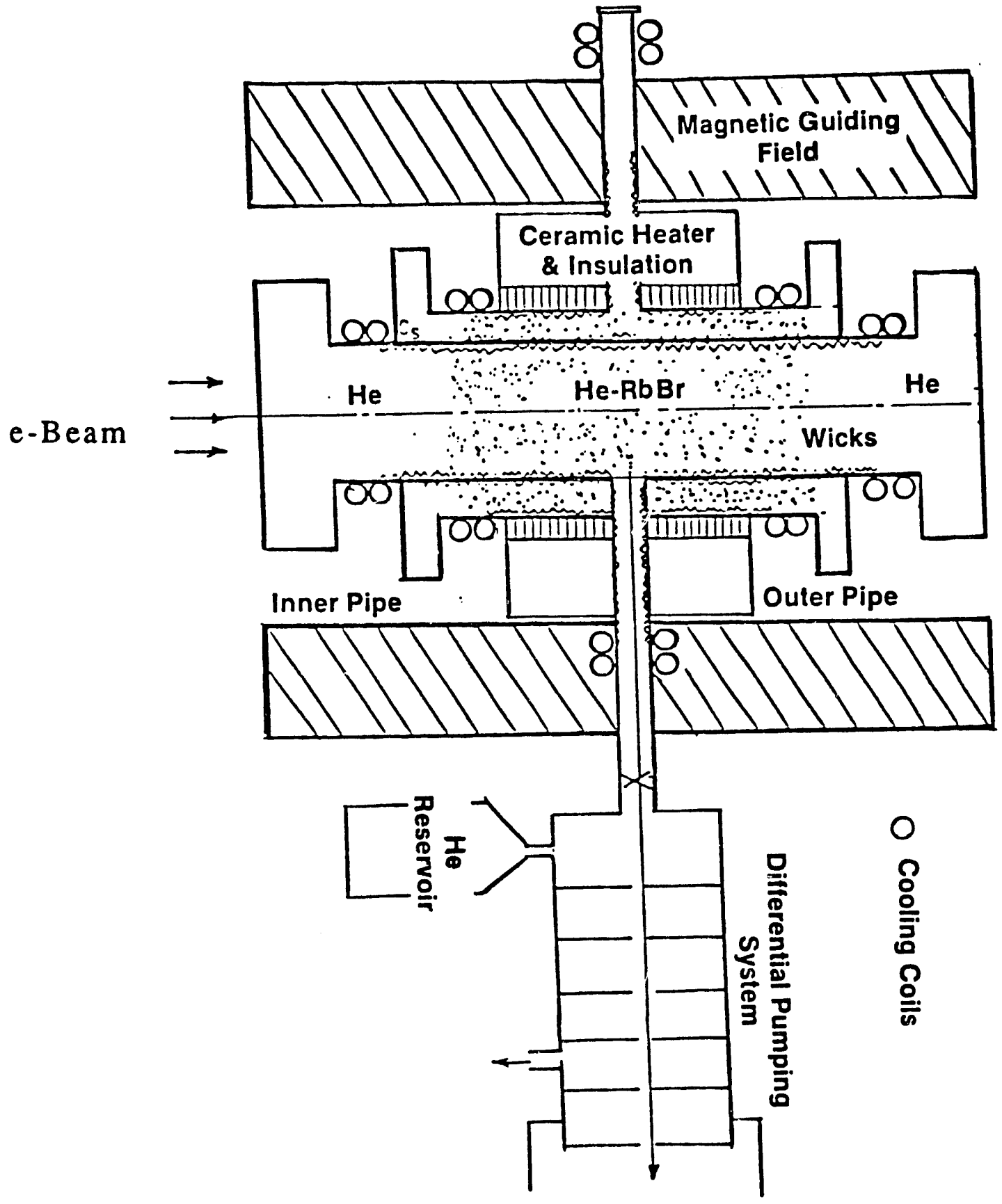

Figure 3-6 Schematic diagram of concentric heatpipe used in electron beam excitation experiments. The outer heatpipe used $\mathrm{Cs}$ as a working fluid. The alkali halide and buffer gas are in the inner heatpipe. 
pipe which has Cs as a working fluid. This heatpipe was constructed of inconel to allow operation over $1000^{\circ} \mathrm{C}$ and up to $40 \mathrm{~atm}$. of pressure. Two ports allowed the monochromators to view the plasma brth longitudinally and transversely to the e-beam. A photograph of HPH-1 is shown is Figure 3-7. The second heatpipe (HPH-2) was of a more conventional linear design and could operate up to 10 atms. of pressure.

During the design of HPH-1, the issues of electron charge neutralization, e-beam propagation, and the magnetic field required for beam confinement were considered.

Several correlations for beam propagation range in an absorbing medium have been proposed by Marmier and Sheldon 18 , Evans 19 and Frauenfelder and Henley 20 . These correlations and their applicable energy range are summarized as follows.

$$
\begin{aligned}
& R=0.543 E-0.160 \\
& R=0.571 E-0.161 \\
& R=0.4037 E-1.38 \\
& R=0.542 E-0.133 \\
& R=0.412 E^{n}
\end{aligned}
$$$$
(\mathrm{E}>0.7 \mathrm{MeV})
$$$$
(1.2<\mathrm{E}<2.3 \mathrm{MeV})
$$$$
(0.15<\mathrm{E}<0.8 \mathrm{MeV})
$$$$
(0.8<\mathrm{E}<3 \mathrm{MeV})
$$$$
(0.01<\mathrm{E}<3 \mathrm{MeV})
$$

$$
\mathrm{n}=1.265-0.0954 \ln \mathrm{E}
$$

$$
\begin{array}{ll}
R=0.530 \mathrm{E}-0.106 & (2.5<\mathrm{E}<20 \mathrm{MeV}) \\
R=0.526 \mathrm{E}-0.094 & (0.6<\mathrm{E}<12 \mathrm{MeV})
\end{array}
$$

Where $R$ is the mean propagation range and $E$ is the electron kinetic energy, Figures $3-8 a$ and $3-8 b$ plot the mean range, in $\mathrm{g} / \mathrm{cm}^{2}$, as a function of electron kinetic energy, E. The results were calculated for a density of 10 amagats for electron energies varying from 0.5 to 3 $\mathrm{MeV}$. These figures provide a convenient picture for estimating a beam propagation range for a specified electron beam energy and medium density. The results shown are based on predictions calculated by a Monte Carlo program in the literature 21 . According to Eq. (3) a $600 \mathrm{KeV}$ beam of electrons generated from a Febetron 706 can propagate $56 \mathrm{~cm}$ in 20 atmospheres of helium. 

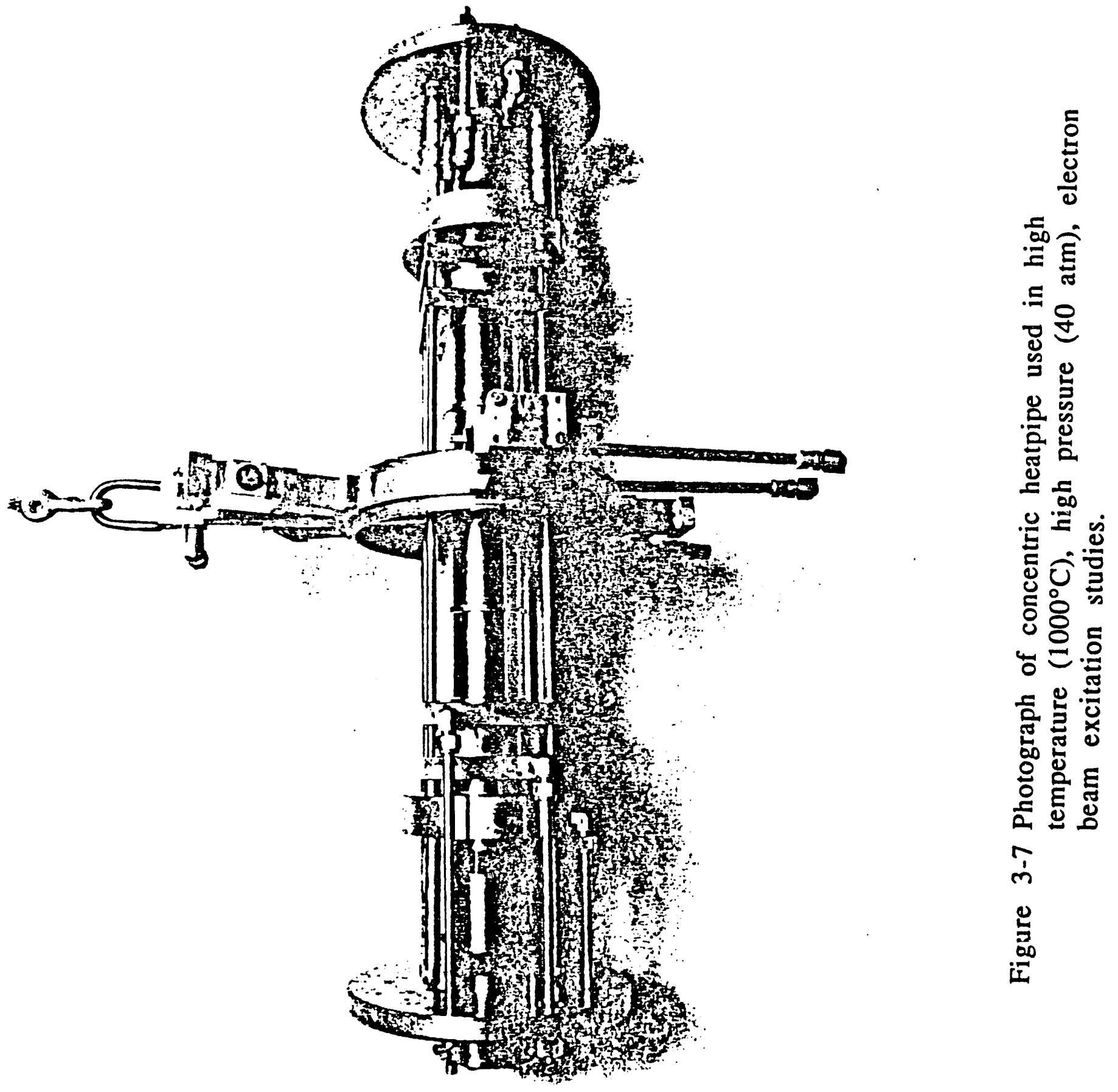


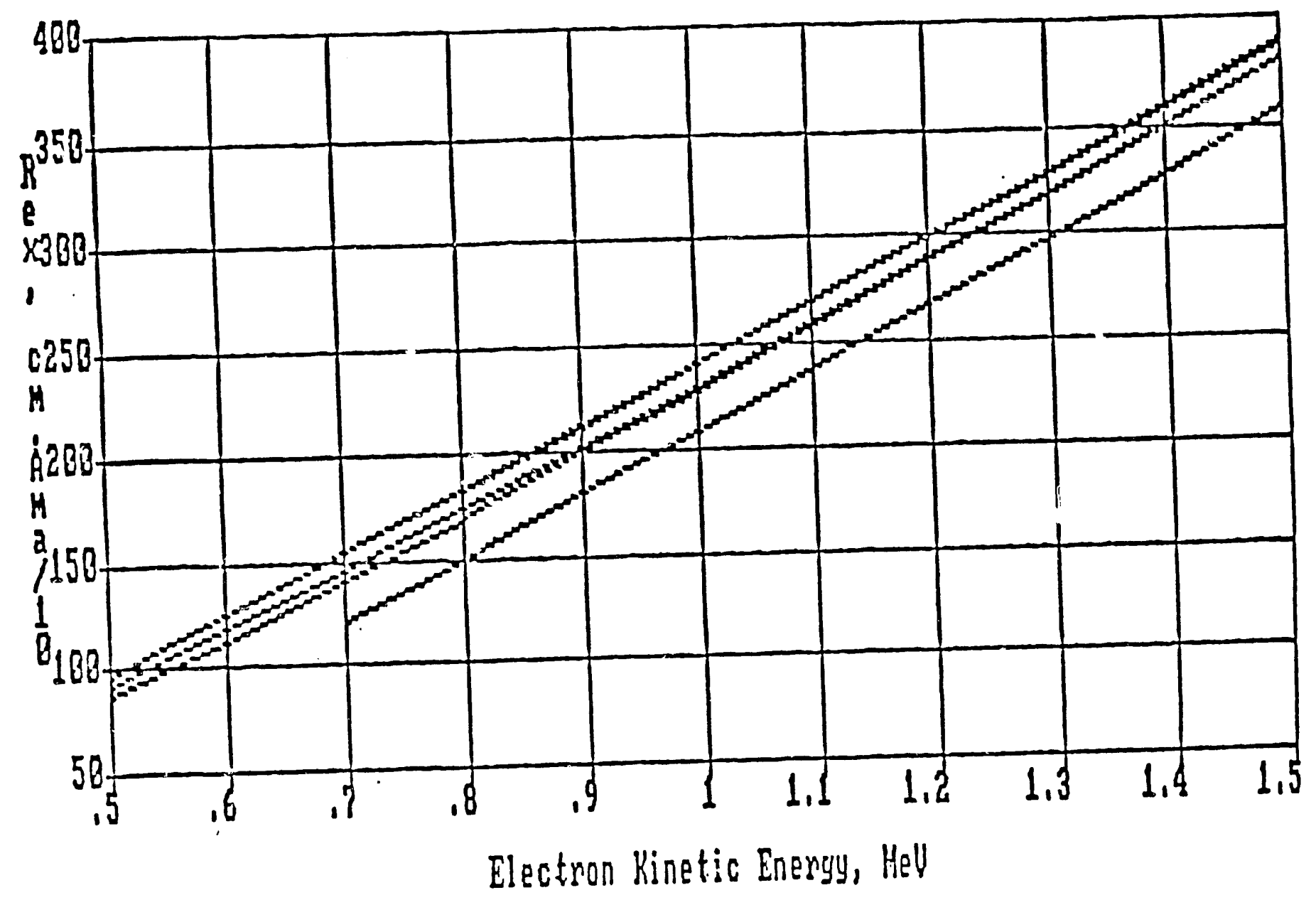

Figure 3-8a. Electron bearn propagation range as a function of electron energy $E$. 


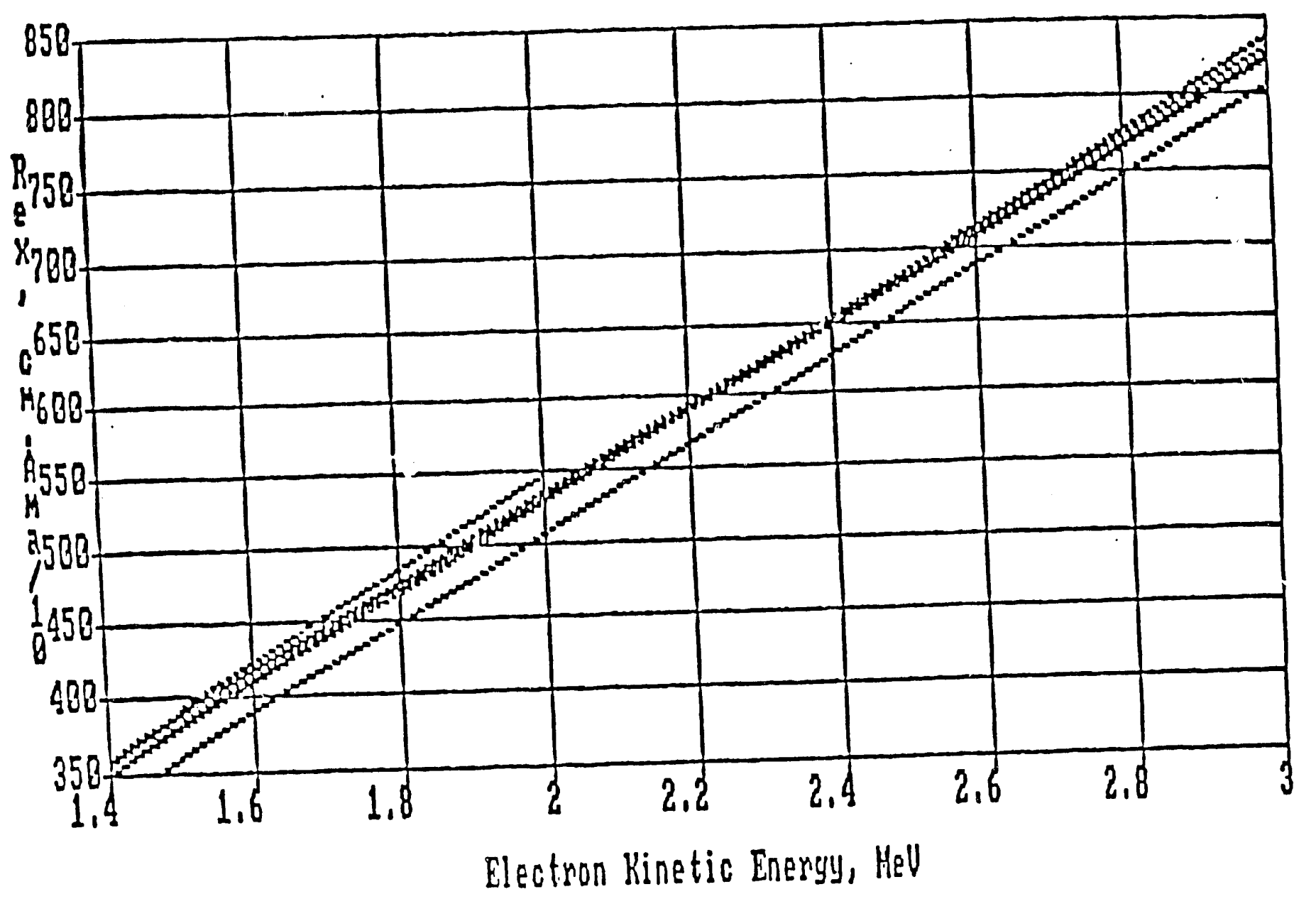

Figure 3-8b. Electron beam propagation range as a function of electron energy $\mathrm{E}$. 
Woodworth and Rice 22 have shown that loss of e-heam energy to the walls of a cell due to various scattering processes is negligible, allowing one to place uncertainties of less than $20 \%$ on the amount of e-beam energy deposited on the axis of the cell. Figures 3-9 and 3-10 show the $\mathrm{He}$ and $\mathrm{Ne}$ stopping power, $\mathrm{dE} / \mathrm{dX}$, as a function of electron kinetic energy. The upper curve was calculated using $E / R$ based on Eqs. (5) and (6), and the lower curve was obtained by using Eq (4122) of Ref. 19 The difference between the upper and lower curves is that the former one is the total stopping power and the latter one the half stopping power.

The electron beam facility employed two relativistic electron sources. An HP-43710A and a Febetron 706. The HP-43710A can generate an electron burst with a peak current of $2 \times 10^{3} \mathrm{~A}$. The full width at halfmaximum (FWHM) of the burst is $30 \mathrm{nsec}$. The average electron excitation energy is $1.0 \mathrm{MeV}$.

The Febetron 706 can generate an electron burst with a peak current of $7 \times 10^{3} \mathrm{~A}$ at $0.6-\mathrm{MV}$ peak potential. The FWHM is $3 \mathrm{nsec}$. Previous work has shown that the 706 an produce a nominal $0.5 \mathrm{MeV}$ electron beam through a 0.001 inch thick titanium foil. The 706 e-beam gun can emit $2 \times 10^{14}$ electrons per 3-nanosecond pulse.23 Divergence of the beam is reported to be $30^{\circ}$ so that, at a distance $\mathrm{L}$, normal to the window, there can be expected to be

$$
\mathrm{N}_{\mathrm{p}}=1.5 \times 10^{14}\left[1+0.81 \mathrm{~L}+0.165 \mathrm{~L}^{2}\right]^{-1}
$$

primary electrons per $\mathrm{cm}^{2}$ incident upon the HPH entrance window. From values of average range, energy expended per ion-electron pair, and gas density, an average charge multiplication factor in helium of

$$
M=15.6 \mathrm{~cm}^{-1} \mathrm{~atm}^{-1}
$$

can be computed.

To confine the electron beams two powerful solenoid magnets capable of producing a $6.4 \mathrm{KG}$ magnetic field were used. A photograph of one of the magnets in place around the heatpipe is shown in Figure 3-11. With the application of a $6.4 \mathrm{KG}$ magnetic field, the focussed electron beam was determined to be about $19 \mathrm{~mm}$ in diameter at the midpoint

$$
-25-
$$




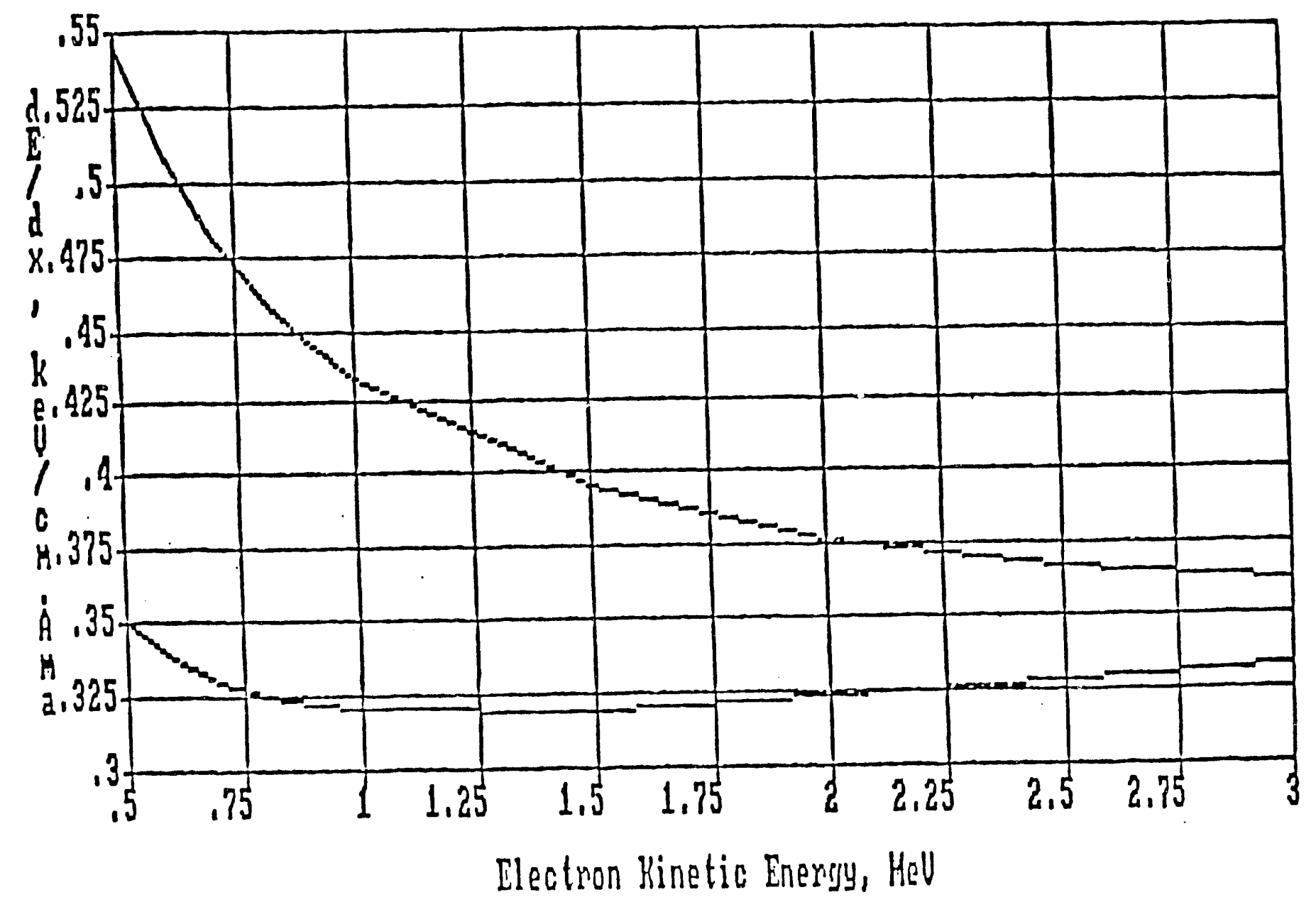

Figure 3-9. Helium e-beam stopping power as a function of electron energy. 


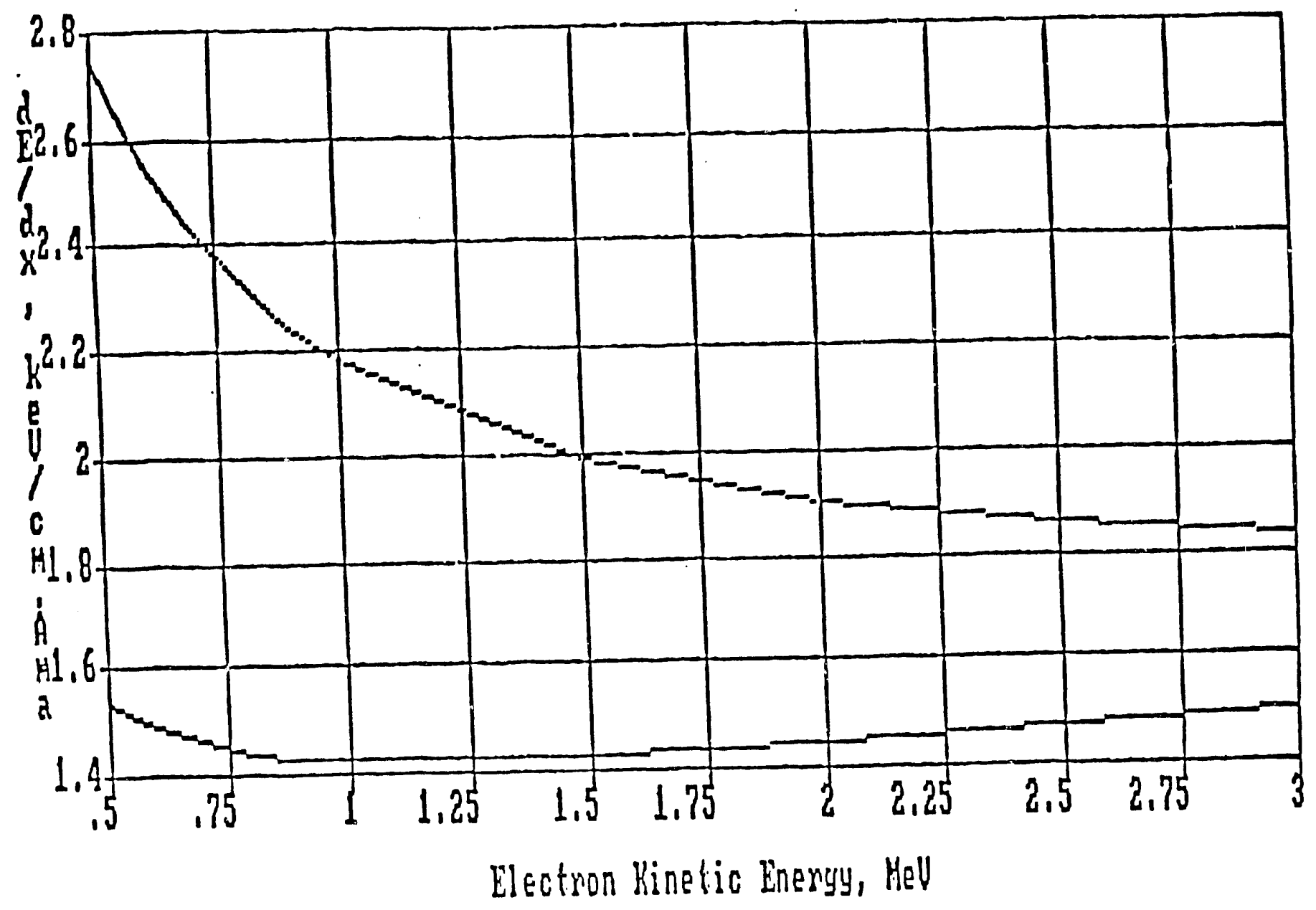

Figure 3-10. Neon e-beam stopping power as a function of electron energy. 


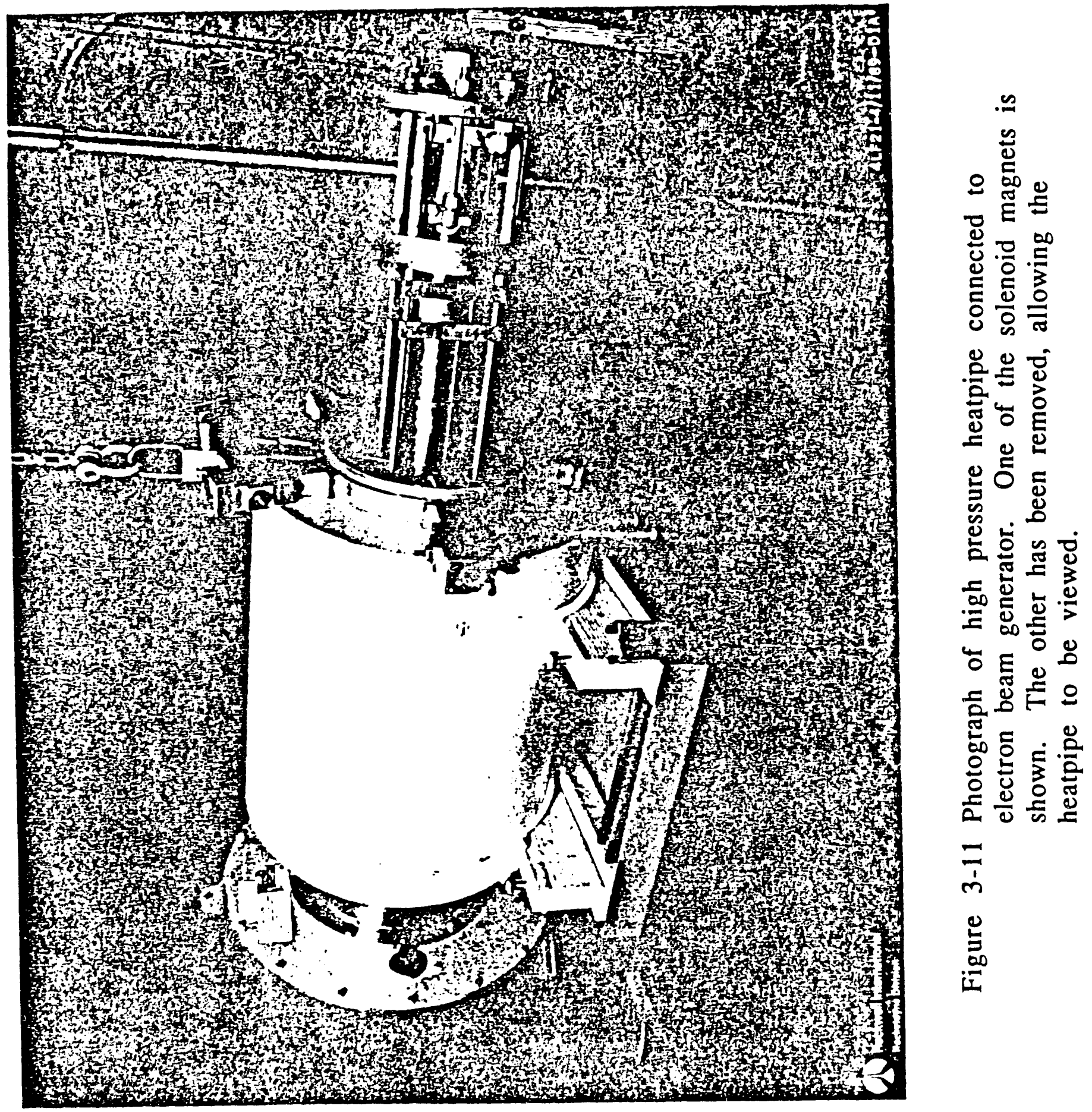


of the heatpipe (where the HPH-1 transverse monochromator viewing arm is located). Dosimetry measurements were made using a roscolene plastic as a thermoluminescent dosimeter. The electron beam profile shown in Figure 3-12 was obtained by analyzing the exposed roscolene with a microdensitometer. The electron beam profile exhibits a fairly uniform peak intensity.

The data obtained with HPH-1 and discussed in Section 4.3 were obtained using high pressures of helium buffer gas with the e-beam gun located a distance of $7 \mathrm{~cm}$ from the HPH entrance foil. For these parameters, the initial helium ion concentration should be at least

$$
[+] \sim 5 \times 10^{14} \mathrm{~cm}^{-3}
$$

Considering the specified beam energy of 4.8 Joules and range of 450 $\mathrm{cm} / \mathrm{atm}$ at the $50 \%$ power of $300 \mathrm{KeV}$, the average beam energy deposited in the plasma is

$$
\mathrm{E}_{\mathrm{b}}=7.8 \times\left[1+0.81 \mathrm{~L}+0.165 \mathrm{~L}^{2}\right]^{-1} \mathrm{~J} / \mathrm{liter}
$$

Better values for these parameters are contingent upon calibration of beam current and divergence, but it is believed that the interim use of these approximations is consistent with the accuracy of the data reported in the following section.

The fluorescence emission from the e-beam excited gas was monitored with the same detection apparatus as previously described. The fluorescence was dispersed with a VUV monochromator. Time resolved measurements were made with a PMT and an associated scintillator. Spectra were acquired with a VUV Optical Multichannel Analyzer. Figure 3-13 is a photograph showing the assembled apparatus. 


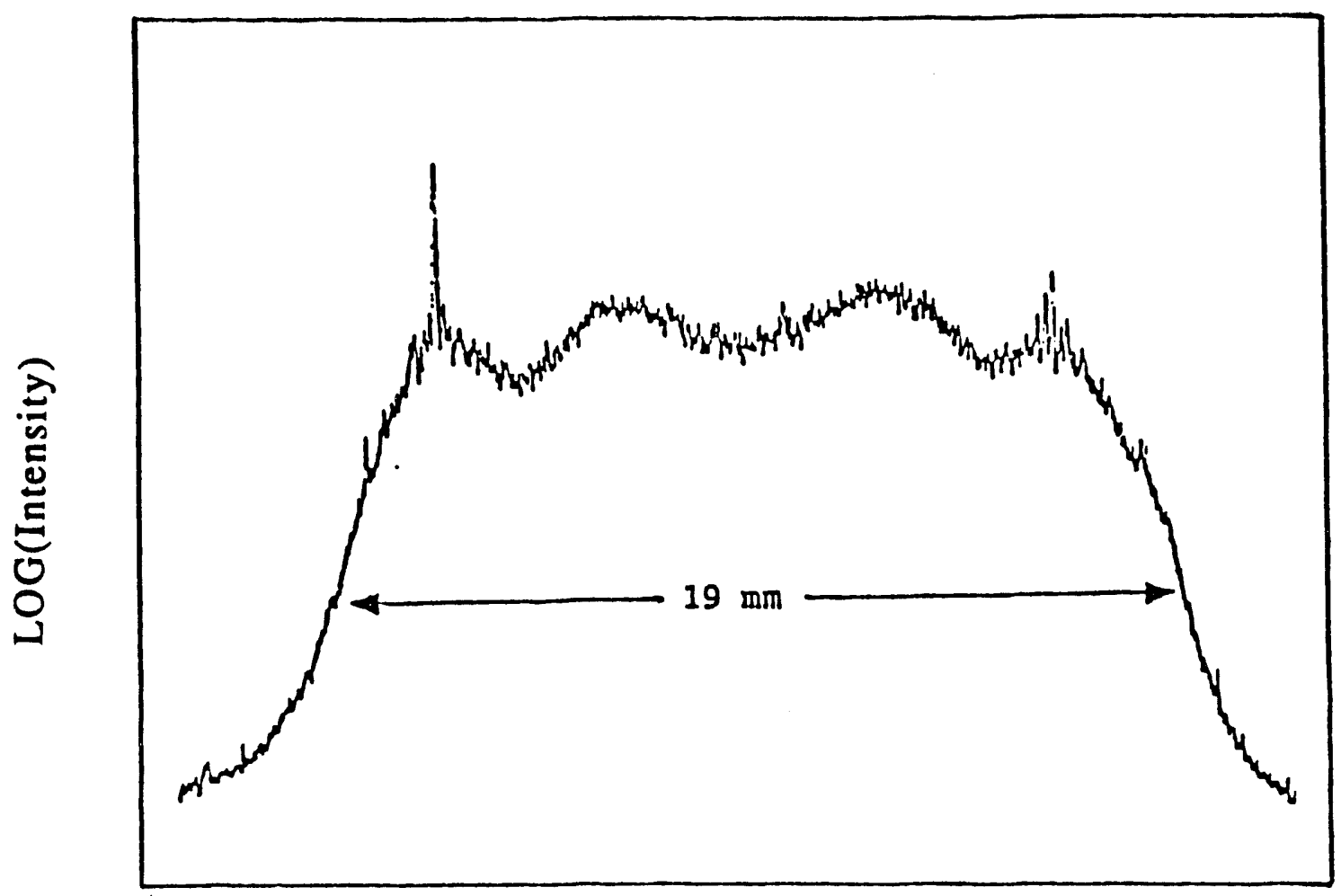

Figure 3-12. Electron beam profile obtained in the center of HPH-1 (56 $\mathrm{cm}$ away from the HP-43710A exit window) with a $6.4 \mathrm{KG}$ magnetic field applied. The profile shown was obtained by analyzing exposed roscoiolene thermoluminesient dosimeter with a microdensitometer. 


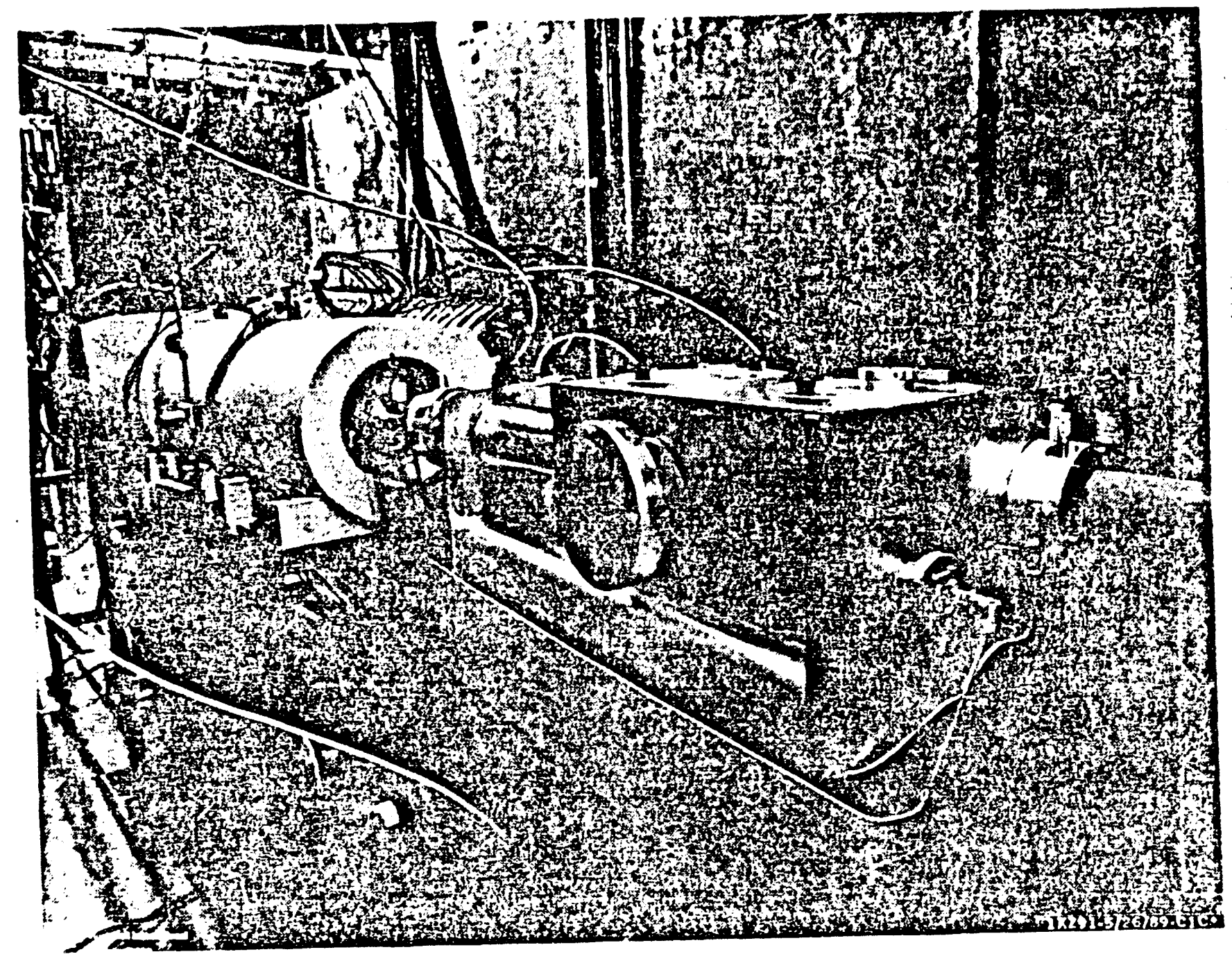

Figure 3-13 Photograph of the assembled electron beam excitation apparatus inside the lead shielded room. The 1-meter monochromator is in the foreground. It is connected to the heatpipe which is surrounded by the solenoid magnets to confine the electron beam. In the background is the electron beam generator. 


\subsection{Technical Results}

Two approaches for demonstrating fluorescence of ionic alkali-halide molecules such as $\mathrm{RbF}, \mathrm{RbBr}$ and $\mathrm{CsF}$ have been selected. The first produces the ionic excited states of alkali halides by incoherent soft $x$-rays emitted from a laser produced plasma. The second pumps the excited states by means of an electron beam. The first technique was selected for demonstration of some of the basic principles and for making preliminary spectroscopic measurements, such as transition wavelengths, lineshape, linewidth and fluorescence decay time. The use of electron beam excitation is intended for investigation of scaling feasibility for these systems.

In this section we present the results from production of $R^{2}+F-$, $\mathrm{Rb}^{2+} \mathrm{F}^{-}$and $\mathrm{Cs}^{2}+\mathrm{F}^{-}$excited ionic states. Fluorescence was observed from $\mathrm{Rb}^{2+} \mathrm{F}^{-}$and $\mathrm{Cs}^{2}+\mathrm{F}^{-}$while $\mathrm{Rb}^{2}+\mathrm{Br}^{-}$predissociated resulting in atomic $\mathrm{Br}$ emission. For $\mathrm{RbF}$ and $\mathrm{RbBr}$ ions the emission was derived from an inner shell ionization of $\mathrm{RbF}$ and $\mathrm{RbBr}$ accomplished with laser-produced sofit x-rays. For CsF the fluorescence was obtained by direct high energy pulsed electron beam excitation.

The $\mathrm{RbF}$ emission spectrum and time resolved fluorescence intensity are presented and discussed in section 4.2.1. Also included is a discussion of the pressure dependence of the ionic emission of the $\mathrm{RbF}$.

Discussion of soft $x$-ray excitation of $R b B r$ is given in 4.2.2. Due to predissociation of the $\mathrm{RbBr}$ excimer molecule, the anticipated emission near $90 \mathrm{~nm}$ is not observed.

Results of electron beam excitation of $\mathrm{CsF}$ in a high pressure heatpipe are presented in section 4.3. Effects of $\mathrm{Cs}$ vapor pressure and $\mathrm{He}$ and $\mathrm{Ne}$ buffer gas pressure on fluorescence intensity are also reported. Time-resolved fluorescence intensity is also presented. The possible formation and destruction mechanisms of $\mathrm{Cs}^{2+} \mathrm{F}^{-}$are discussed. 
Due to insufficient energies of atomic, molecular metastables and ions of $\mathrm{He}$, direct electron beam excitation of $\mathrm{RbF}$ has not been successful.

Electron beam excitation of three component mixtures such as $\mathrm{He}(\mathrm{Ne}) / \mathrm{Cs} / \mathrm{CF}_{4}\left(\mathrm{SiF}_{4}\right)$ and $\mathrm{He}(\mathrm{Ne}) / \mathrm{Rb} / \mathrm{BF}_{3}\left(\mathrm{SiF}_{4}\right)$ has also been investigated. Reasons for the lack of observable emission have not been fully established but a brief discussion of absence of emission is given in the end of this section.

In order to better understand the mechanisms of soft $x$-ray pumping and to characterize the detection equipment we first conducted a series of experiments using this means of excitation to study VUV emission in $\mathrm{Xe}^{2+}$ and $\mathrm{Kr}^{2+}$ resulting from Auger decay. The reference plasma experimental results using xenon and krypton are given in section 4.1 .

\subsection{Reference Plasma Check (soft $\mathrm{x}$-ray excitation of $\mathrm{Xe}$ and $\mathrm{Kr}$ )}

In our initial soft $x$-ray experiments, we studied $109 \mathrm{~nm}$ Auger emission 24 in $\mathrm{Xe}^{2+}$ and $90.7 \mathrm{~nm}$ emission 25 in $\mathrm{Kr}^{2+}$ pumped by incoherent $x$-rays from a laser produced plasma. In the first of these experiments, soft $x$-rays emitted from a laser produced plasma ionize inner-shell $4 d$ electrons in neutral xenon gas. As shown in Figure 4-1, the resulting highly excited $\mathrm{Xe}^{+}$atoms rapidly undergoes Auger decay to various excited states of $\mathrm{Xe}^{2+}$. The relative Auger decay rates and level degeneracies result in emission at $108.9 \mathrm{~nm}$ between $\mathrm{Xe}^{2+}$ $5 s^{0} 5 p^{6}{ }^{1} S_{0}$ and $5 s^{1} 5 p^{5}{ }^{1} P_{1}$. An analogous transition in Krypton, $\mathrm{Kr}^{2+}$ $4 s^{0} 4 p^{6}{ }^{1} S_{0}$ to $4 s_{1} 4 p^{5} 1 P_{1}$, shown in Figure 4-2, was similarly produced. Both emissions enabled us to determine the sensitivity of our VUV detection system.

The experimental apparatus used in the Auger experiments is shown in Figure 3-1. Briefly, a KrF excimer laser pulse $(700 \mathrm{~mJ}, 25 \mathrm{~ns})$ is focused onto a tantalum target to form a soft $x$-ray source. Radiation from the plasma ionizes xenon or krypton gas approximately $1-2 \mathrm{~cm}$ away from the target surface. The fluorescence was dispersed with a 


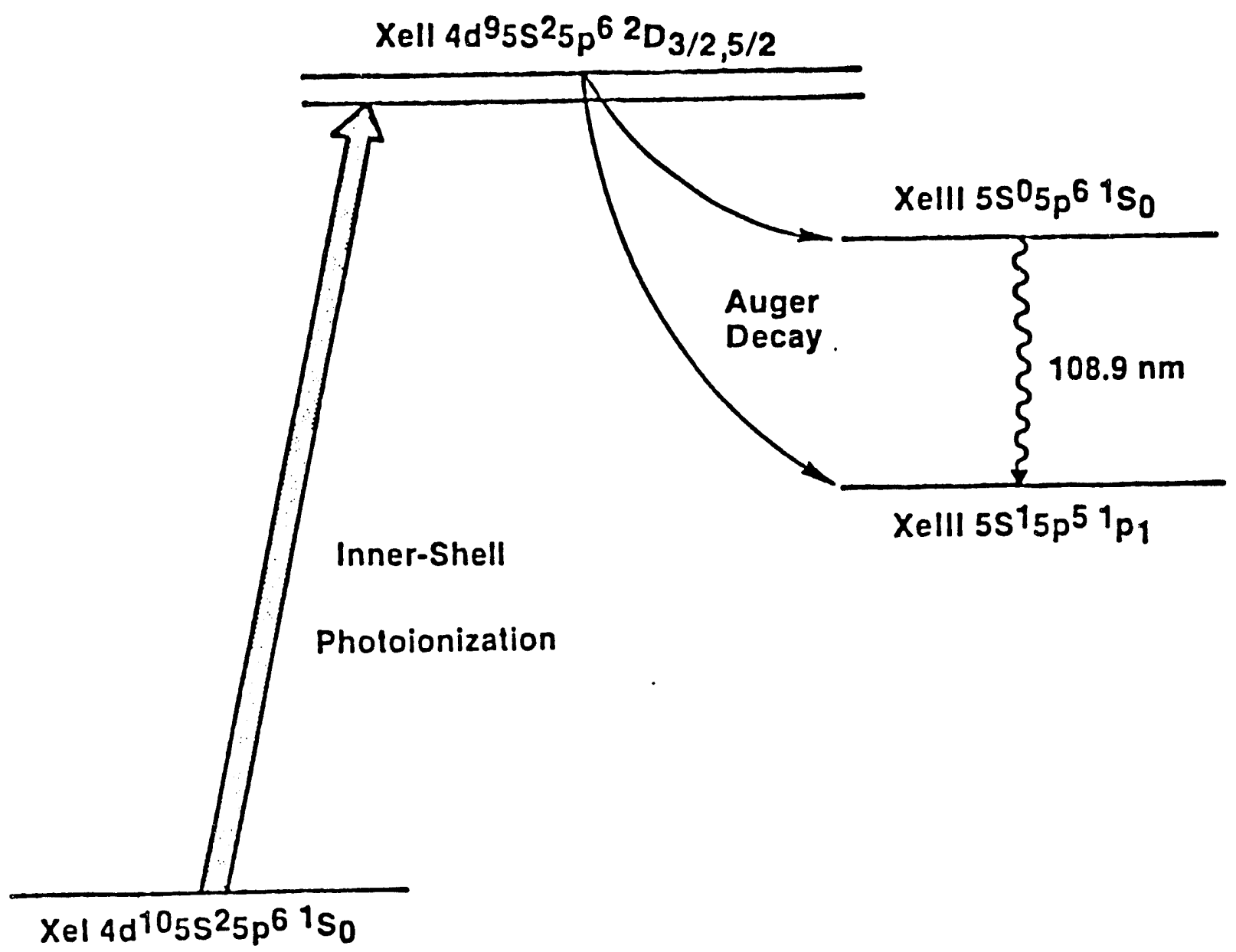

Figure 4-1. Energy levels of xenon showing production of Xe III levels by photoionization (via soft $x$-rays) followed by Auger decay. The emission at $108.9 \mathrm{~nm}$ was monitored. 


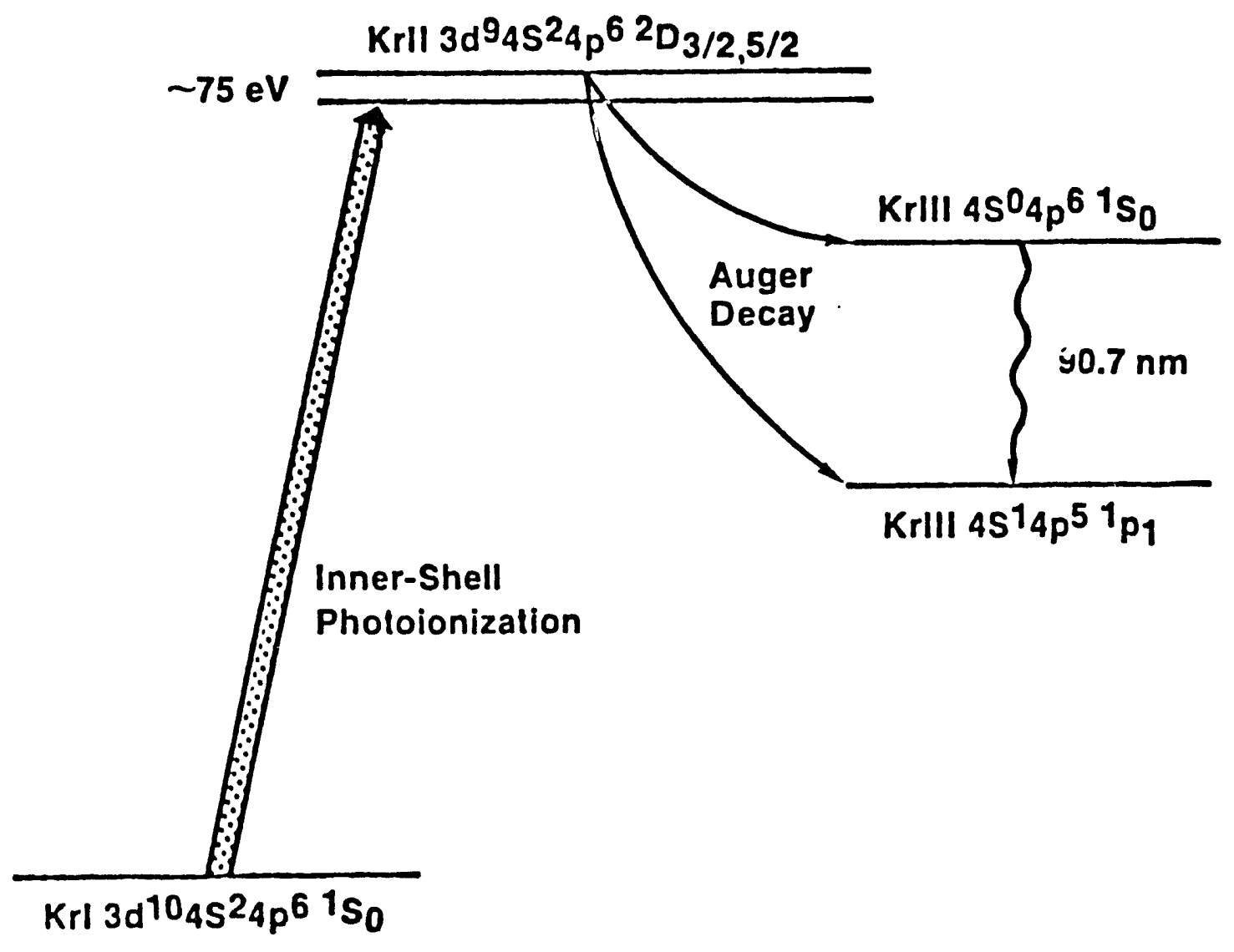

Figure 4-2. Energy levels of Krypton showing production of Kr III levels by photoionization (via soft $\mathrm{X}$-rays) followed by Auguer decay. The emission at $90.7 \mathrm{~nm}$ was monitored. 
monochromator and detected with a photomultiplier equipped with a sodium salicylate scintillator.

The temporarily resolved emission at $109 \mathrm{~nm}$ obtained from soft $\mathrm{x}$ ray excited $\mathrm{Xe}$ at 2 torr is shown in Figure 4-3. Each data point is an average of 30 shots. This emission exhibits a temporal width of about $30 \mathrm{~ns}$, about the same as that of the $\mathrm{KrF}$ excimer laser pulse. A similar emission profile was also observed for $\mathrm{Xe}$ at 4 Torr (Figure 4-4) and at 8 Torr (Figure 4-5), but with reduced intensity. Auger fluorescence dependence on pressure was measured for $\mathrm{Kr}$ pressures of 0.5 Torr (Figure 4-6), 2 Torr (Figure 4-7) and 10 Torr (Figure 4-8). The maximum emission intensity was found to occur with a $\mathbf{K r}$ pressure of 2 Torr. The reduction in intensity at higher pressure may be due to self-absorption by Kr. These "reference plasma" experiments permitted a preliminary characterization of the soft $x$ ray apparatus.

\subsection{Alkali Halide Soft X-ray Experiments}

\subsubsection{Soft X-ray Excitation of RbF}

In this section we present the observation of fluorescence from $\mathrm{Rb}^{2}+\mathrm{F}^{-}$excited ionic states. The emission is derived from an innershell ionization of $\mathrm{RbF}$ that is generated in a heatpipe by laser produced soft $x$-rays. The emission spectrum and the time resolved fluorescence intensity are presented and discussed. The deperdence of the ionic emission on $\mathrm{RbF}$ vapor pressure is also reported.

By using a Rittner potential ${ }^{11}$ for the upper state and a Born-Mayer potential for the repulsive interaction 12 , the range of the emitted wavelengths of $115-130 \mathrm{~nm}$ for the $\mathrm{Rb}^{2}+\mathrm{F}-$ to $\mathrm{Rb}^{+} \mathrm{F}$ transition has been estimated.8,15 The potential diagram for the RbF system is shown in Figure 4-9. The emission should exhibit structure similar to that observed for rare-gas-halide excimers. The main emission bands are due to the $\mathrm{B}-\mathrm{X}$ and $\mathrm{C}-\mathrm{A}$ transitions. 


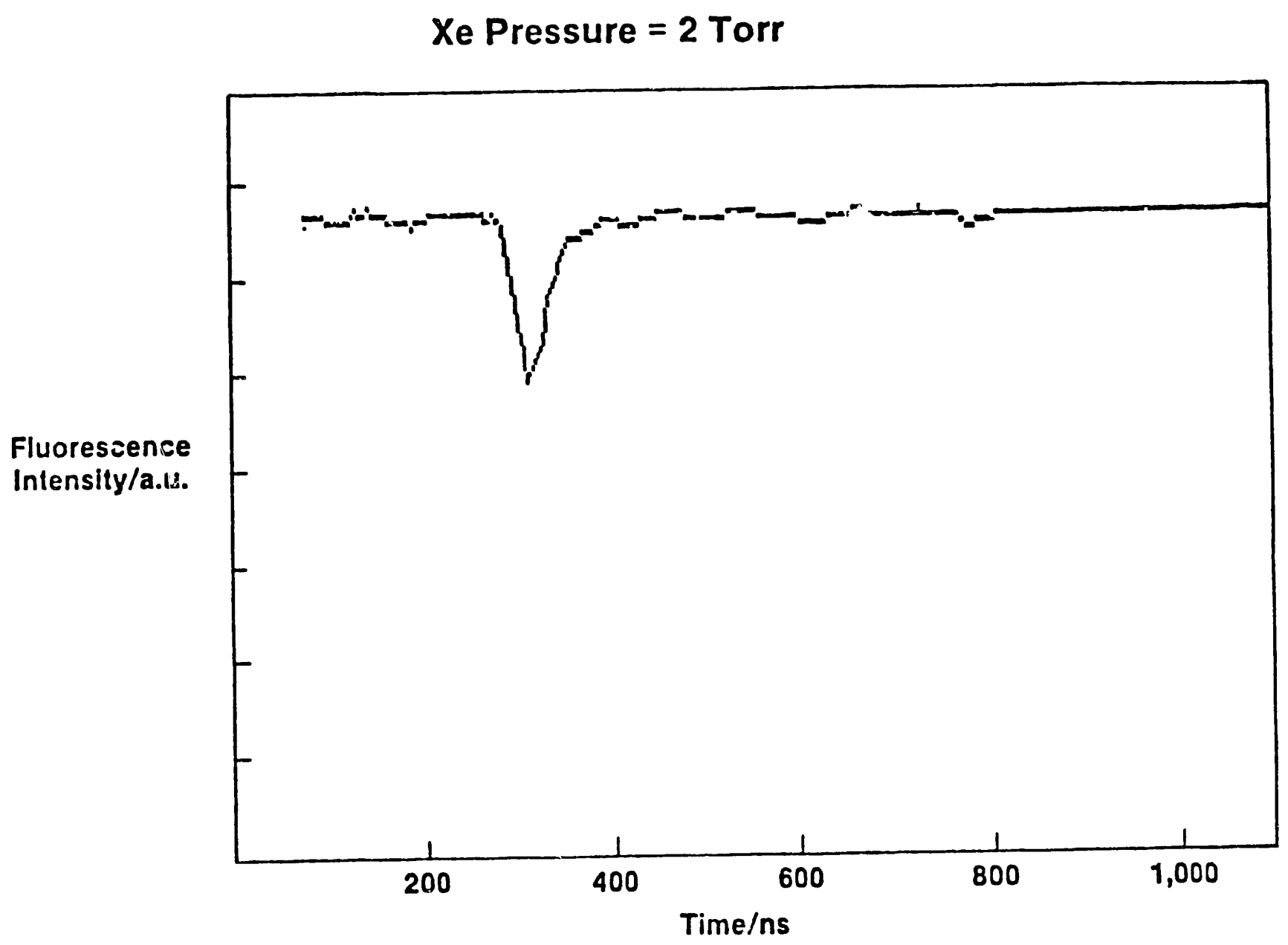

Figure 4-3. Time-resolved XellI Auger fluorescence signal at $108.9 \mathrm{~nm}$. The Xe pressure was 2 Torr. 


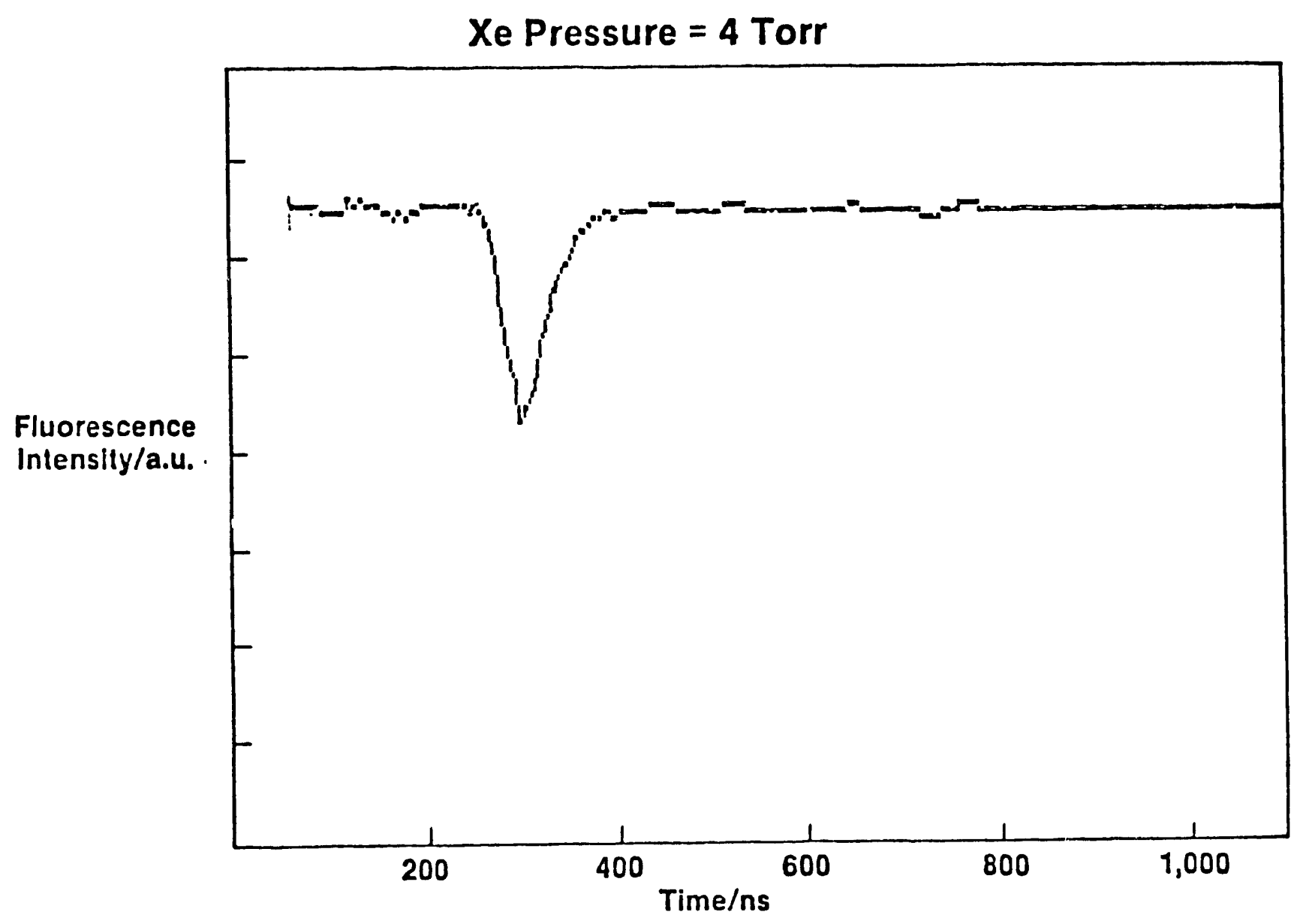

Figure 4-4. Time-resolved XellI Auger fluorescence signal at $108.9 \mathrm{~nm}$. The Xe pressure was 4 Torr. 


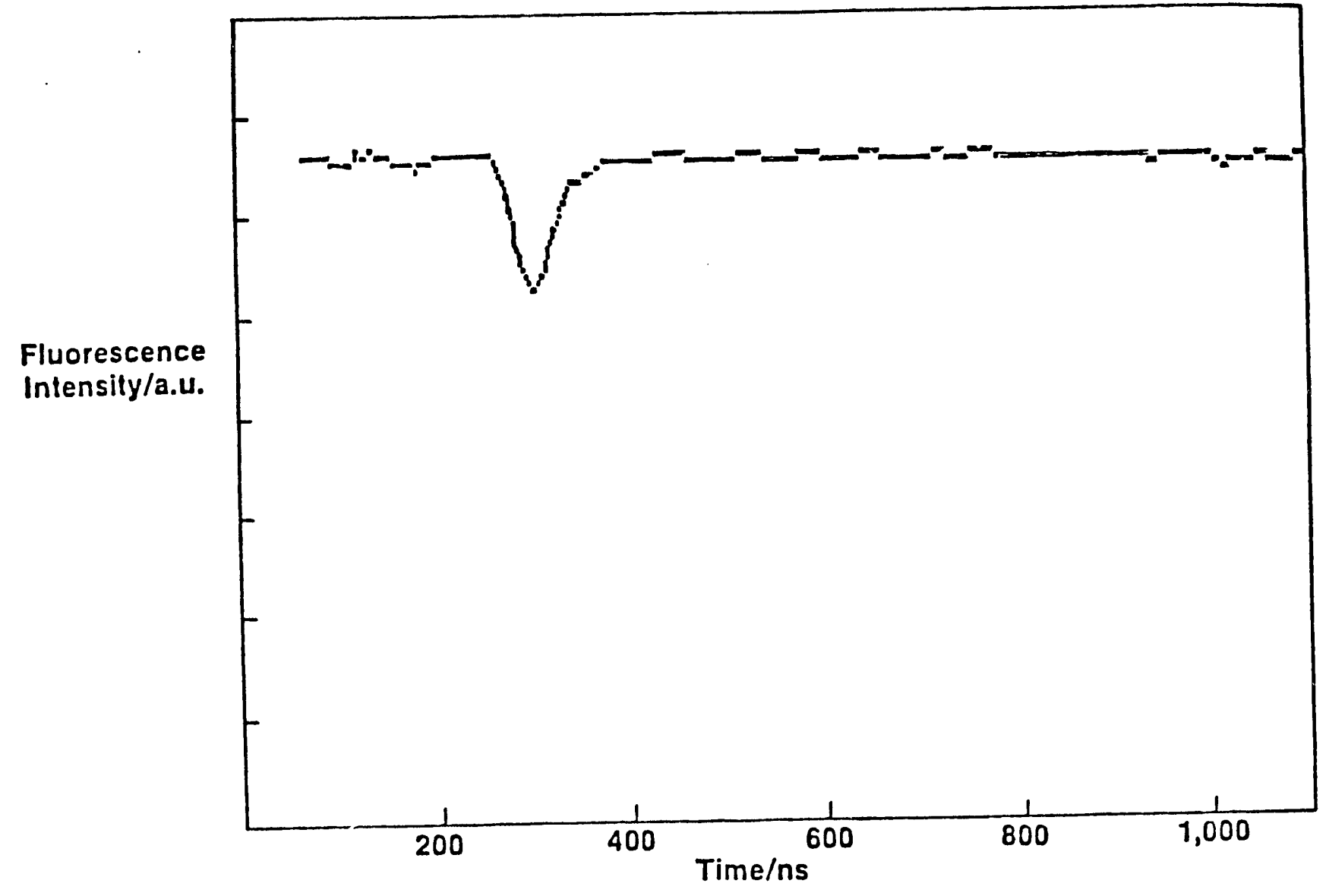

Figure 4-5. Time-resolved Xe III Auger fluorescence signal at108.9 $\mathrm{nm}$. The Xe pressure was 8 Torr. 


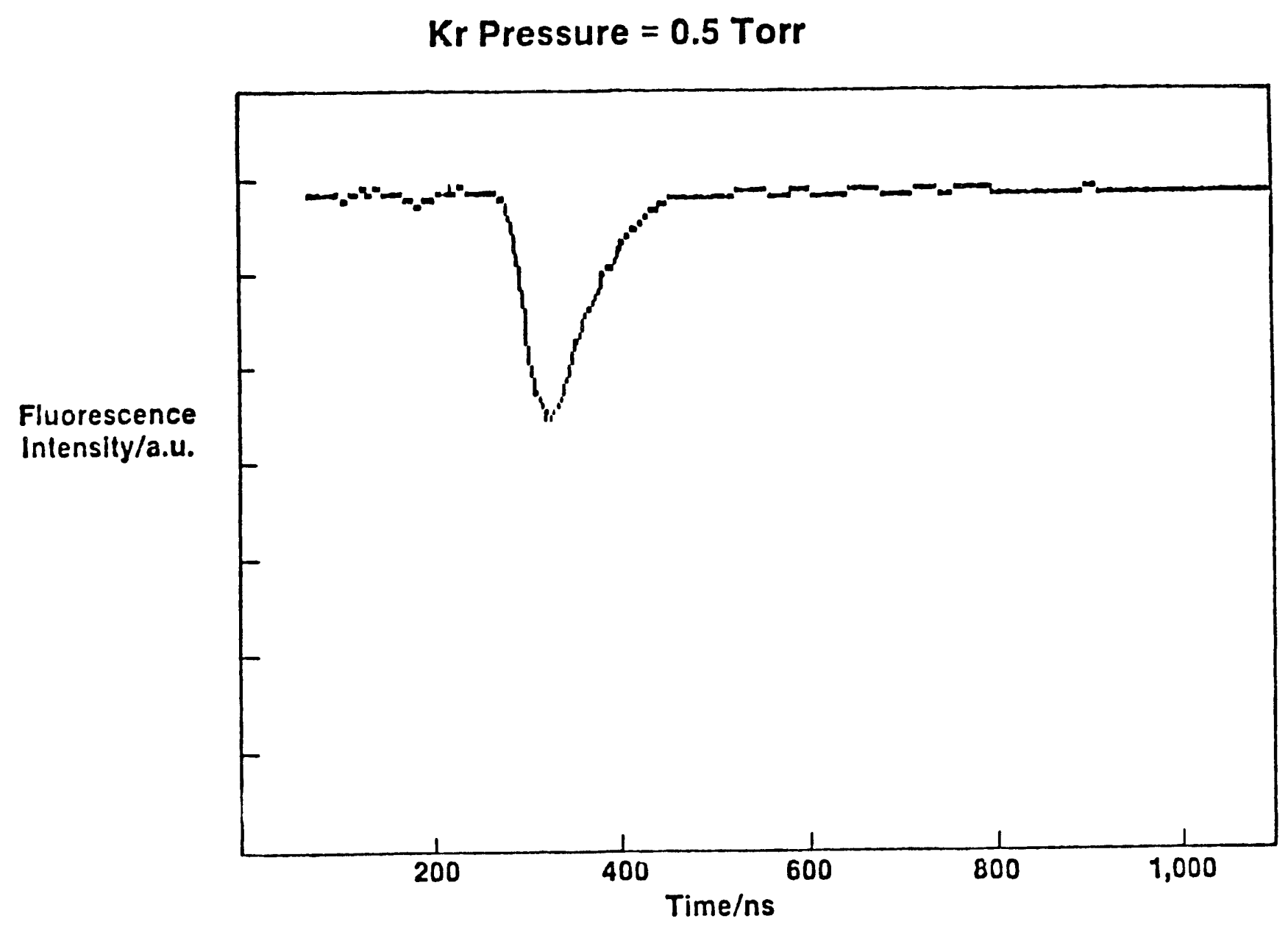

Figure 4-6. Time-resolved Kr III Auger fluorescence signal at $90.7 \mathrm{~nm}$. The $\mathrm{Kr}$ pressure was 0.5 Torr. 


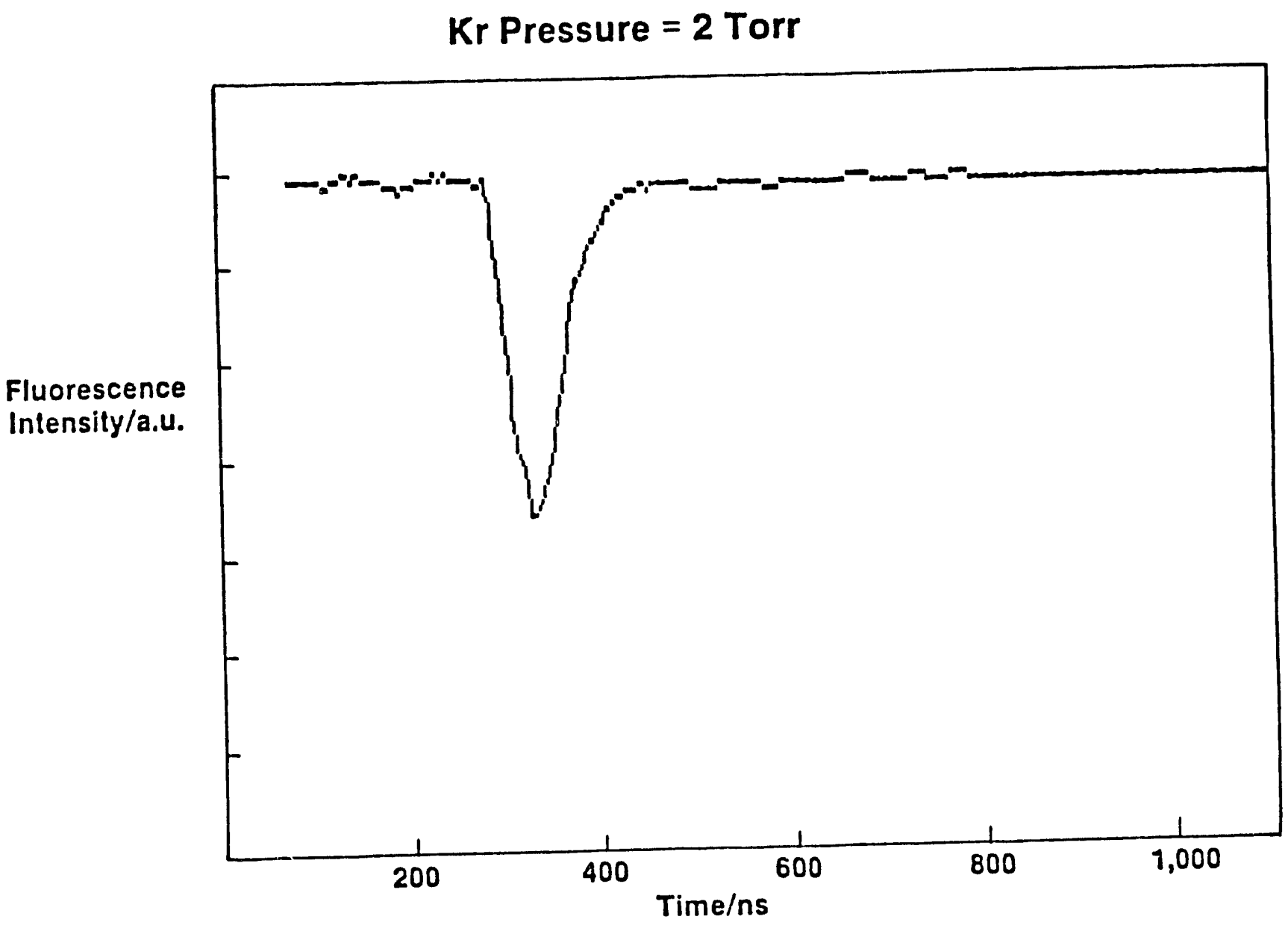

Figure 4-7. Time-resolved Krlll Auger fluorescence signal at $90.7 \mathrm{~nm}$. The $\mathrm{Kr}$ pressure was 2 Torr. 


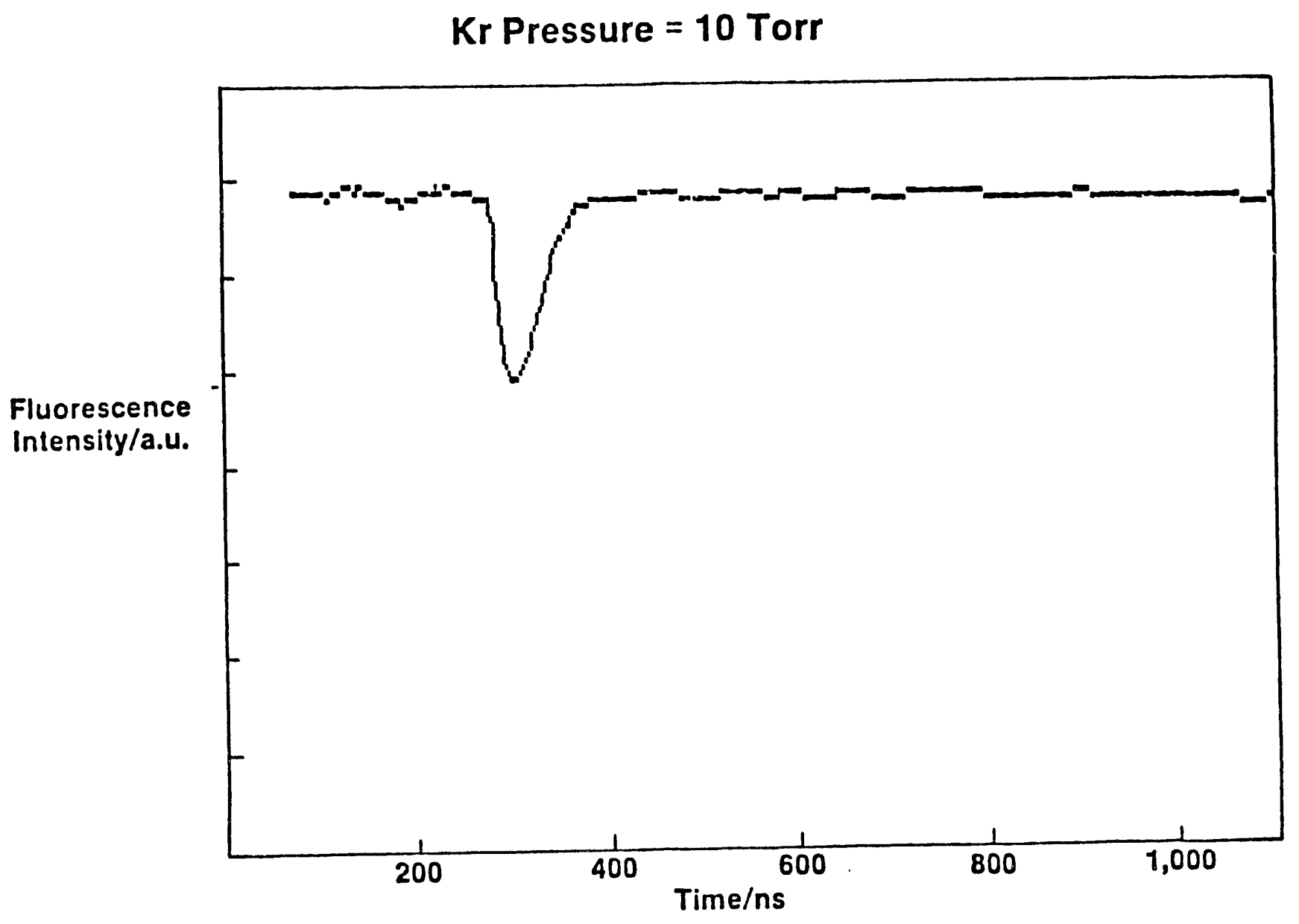

Figure 4-8. Time-resolved $\mathrm{Kr}$ III Auger fluorescence signal at 90.7 $\mathrm{nm}$. The $\mathrm{Kr}$ pressure was 10 Torr. 

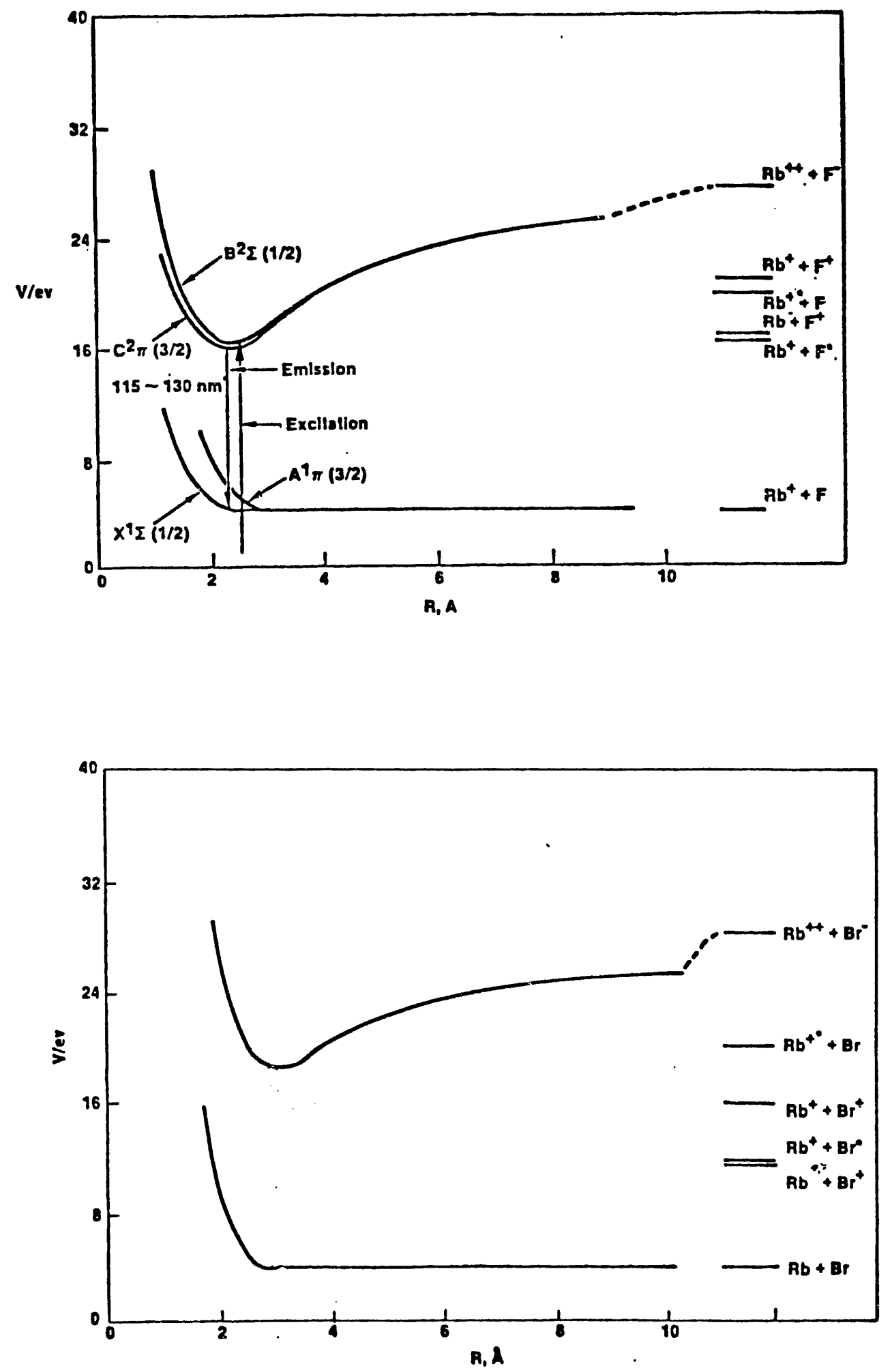

Figure 4-9. Potential curves for the relevant states of the RbF ionic excimer. The observed emission is atuributed to the $\mathrm{Rb}^{2+} \mathbf{F}$ - transition. 
Caro et al. 17 have described the use of laser-produced soft $\mathrm{x}$-rays to obtain densities of core excited atomic metastables or excited ionic molecules that exceed $1015 / \mathrm{cm}^{3}$. This technique for the production of excited ionic molecules can be reasonably simple and shows promise as an excitation source for VUV and XUV spectroscopy. The upper states of ionic excimer molecules are similar to an inner-shell ionized state of an atom; it is therefore believed that these ionic excimer states can be excited efficiently by soft $x$-rays emitted from a laser produced plasma.

The configuration of the experiment described here is essentially the same as that used in the $\mathrm{Xe}$ and $\mathrm{Kr}$ plasma check experiments described in the previous section. A tantalum target was placed inside a heat pipe containing RbF vapor at a density that could vary from $10^{16}$ to $10^{17} / \mathrm{cm}^{3}$. The $248-\mathrm{nm} \mathrm{KrF}$ laser beam beam was focused onto a tantalum target by a quartz lens with a focal length of $50 \mathrm{~cm}$. The $\mathrm{KrF}$ laser provided a $700-\mathrm{mJ}$ pulse with a $25 \mathrm{~ns}$ pulse width. The spot size in the focus was estimated to be approximately $100 \mu \mathrm{m}^{2}$, which corresponded to a power density of the order of $10^{11} \mathrm{~W} / \mathrm{cm}^{2}$ on the target. The conversion efficiency from the incident laser energy to the energy of soft $x$-rays emitted from the laser produced plasma was estimated to be approximately $14 \% .26$ The emitted soft $x$-ray radiation propagated into the surrounding vapor (Figure 4-10) causing photoionization and production of excited ionic molecules.

In the soft $x$-ray apparatus shown in Figure 3-1 the distance of the tantalum target from the optical axis could be varied. For most of the measurements the target was placed approximately $0.5 \mathrm{~cm}$ away from the optical axis. The spectrometer was connected windowless to the heat-pipe cell. The helium buffer gas pressure in the system was measured with a Baratron pressure gauge. The spectrometer slit widths used in these experiments ranged from 50 to $150 \mathrm{um}$. A photomultiplier with a sodium salicylate scintillator was used as a detector. The rise time of this detector was about $5 \mathrm{nsec}$. The output of the photomultiplier tube was fed into a boxcar integrator. A gate width of $30-50 \mathrm{nsec}$ was used to discriminate the $\mathrm{Rb}^{2}+\mathrm{F}^{-}$emission from background light.

Inside the cell, soft $x$-rays emitted from the laser produced plasma ionized the $\mathrm{RbF}$ vapor, which produced inner-shell ionized $\mathrm{Rb}^{2}+\mathrm{F}-$ and 


\section{Schematic of Soft X-Ray Excitation}

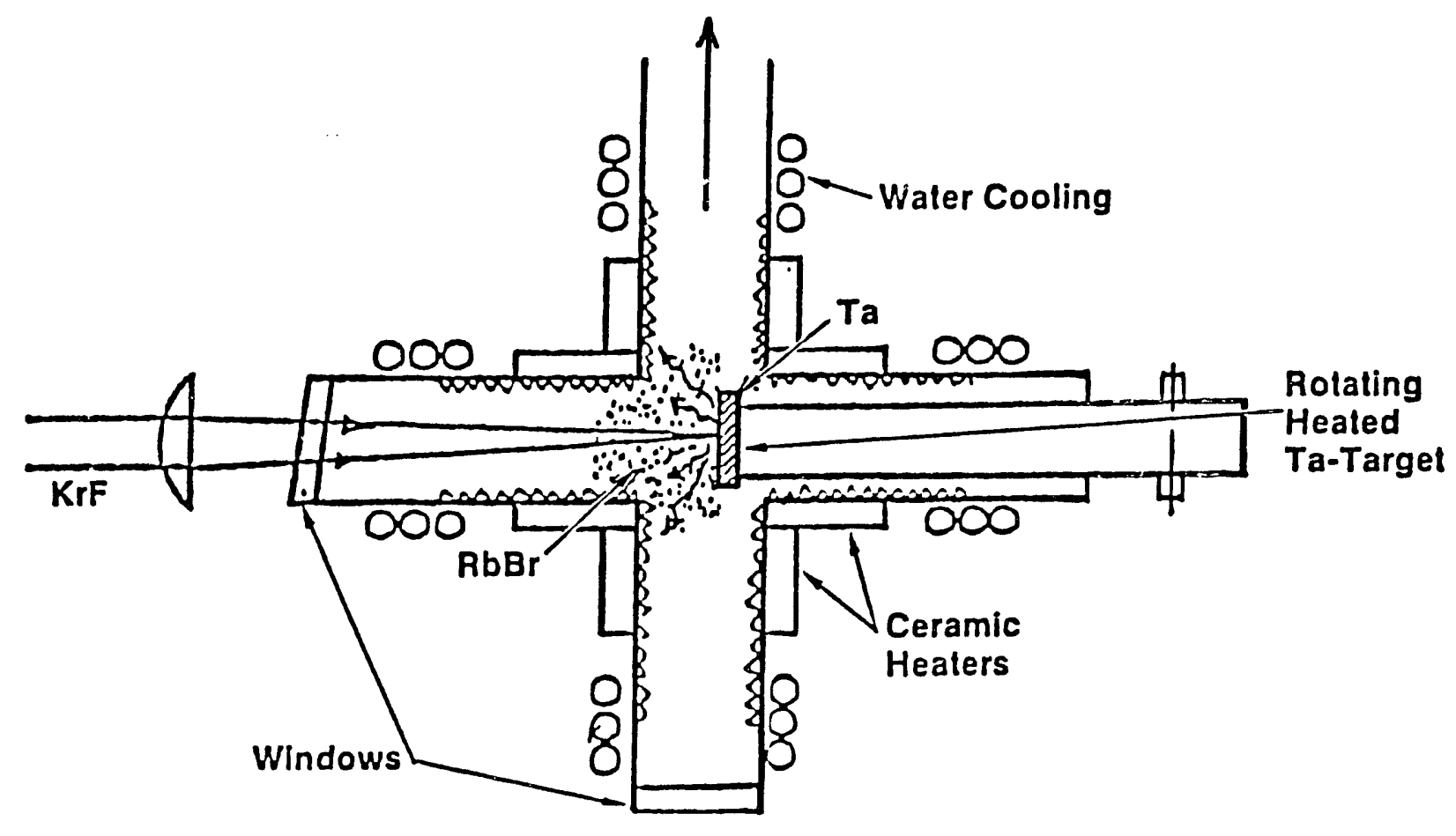

Figure 4-10. Schematic of the low presure heatpipe (LPH). 
hot electrons. 27 The hot electrons may also produce $\mathrm{Rb}^{2+} \mathrm{F}$ - by direct impact ionization. The emission spectrum obtained between 100 and $190 \mathrm{~nm}$ for a RbF vapor pressure of 4.0 Torr is shown in Figure 4-11. For comparison, a background spectrum obtained in a cold cell with 4.0 Torr of helium is shown in Figure 4-12. The strongest emission peaks were observed at 121,130,157, 160 and $164 \mathrm{~nm}$. The 121and 164-nm emissions are due to well-known He II transitions. 28 The fluorescence at 157 and $160 \mathrm{~nm}$ is attributed to excited $F_{2}$ emission 29. The strong peak at $130 \mathrm{~nm}$ is believed to correspond to the $B \rightarrow X$ transition in $R b F$. The estimated wavelength of $115-130 \mathrm{~nm}$ shown in Figure 4-9 is in good agreement with the experimentally observed value. The fluorescence wavelength is identical within the experimental uncertainty to that recently reported by Steigerwald and Langhoff, 14 for which an ion beam excitation of $\mathrm{RbF}$ was used.

In addition to these narrow-band features, it appears that there is a broadband emission centered around $155 \mathrm{~nm}$. Interpretation of this broadband emission is complicated by the fact that the emission is overlapped by the $\mathrm{F}_{2}{ }^{*}$ and $\mathrm{He}$ II emissions. Also, the appearance of the spectrum depends on the vibrational energy in the upper state as well as on the shape of the lower state. Nevertheless, it appears that much of the fluorescence at $155 \mathrm{~nm}$ originates from $\mathrm{Rb}^{2}+\mathrm{F}-$. With no known lines at this wavelength, one can tentatively assign this broadband emission to the $\mathrm{C} \rightarrow \mathrm{A}$ transition of this molecule.

In order to identify the broadband $155 \mathrm{~nm}$ emission, one must examine the energy-level diagram for $\mathrm{Rb}^{2}+\mathrm{F}-$. Analogous to the raregas halogen excimers, this ionic molecule is expected to have closely spaced, deeply bound excited ionic states, B and C,30 as shown in Figure 4-9. There are also two lower states, one weakly bound and one repulsive (the $X$ and $A$ states, respectively). There is a small binding energy in the $R b+F$ state, 31 and, as a result, the $B \rightarrow X$ transition is expected to be relatively narrow-banded.

Krauss found that the energy splitting between the $\mathrm{B}$ and $\mathrm{C}$ states in rare-gas-halide excimers is strongly dependent on the extent of configuration mixing between the $\mathrm{B}$ and $\mathrm{C}$ states. ${ }^{32}$ Furthermore, the extent of configuration mixing was found to depend strongly on the extent of binding within the ground state.33.34 As a consequence, we expect_a relationship to exist between this binding energy and the 


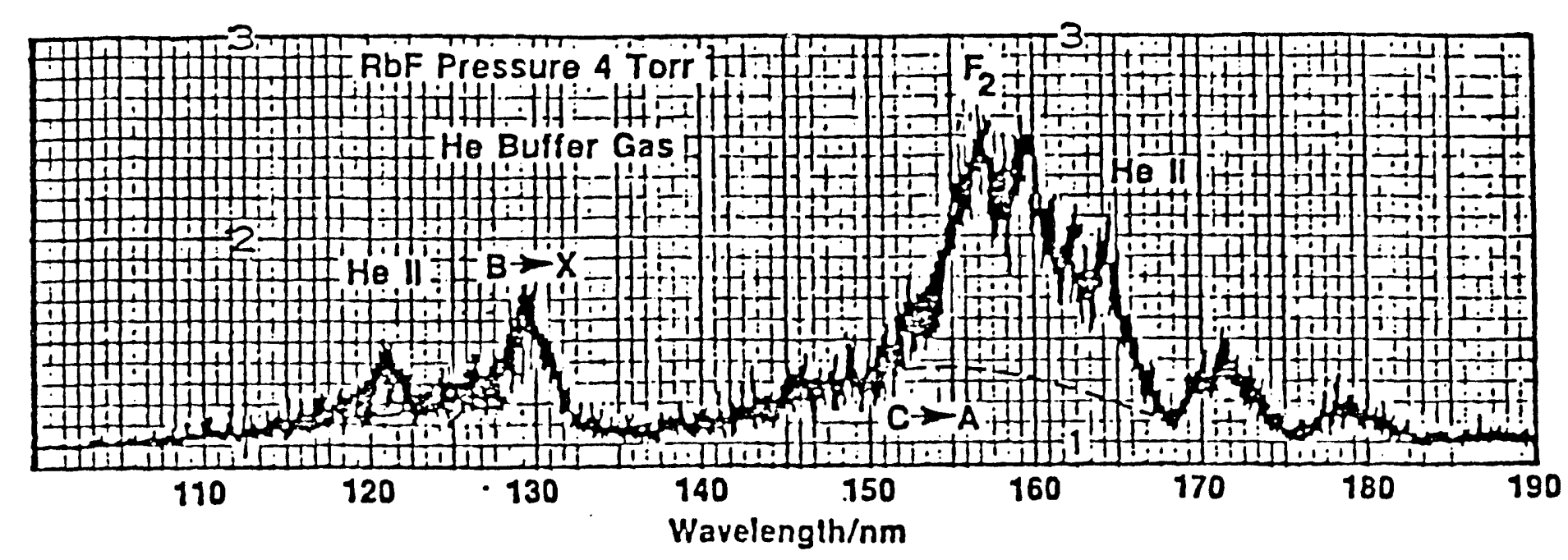

Figure 4-11. Emission spectrum laser-produced plasma excited RbF vapor. The RbF pressure was 4 Torr.

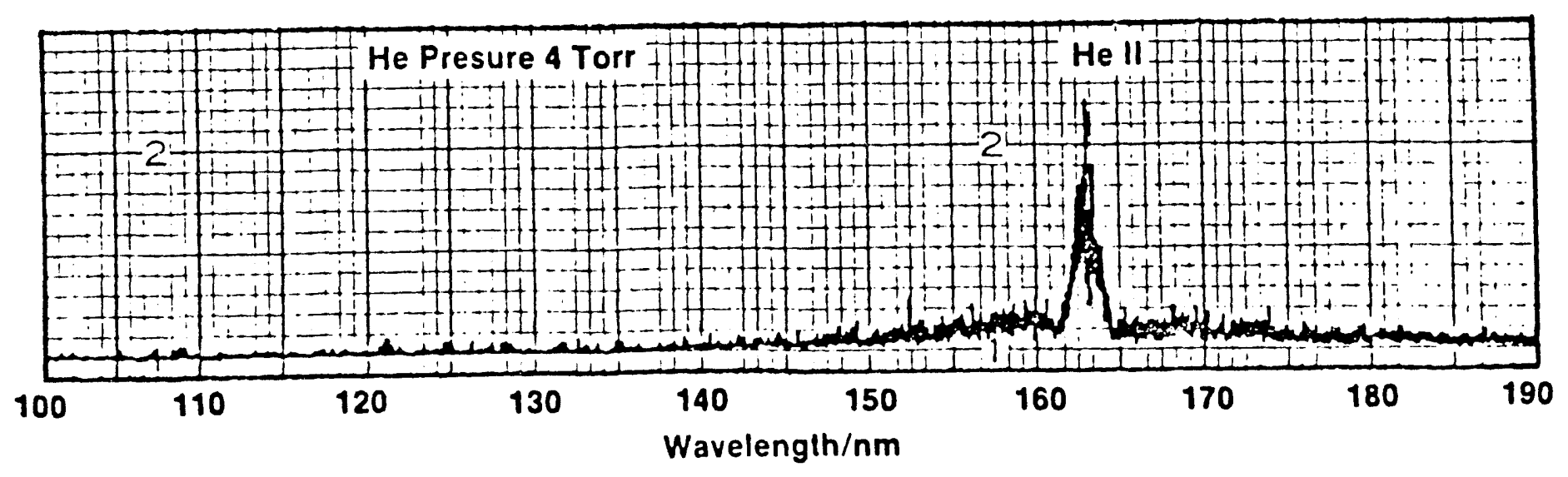

Figure 4-12. Emission spectrum of 4 Torr of helium excited by soft-x-rays emitted from a laser produced plasma. 
separation of the B and C states.35 A correlation of B-C splitting with the binding energy of the ground state obtained for several rare-gashalide excimer molecules is shown in Figure 4-13. The same correlation is assumed to apply to the isoelectronic ionic alkali-halide excimers. This simple correspondence indicates that for a groundstate binding energy in $R b^{+} F$ of $1130 \mathrm{~cm}^{-1}$ the expected $B-C$ split should be in the neighborhood of $800 \mathrm{~cm}^{-1}$. For heavy-particle B-C mixing a rate constant of $k_{\mathrm{BC}} \sim 10^{-12} \mathrm{~cm}^{3} / \mathrm{sec}$ is estimated by analogy with $\mathrm{XeF}, 9,10$ (slow interconversions). Accordingly, at densities near $1017 / \mathrm{cm}^{3}$ it is not expected that the B-C coupling by this process will be important relative to the radiative lifetime. On the other hand, it is conceivable that collisional coupling by plasma electrons could become a $10 \%$ effect. This would result from an assur.ption of 10-6 $\mathrm{cm}^{3} / \mathrm{sec}$ for the coupling constant and an electron density of $10^{14} / \mathrm{cm}^{3}$.

Because of the steep rise of the A-state energy curve with respect to the $\mathrm{X}$ state, the C-A emission band is expected to be broad and shifted toward the long-wavelength region of the spectrum relative to $B-X$ emission. The FWHM of the observed peak is approximately $25 \mathrm{~nm}$ to the red side of the B-X transition peak. $\mathrm{Kr}^{+} \mathrm{F}^{-}$, which is the isoelectronic rare-gas-halide excimer molecule analogous to $\mathrm{Rb}^{2}+\mathrm{F}^{-}$, has a B-X transition wavelength of $248 \mathrm{~nm}$ and a broadband C-A transition centered near $285 \mathrm{~nm}$. Since $\mathrm{Rb}^{2+} \mathrm{F}^{-}$is likely to have a similar molecular-state structure and spectrum, the assignment of the observed features at 130 and $155 \mathrm{~nm}$ as $\mathrm{B}-\mathrm{X}$ and $\mathrm{C}-\mathrm{A}$ in $\mathrm{Rb} \mathrm{b}^{2+\Gamma-\text { is }}$ consistent with the known transitions of the $\mathrm{Kr}^{+} \mathrm{F}$-spectrum. It should be noted that the emission spectrum shown in Figure 4-11 was not corrected for grating efficiency. When the correction is included, the magnitude of the intensity of the B-X transition will be much larger than C-A emission intensity.

The time-resolved $\mathrm{Rb}^{2}+\mathrm{F}^{-}$fluorescence intensity at $130 \mathrm{~nm}$ is shown in Figure 4-14. The emission exhibits a temporal width of approximately $35 \mathrm{nsec}$, (FWHM). This temporal width is approximately the same as that observed by Kubodera et al.36 for the ionic $\mathrm{Cs}^{2}+\mathrm{F}-$ excimer transition. The decay time of the fluorescence pulse shown in Figure 4-14 is approximately $20 \mathrm{nsec}$. The temporal decay to the $\mathrm{Rb}^{2+} \mathrm{F}$ - fluorescence is controlled either by the pumping process or by the overall decay of the upper states. Since the lifetime appears longer than the expected 1 nsec radiative term, 8 the $B$ state 


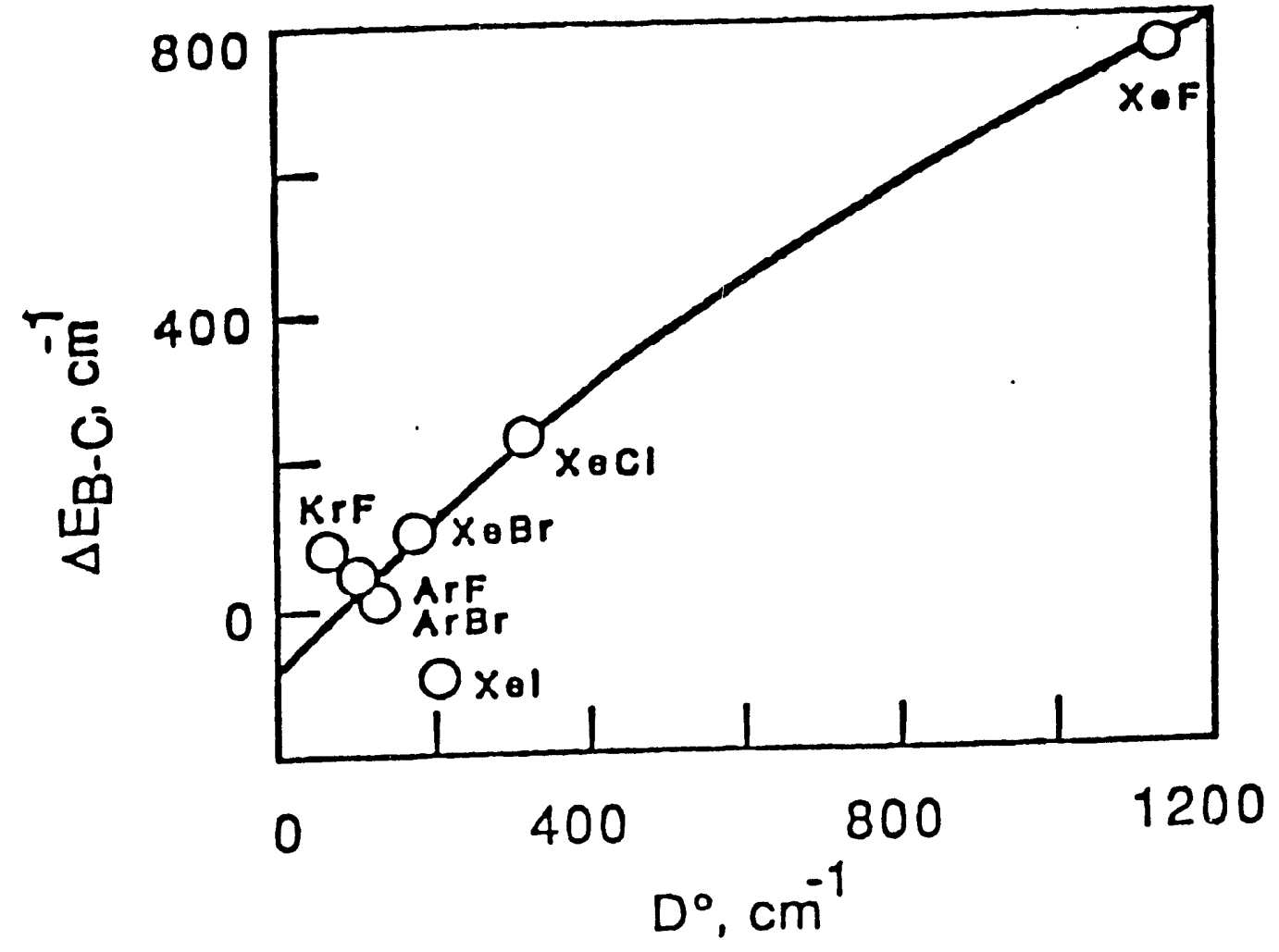

Figure 4-13. Correlation of B - C splitting with binding energy of ground state for rare-gas-halide excimer molecules. 


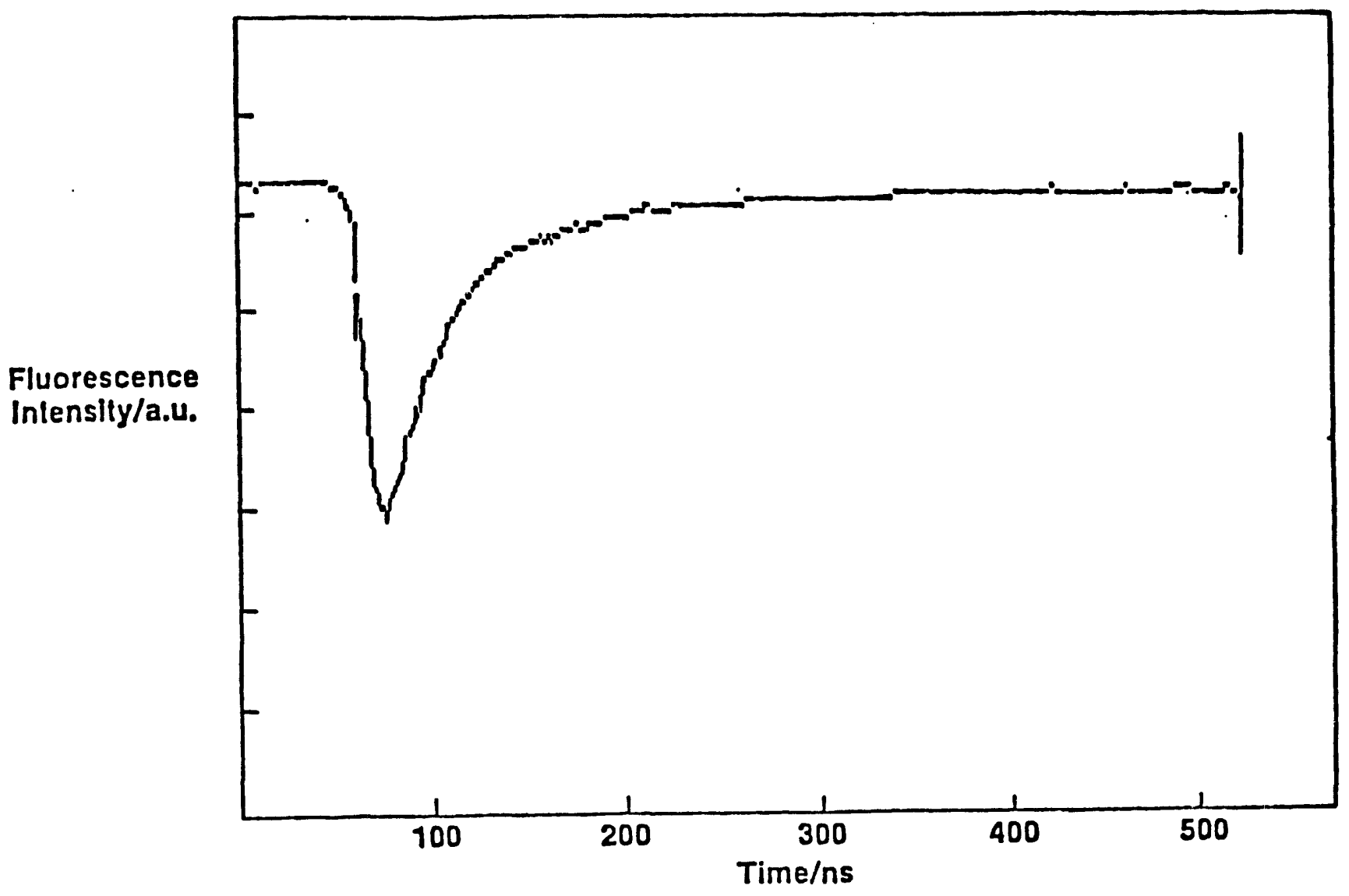

Figure 4-14. Time-resolved $\mathrm{Rb}^{2}+\mathrm{F}$ - fluorescence signal at $130 \mathrm{~nm}$ for a $\mathrm{RbF}$ pressure of 4.0 Torr. 
must be continuously populated for the entire $20 \mathrm{nsec}$. This may be due to the transfer of the expected long lived $C$ state. At present we do not have a specific explanation for this phenomenon.

The dependence of the $130 \mathrm{~nm} \mathrm{B-X}$ and $155 \mathrm{~nm} \mathrm{C-A}$ fluorescence on the $\mathrm{RbF}$ pressure was also investigated. Results obtained for $\mathrm{RbF}$ pressures of 2, 4 and 6 Torr are shown in Figure 4-15. While spectra obtained under different pressures are similar, the details of the structure varied. The structure is believed to be due to vibrationalrotational relaxation of the upper state rather than to detector noise. 15,36 The emission peak at $130 \mathrm{~nm}$ appeirs to increase slightly with increasing $\mathrm{RbF}$ pressure in the pressure range investigated. This indicates that the observed pressure-dependent fluorescence intensity is not significantly influenced by self-absorption of the RbF vapor or by electron quenching for RbF pressures between 2 and $u$ Torr.

In summary, the fluorescence of the ionic metastable $\mathrm{Rb}^{2}+\mathrm{F}^{-}$molecule pumped by laser-produced soft $\mathrm{x}$-rays has been observed. This technique for the production of ionic and core metastables can be reasonably simple and shows promise for applications in XUV spectroscopy.

\subsubsection{Soft X-ray Excitation of $\mathrm{RbBr}$}

The soft $x$-ray excitation technique was also used to study $\mathrm{RbBr}$. Figure 4-16 shows the results obtained for $\mathrm{RbBr}$ at pressures of 2,4 and 6 Torr. The anticipated emission near $90 \mathrm{~nm}$ from the $\mathrm{Rb}^{2}+\mathrm{Br}^{-}$to $\mathrm{Rb}^{+} \mathrm{Br}$ transition was not observed. The emission lines shown in Figure 4-16 have been identified to be transitions in atomic bromine. It is presumed that the absence of this emission and the observation of atomic bromine line emission is due to predissociation of the excimer molecule. Since the $\mathrm{Rb}^{+}+\mathrm{Br}^{*}$ and states are located lower than $\mathrm{Rb}^{2+}+\mathrm{Br}^{-}$states, the $\mathrm{Rb}^{2+} \mathrm{Br}^{-}$is not stable against predissociation as indicated in Figure 4-9. The $\mathrm{Rb}^{2}+\mathrm{Br}^{-}$curve is therefore expected to cross the $\mathrm{Rb}^{+}+\mathrm{Br}^{+}$and $\mathrm{Rb}^{+}+\mathrm{Br}^{*}$ potential curves at short $\mathrm{Rb}^{+}+\mathrm{Br}$ separation. 

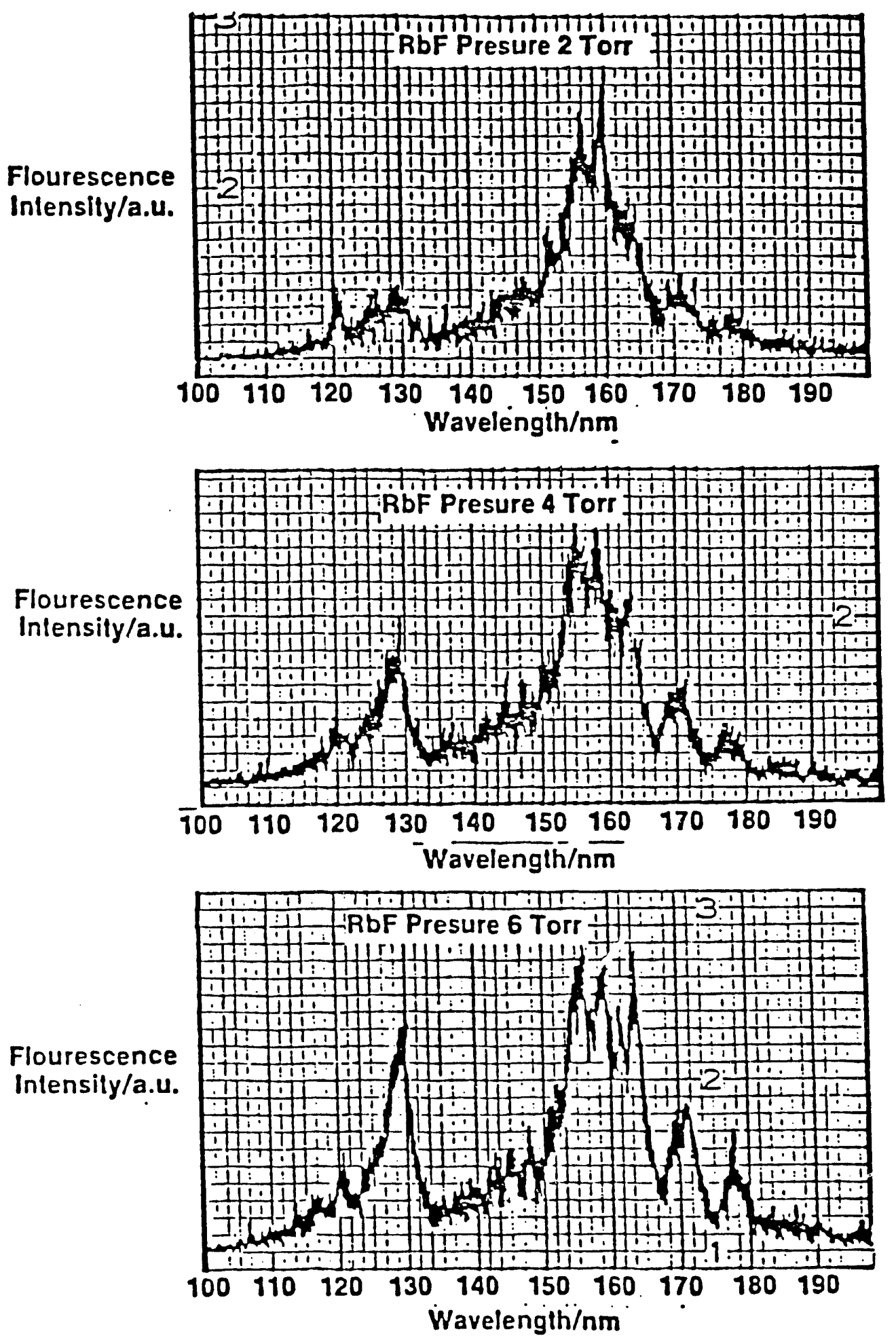

Figure 4-15. Pressure dependence of the RbF spectrum. The $130 \mathrm{~nm} \mathrm{~B} \rightarrow \mathrm{X}$ emission increased with increasing RbF . pressure. There was no evidence of self absorption. 

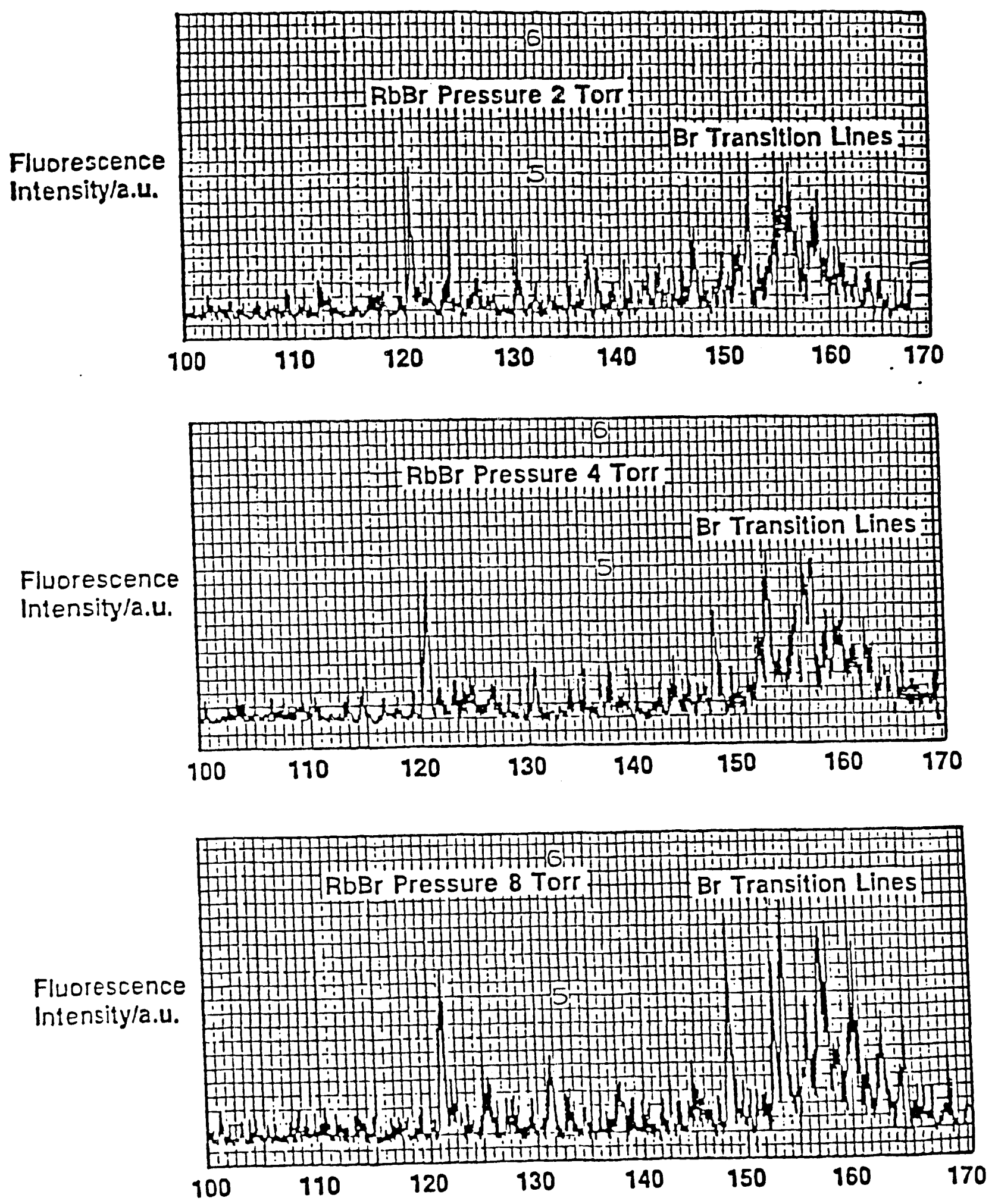

Figure 4-16. Pressure dependence of $\mathrm{RbBr}$ excited by soft-x-rays emitted from a laser produced plasma. The prescence of $\mathrm{Br}$ atomic emission lines suggests that $\mathrm{Rb}^{2}+\mathrm{Br}-$ predissociates. 


\subsection{Alkali Halide Electron Beam Experiments}

\subsubsection{Electron-beam Excited Helium}

Inert gases such as helium are naturally monatomic. Therefore any excitation events first produce atomic ions and atomic metastables. Previous studies of helium plasmas have indicated that in a high pressure e-beam discharge, electrical energy is initially converted into dense populations of $\mathrm{He}^{+}$ions and some excited atomic species such as $\mathrm{He}^{*}\left(2^{1} \mathrm{~S}\right)$ and $\mathrm{He}^{*}\left(2^{3} \mathrm{~S}\right)$ metastables. The fast formation of $\mathrm{He}_{2}{ }^{+}$molecular ions from the $\mathrm{He}^{+}$atomic ions and the subsequent reactions of the molecular ions will be discussed in Section 4.3.1.1. The rapid de-excitation of $\mathrm{He}^{*}\left(2^{1} \mathrm{~S}\right)$ to $\mathrm{He}^{*}\left(2^{3} \mathrm{~S}\right)$ and the ensuing loss processes of $\mathrm{He}^{*}\left(2^{3} \mathrm{~S}\right)$ will be summarized in Section 4.3.1.2.

\subsubsection{Reactions of Iors}

Studies have shown that the $\mathrm{He}^{+}$atomic ions which are initially produced by excitation from an electron beam rapidly form $\mathrm{He}_{2}{ }^{+}$ions, either by termolecular association 16

$$
\mathrm{He}^{+}+2 \mathrm{He} \rightarrow \mathrm{He}_{2}^{+}+\mathrm{He}
$$

This process is extremely fast. For example, this reaction has a reported rate coefficient of $1.08 \times 10^{-31} \mathrm{~cm}^{6} / \mathrm{sec}$ at room temperature. 37,28 using this value and a pressure of three atmospheres of helium, conversion of atomic to molecular ions by termolecular association occurs in a time of about 5 nanoseconds.

When the alkali halide (AX) is added, $\mathrm{He}_{2}{ }^{+}$molecular ions give up their energy via the bimolecular and the termolecular charge transfer reactions described by Equations 4-4 and 4-5.

$$
\mathrm{He}_{2}++\mathrm{AX} \rightarrow \mathrm{A}^{2+\mathrm{X}^{-}}+2 \mathrm{He}
$$




$$
\mathrm{He}_{2}^{+}+\mathrm{AX}+\mathrm{He} \rightarrow \mathrm{A}^{2+} \mathrm{X}^{-}+3 \mathrm{He}
$$

The main loss mechanisms of $\mathrm{He}_{2}{ }^{+}$are ion-electron recombinations. 39

$$
\mathrm{He}_{2}++\mathrm{e}^{-} \rightarrow \mathrm{He}^{*}\left(2^{3} \mathrm{~S}\right)+\mathrm{He}\left(1^{1} \mathrm{~S}\right)
$$

and

$$
\mathrm{He}_{2}++\mathrm{e}^{-} \rightarrow \mathrm{He}\left(1^{1} \mathrm{~S}\right)+\mathrm{He}\left(1^{1} \mathrm{~S}\right)
$$

The rate coefficients for the reactions described by Equations 4-4 and 4-5 were measured to be $5 \times 10^{-9} \mathrm{~cm}^{3} / \mathrm{sec}$ and $4 \times 10^{-9} \mathrm{~cm}^{3} / \mathrm{sec}$ respectively.

\subsubsection{Reactions of Metastables}

Besides the $\mathrm{He}^{+}$state there are also several excited singlet states of atomic helium, such as the $\mathrm{He}^{*}\left(2^{1} \mathrm{~S}\right)$ state, which are initially produced with the discharge. Most of these excited atomic singlet states are destroyed very rapidly. For example, Phelps 50 reported the rate coefficient for the rapid de-excitation of the $\mathrm{He}^{*}\left(2^{1} \mathrm{~S}\right)$ to $\mathrm{He}^{*}\left(2^{3} \mathrm{~S}\right)$ atoms,

$$
\mathrm{He}^{*}\left(2^{1} S\right)+\mathrm{e}^{-} \rightarrow \mathrm{He}^{*}\left(2^{3} S\right)+\mathrm{e}^{-}+\Delta \mathrm{E},
$$

through superelastic collisions with electrons to be $3.5 \times 10^{-7} \mathrm{~cm}^{3} / \mathrm{sec}$. $\mathrm{He}^{*}\left(2^{3} \mathrm{~S}\right)$ then excites $\mathrm{AX}$ through the bimolecular and termolecular Penning reactions given by Equations $4-7$ and $4-8$ respectively.

$$
\begin{aligned}
& \mathrm{He}^{*}\left(2^{3} \mathrm{~S}\right)+\mathrm{AX} \rightarrow \mathrm{A}^{2+\mathrm{X}^{-}}+\mathrm{He}+\mathrm{e}, \\
& \mathrm{He}^{*}\left(2^{3} \mathrm{~S}\right)+\mathrm{AX}+\mathrm{He} \rightarrow \mathrm{A}^{2+\mathrm{X}^{-}}+2 \mathrm{He}+\mathrm{e}
\end{aligned}
$$

Three other moderate loss mechanisms for $\mathrm{He}^{*}\left(2^{3} \mathrm{~S}\right)$ have been established from studies ${ }^{4-43}$ of pure helium plasmas. 


$$
\begin{aligned}
& \mathrm{He}^{*}\left(2^{3} S\right)+\mathrm{e} \rightarrow \mathrm{He}\left(1^{1} S\right)+\mathrm{e} \\
& \mathrm{He}^{*}\left(2^{3} S\right)+\mathrm{He}^{*}\left(2^{3} S\right) \rightarrow \mathrm{He}_{2}{ }^{+}+\mathrm{e} \\
& \mathrm{He}^{*}\left(2^{3} S\right)+2 \mathrm{He} \rightarrow \mathrm{He}_{2}^{*}\left(\mathrm{a}^{3} \Sigma_{\mathrm{u}}\right)+\mathrm{He}
\end{aligned}
$$

The rates 41,43 for reactions $4-9$ and $4-10$ are of the order of $2.9 \times 10^{-9} \mathrm{~cm}^{3} / \mathrm{sec}$, while reaction $4-11$ occurs at a rate 42 of

$$
\mathrm{k}=2.0 \times 10^{-34} \mathrm{~cm}^{6} / \mathrm{sec} \text {. }
$$

If the initial number density of $\mathrm{He}^{*}\left(2^{3} \mathrm{~S}\right)$ atoms is smaller than the alkali halide concentration, rates for the Penning reactions of equations 4-7 and 4-9 would be dominent. The rate constant for reaction (4-8) is not known.

An inspection Equation 4-12 indicates that the formation of $\operatorname{He}_{2} *\left(a^{3} \Sigma\right)$ molecules from the $\mathrm{He}^{*}\left(2^{3} \mathrm{~S}\right)$ atomic metastables is much slower than the analogous reaction previously discussed for ions. For example, at three atmospheres of pressure and at room temperature, using the rate coefficient given by Equation 4-12, the termolecular association reaction described by Equation 4-11 occurs in a time of about 1 microsecond. Therefore, provided there is sufficient time for conversion, a large population of metastable molecules may exist as an energy storing species.

In summary, previous studies have shown that at atmospheric pressures, the excited state chemistry of the inert gas plasmas spans two distinct periods following the termination of an external source of ionization. If small admixtures of other gases are present, a few Torr of alkali halide vapor, the economy of the excitation energy is dominated by ion-molecules reactions of the atomic and molecular ions of the inert gas with atoms, molecules or ions of the minority species and by recombination with secondary electrons. Subsequently, there is a time during which the energy is mainly carried by the neutral species, which generally have smaller 
reactivities and hence, longer lifetimes. The principle reactions occurring during the "early" or "ionic" period are described by equations

$$
\begin{aligned}
& \mathrm{He}_{2}^{+}+\mathrm{AX} \rightarrow \mathrm{A}^{2+\mathrm{X}^{-}+2 \mathrm{He}} \\
& \mathrm{He}_{2}^{+}+\mathrm{AX}+\mathrm{He} \rightarrow \mathrm{A}^{2+X^{-}+3 \mathrm{He}}
\end{aligned}
$$

The principle reactions occurring at subsequent times or the "late" period can be written

$$
\begin{aligned}
& \mathrm{He}^{*}\left(2^{3} S\right)+\mathrm{AX} \rightarrow \mathrm{A}^{2+X^{-}}+\mathrm{He} \\
& \mathrm{He}^{*}\left(2^{3} \mathrm{~S}\right)+\mathrm{AX}+\mathrm{He} \rightarrow \mathrm{A}^{2+X^{-}}+2 \mathrm{He}
\end{aligned}
$$

Due to their short lifetimes, the atomic $\mathrm{He}^{+}$ions and the $\mathrm{He}^{*}\left(2^{1} \mathrm{~S}\right)$ atomic singlets were considered not to be major energy storing species, even at the high levels of electron beam excitation energies used in this work. The most important energy storing species in the afterglow at high pressures are the $\mathrm{He}_{2}{ }^{+}$ions and the $\mathrm{He}^{*}\left(2^{3} S\right)$ and the $\mathrm{He}_{2} *\left(\mathrm{a}^{3} \Sigma\right)$ metastables with the available excitation energies shown in Figures 2-1 and 2-2.

\subsubsection{Electron Beam Excitation of CsF}

The emission spectrum of e-beam pumped $\mathrm{Cs}^{2}+\mathrm{F}^{-}$was recorded for various concentrations of $\mathrm{CsF}$ and buffer gases, $\mathrm{He}$ and $\mathrm{Ne}$. The effect of $\mathrm{He}$ concentration on the $\mathrm{Cs}^{2+}+\mathrm{F}-$ emission is shown in Figure 4-17. Both spectra have 2 torr of $\mathrm{CsF}$ but the $\mathrm{He}$ pressure is $3.28 \mathrm{~atm}$ in upper spectrum and $9.21 \mathrm{~atm}$ in the lower spectrum. The $\mathrm{Cs}^{2}+\mathrm{F}^{-}$is most likely formed by the charge transfer and Penning ionization reactions.

$$
\begin{aligned}
& \mathrm{He}^{+}+\mathrm{CsF} \rightarrow \mathrm{Cs}^{2+\mathrm{F}^{-}}+\mathrm{He} \\
& \mathrm{He}_{2}^{+}+\mathrm{CsF} \rightarrow \mathrm{Cs}^{2+\mathrm{F}^{-}}+2 \mathrm{He} \\
& \mathrm{He}^{*}\left(2^{3} \mathrm{~S}\right)+\mathrm{CsF} \rightarrow \mathrm{Cs}^{2+\mathrm{F}^{-}}+\mathrm{He}+\mathrm{e}^{-}
\end{aligned}
$$



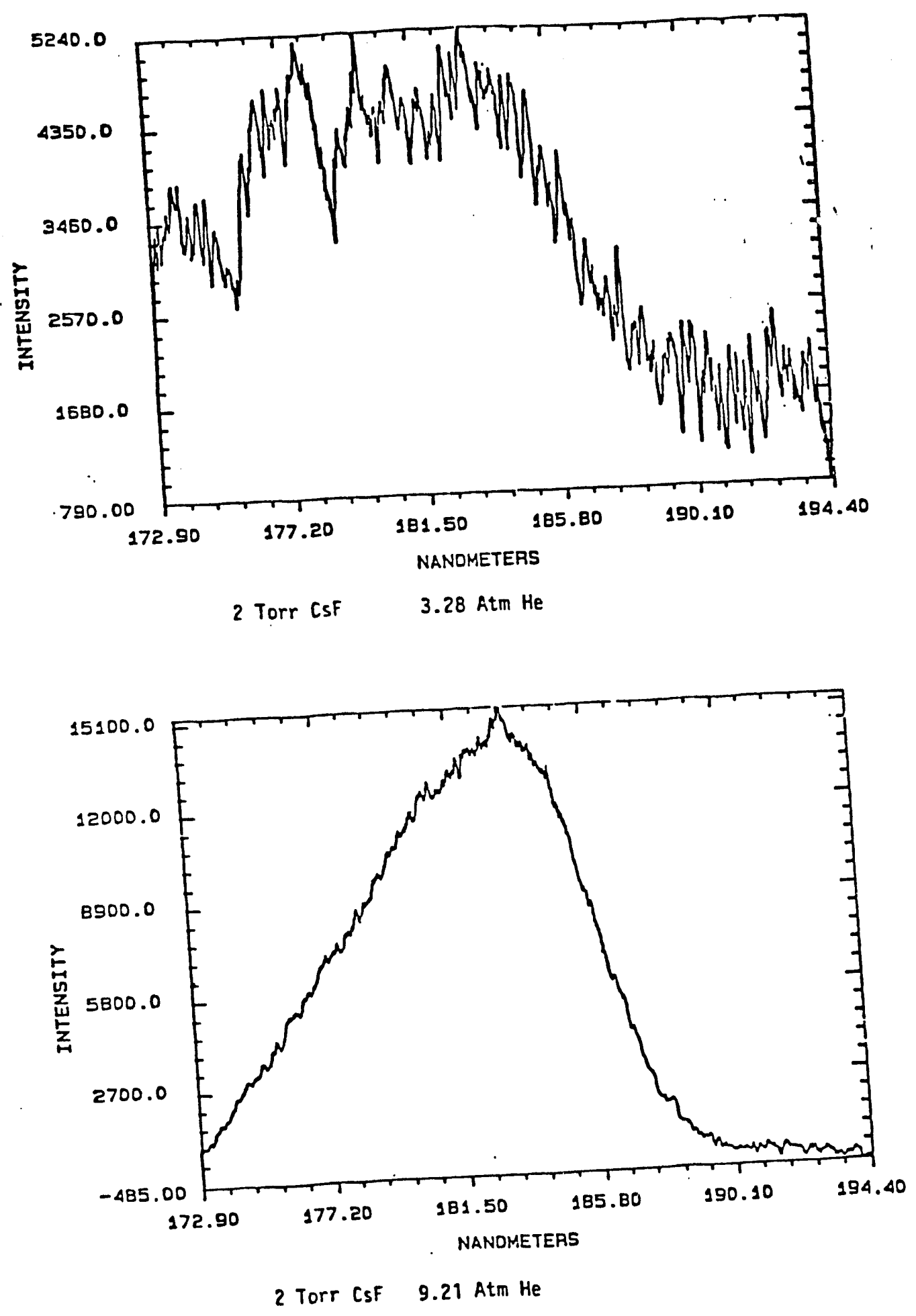

Figure 4-17. $\mathrm{Cs}^{2}+\mathrm{F}$ - fluorescence from an e-beam pumped gas mixture of 2 Torr CsF and He pressures of 3.3 and $9.2 \mathrm{~atm}$. 
The spectrum with 3.28 atm of $\mathrm{He}$ is the sum of six e-beam pulses whereas the spectrum at 9.21 atm of $\mathrm{He}$ is a single e-beam pulse. Thus, increasing the $\mathrm{He}$ pressure a factor of three caused approximately a factor of 15 increase in the $\mathrm{Cs}^{2}+\mathrm{F}-$ emission intensity. This increase in intensity is the result of several effects. First, increasing the $\mathrm{He}$ pressure increases ion-pair production rate.9,10 Secondly, increasing the $\mathrm{He}$ pressure raises the importance of three body processes. The increase in ion-pair production rate would account for approximately a factor of three increase in signal. This leaves a factor of 5 to be accounted for by the kinetics. The kinetics of this system are quite complicated, however the rate of a three body process involving two $\mathrm{He}$ atoms would increase nine fold for an increase of 3 in He pressure. Thus it is not unreasonable that the $\mathrm{Cs}^{2+} \mathrm{F}^{-}$emission intensity could increase by a factor of 5 due to kinetic considerations.

Figure 4-18 shows the $\mathrm{Cs}^{2+}+\mathrm{F}^{-}$emission spectrum for 2 torr of $\mathrm{CsF}$ and $2.3 \mathrm{~atm}$ of Ne. The spectrum is the sum of six e-beam shots. Since the stopping power of the gas is approximately proportional to its atomic number, $2.3 \mathrm{~atm}$ of $\mathrm{Ne}$ should have the same stopping power as $11.5 \mathrm{~atm}$ of $\mathrm{He}$. Therefore, the decrease in $\mathrm{Cs}^{2}+\mathrm{F}^{-}$emission intensity relative to the 9.21 atm $\mathrm{He}$ spectrum is due to the relative kinetics and energetics of the two systems. In the case of $\mathrm{He}$ all of $\mathrm{He}^{+}, \mathrm{He}_{2}{ }^{+}$and $\mathrm{He}^{*}\left(2^{3} \mathrm{~S}\right)$ are sufficiently energetic to produce $\mathrm{Cs}^{2+} \mathrm{F}^{-}$ either by charge transfer or Penning ionization. However, with $\mathrm{Ne}$ buffer gas, only $\mathrm{Ne}^{+}$and $\mathrm{Ne}_{2}{ }^{+}$have sufficient energy. This suggests that $\mathrm{He}^{*}\left(2^{3} \mathrm{~S}\right)$ plays a major role in the excitation of $\mathrm{Cs}^{2}+\mathrm{F}^{-}$in the $\mathrm{He}$ buffer system.

The $\mathrm{Cs}^{2}+\mathrm{F}^{-}$emission spectrum dependence on the $\mathrm{CsF}$ concentration is shown in Figure 4-19. The emission intensity is observed to decrease dramatically increasing CsF concentration. This could be due to ground state adsorption of the $185 \mathrm{~nm}$ light emitted by $\mathrm{Cs}^{2}+\mathrm{F}^{-}$.

The time-resolved fluorescence intensity of the $\mathrm{Cs}^{2+} \mathrm{F}^{-}$was determined with the electron beam excitation scheme shown in Figure 3-3. A Febetron 706 was used as the e-beam source. It has a 3 


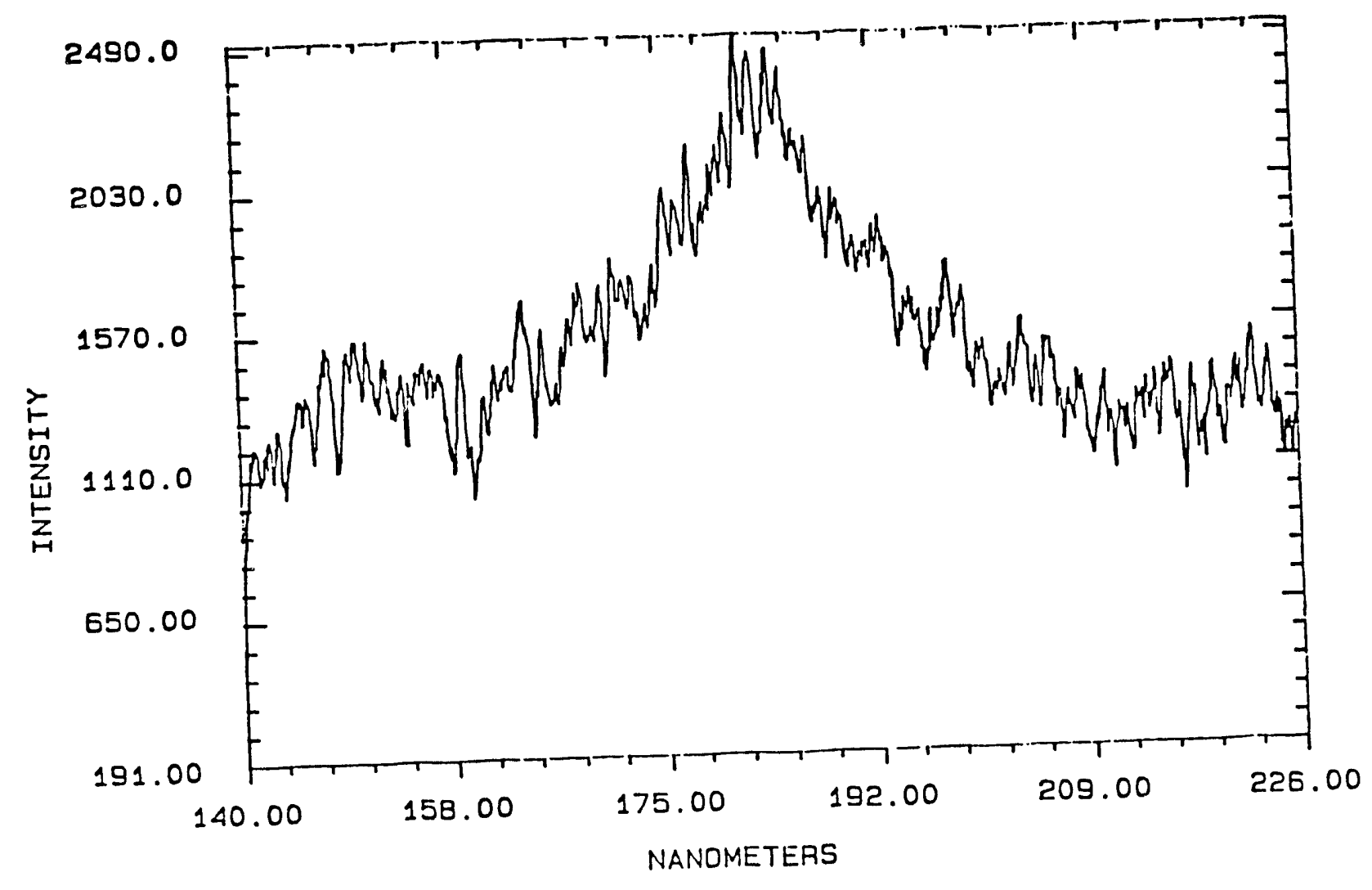

Figure $4.18 \mathrm{Cs}^{2}+\mathrm{F}^{-}$fluorescence from an e-beam pumped gas mixture of 2 Torr CsF and 2.3 atom Ne. 


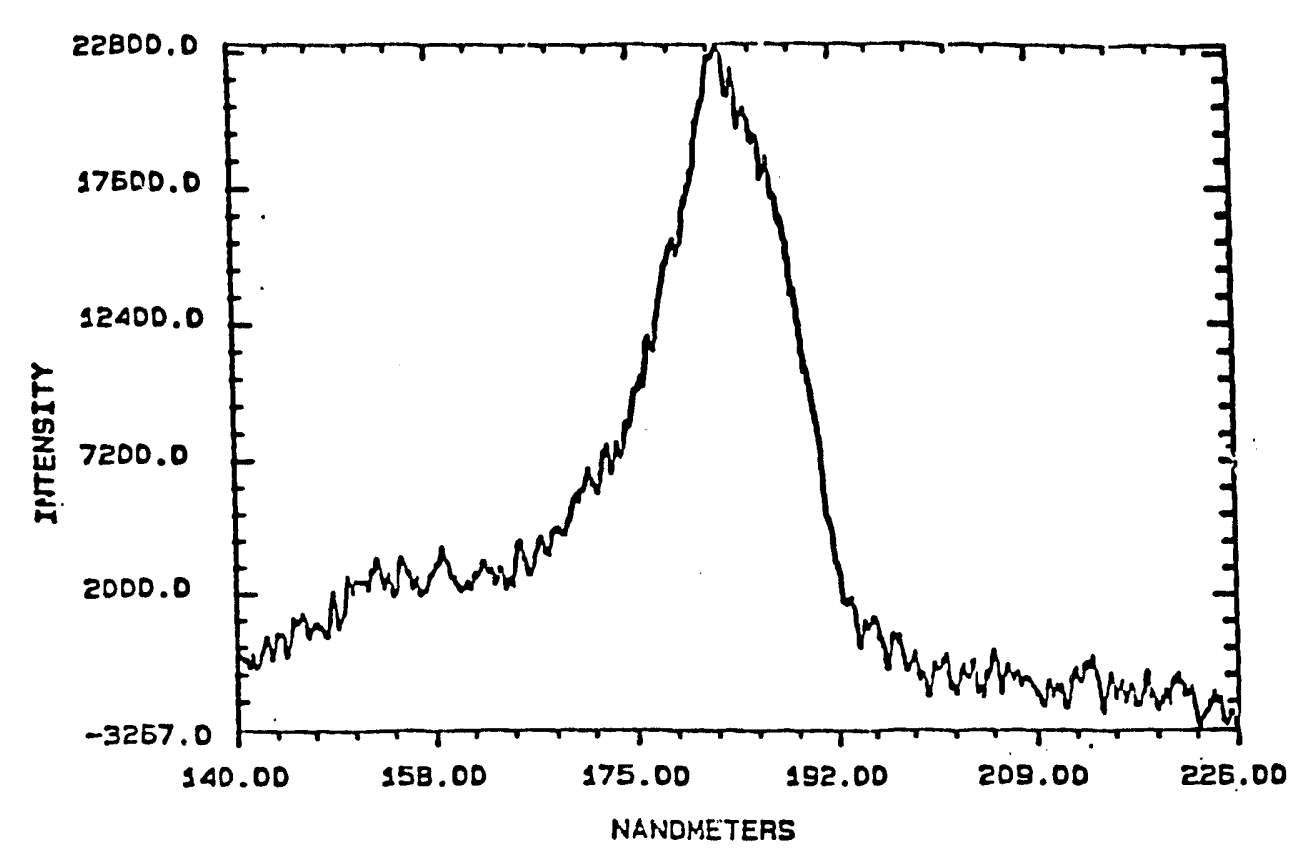

Heatpipe Temperature $825^{\circ} \mathrm{C}$ (2 Torr CsF) Helium Pressure 9.2 Atm 3000 Entrance Slit

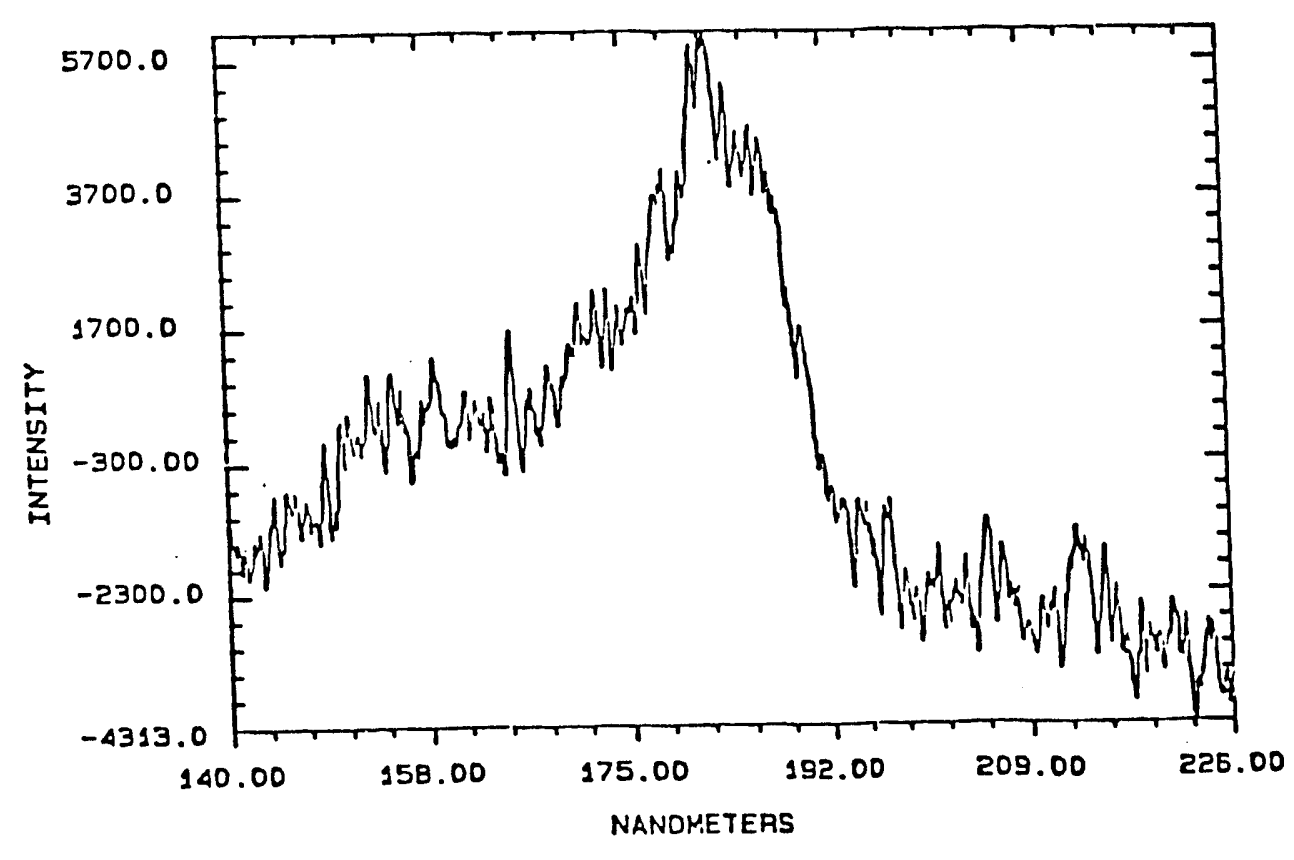

Heatpipe Temperature $671^{\circ} \mathrm{C}$ (10 Torr CSF)

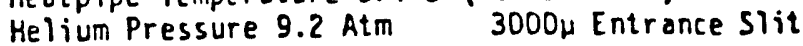

Figure $4.19 \mathrm{Cs}^{2+} \mathrm{F}$ - fluorescence from an e-beam pumped gas mixture of $9.2 \mathrm{~atm} \mathrm{He}$ and $\mathrm{CsF}$ pressures of 2 and 10 Torr. 
nsec pulse width and a peak current of 7000A. The fluorescence was detected with a 1-meter VUV monochromator and solar blind photomultiplier tube. The output of the photomultiplier tube was recorded with an digital storage oscilloscope. Several e-beam shots could be averaged together on the oscilloscope.

Time decays were recorded at various $\mathrm{CsF}$ and $\mathrm{He}$ buffer gas concentrations. Figures 4-20,4-21, 4-22, and 4-23 shows the time decay at the $\mathrm{Cs}^{2}+\mathrm{F}-$ emission for 2 Torr of $\mathrm{CsF}$ at He buffer gas pressure at $813,2580,4088$ and $6795 \mathrm{~T}$ respectively. Note the different time bases on the decays. The initial decay rate increases with increasing $\mathrm{He}$ pressure. Figure 4-24 shows the time dependence for $10 \mathrm{~T} \mathrm{CsF}$ and $8113 \mathrm{~T}$ He. Comparing Figures 4-23 and 4-24 shows that increasing (CsF) has little effect on the initial decay but decreases the long time component of the fluorescence. The time evolution of the $\mathrm{Cs}^{2}+\mathrm{F}-$ emission in a neon buffer is shown in Figure 4-25. The (CsF) was $2 \mathrm{~T}$ and (He) was $2595 \mathrm{~T}$. The initial species are believed to be the $\mathrm{Cs}^{2}+\mathrm{F}^{-}$emission and the long decay may be fluorescence from the window. $\mathrm{Ne}^{*}\left(3^{3} \mathrm{P}_{2}\right)$ is the only long lived species which should be present. Since $\mathrm{Ne}\left(3^{3} \mathrm{P}_{2}\right)$ does not have sufficient energy to excite $\mathrm{CsF}$ to $\mathrm{Cs}^{2+} \mathrm{F}^{-}$, there should be no long term production of $\mathrm{Cs}^{2+\mathrm{F}^{-}}$.

The $\mathrm{Cs}^{2}+\mathrm{F}-$ radiative lifetime is reported to be approximately $1 \mathrm{nsec} .8$ Thus the $\mathrm{Cs}^{2}+\mathrm{F}-$ emission intensity should reach steady state in approximately $1 \mathrm{nsec}$. The time response of the detection system was estimated to be approximately $20 \mathrm{nsec}$. The observed risetime of the $\mathrm{Cs}^{2}+\mathrm{F}^{-}$emission is may be the response time of the detection electronics. The decay should be due to a decline in $\mathrm{Cs}^{2}+\mathrm{F}^{-}$production rite. Both $\mathrm{He}_{2}{ }^{+}$and $\mathrm{He}^{*}\left(2^{3} \mathrm{~S}\right)$ have sufficient energy to excite $\mathrm{CsF}$ to $\mathrm{Cs}^{2+} \mathrm{F}^{-}$. The $\mathrm{Cs}^{2+} \mathrm{F}^{-}$emission decay rate is then due to the disappearance of these energetic species. As the pressure is increased the species disappear faster.

The deactivation of $\mathrm{Cs}^{2}+\mathrm{F}-$ can occur by recombination with electrons and negative ions, by collisions with electrons and molecules or by radiation. Examples are

$$
\begin{aligned}
\mathrm{Cs}^{2+} \mathrm{F}^{-}+\mathrm{e}^{-} & \rightarrow \mathrm{CsF}^{*} \\
\rightarrow & \mathrm{Cs}^{*}+\mathrm{F} \\
& -62-
\end{aligned}
$$




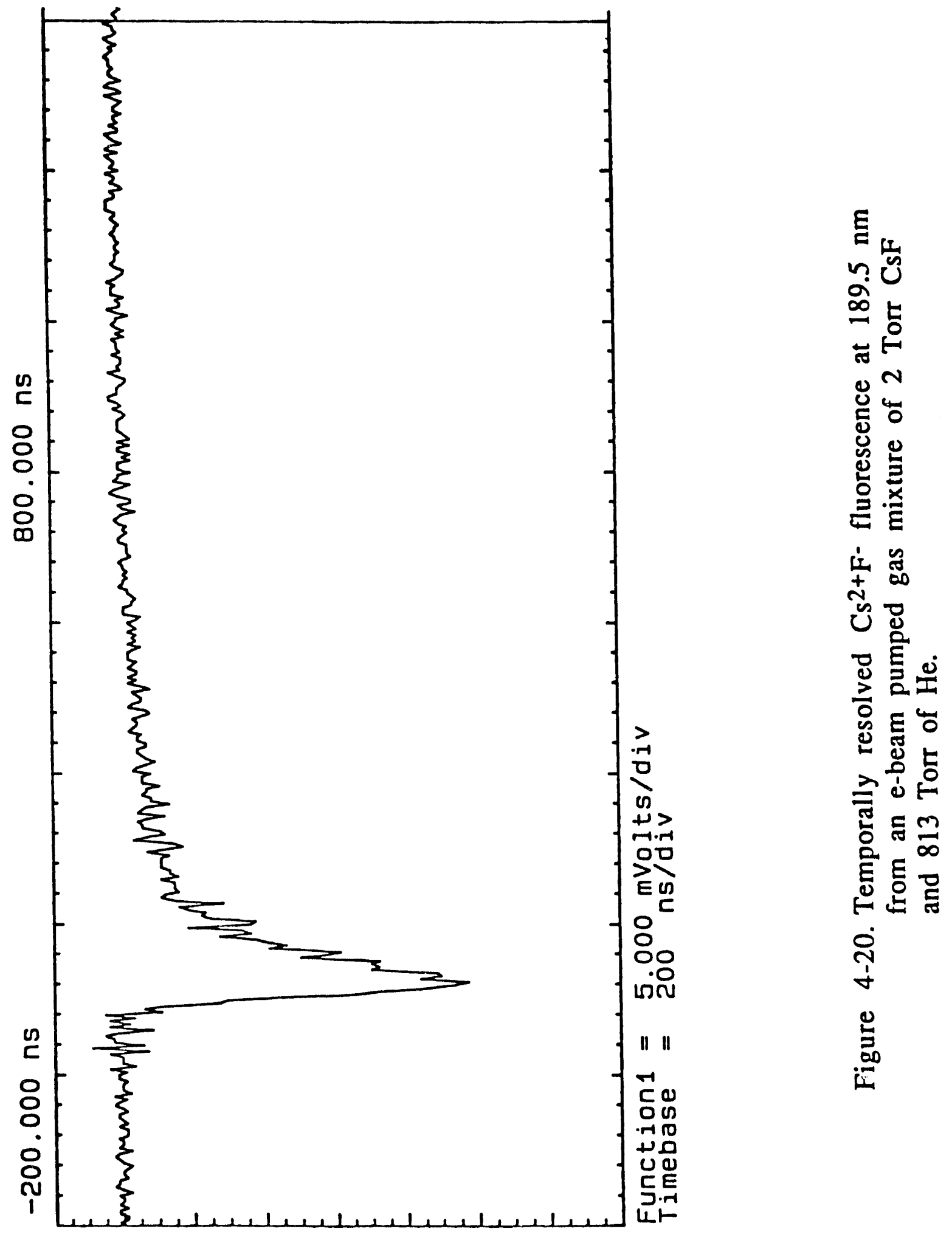




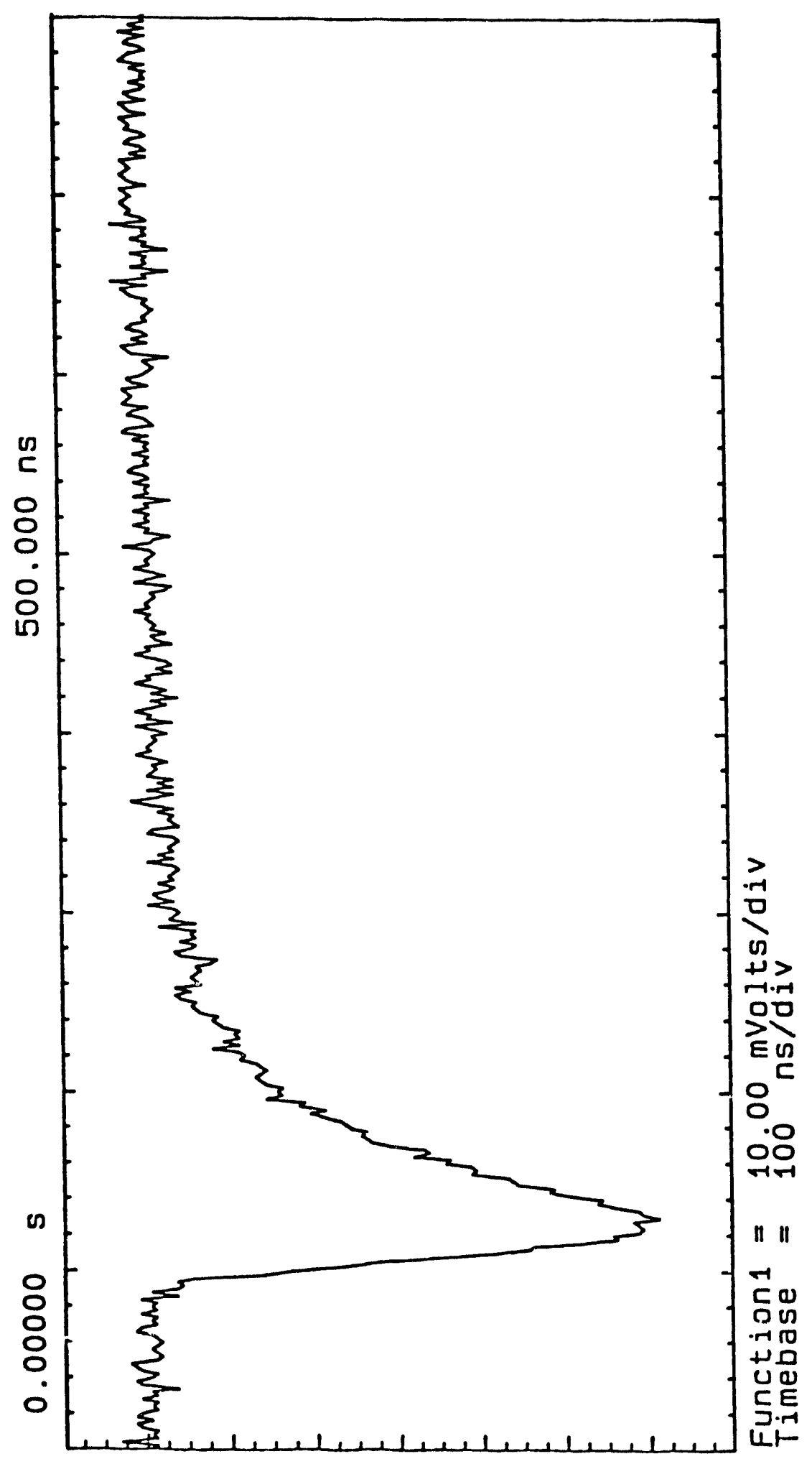

E

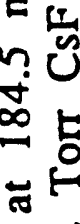

$0 N$

包

Uू

牲

를

i.

N

थै

ఫ

올

¿

출

를 옹

$\vec{\gamma}$

莺 

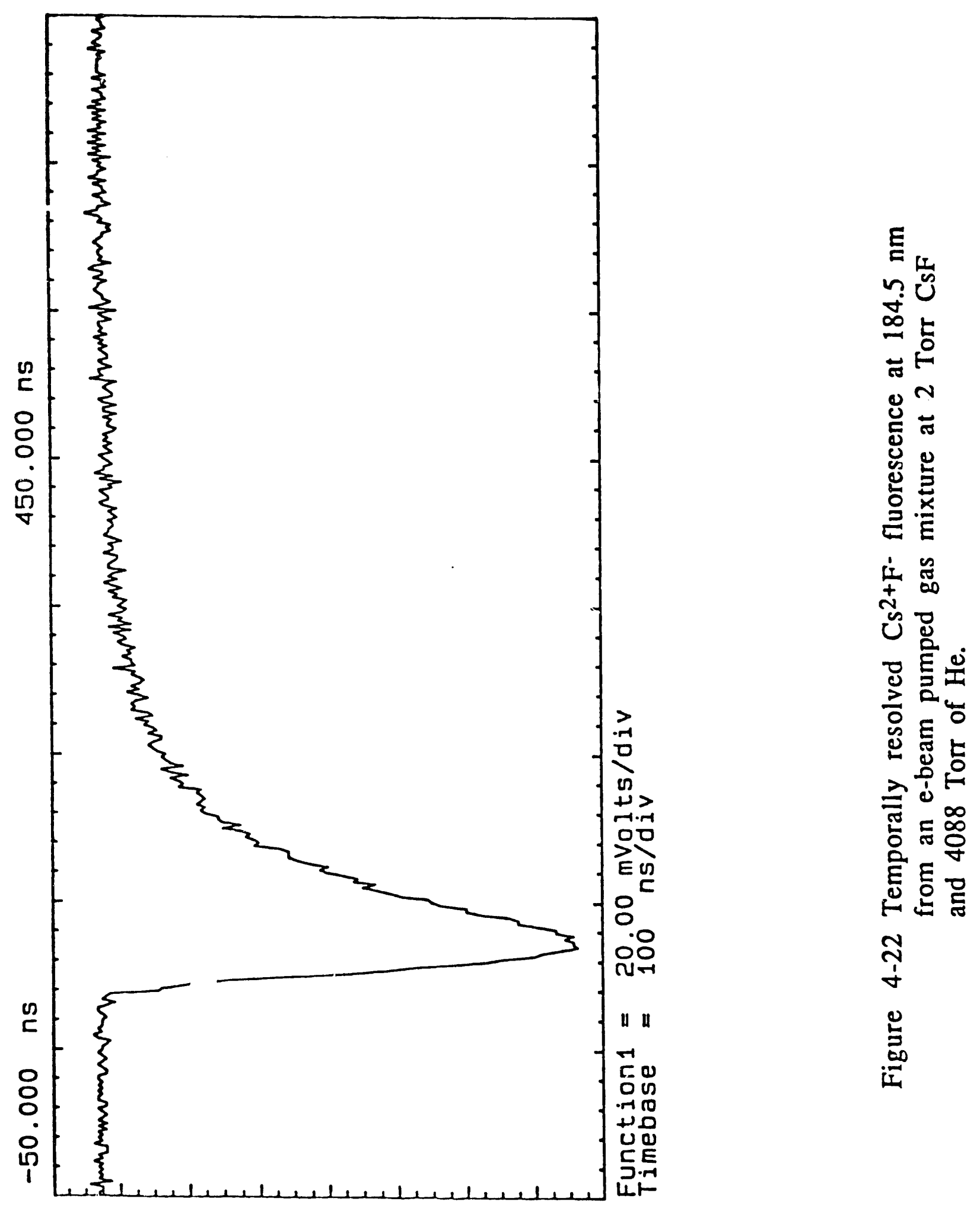


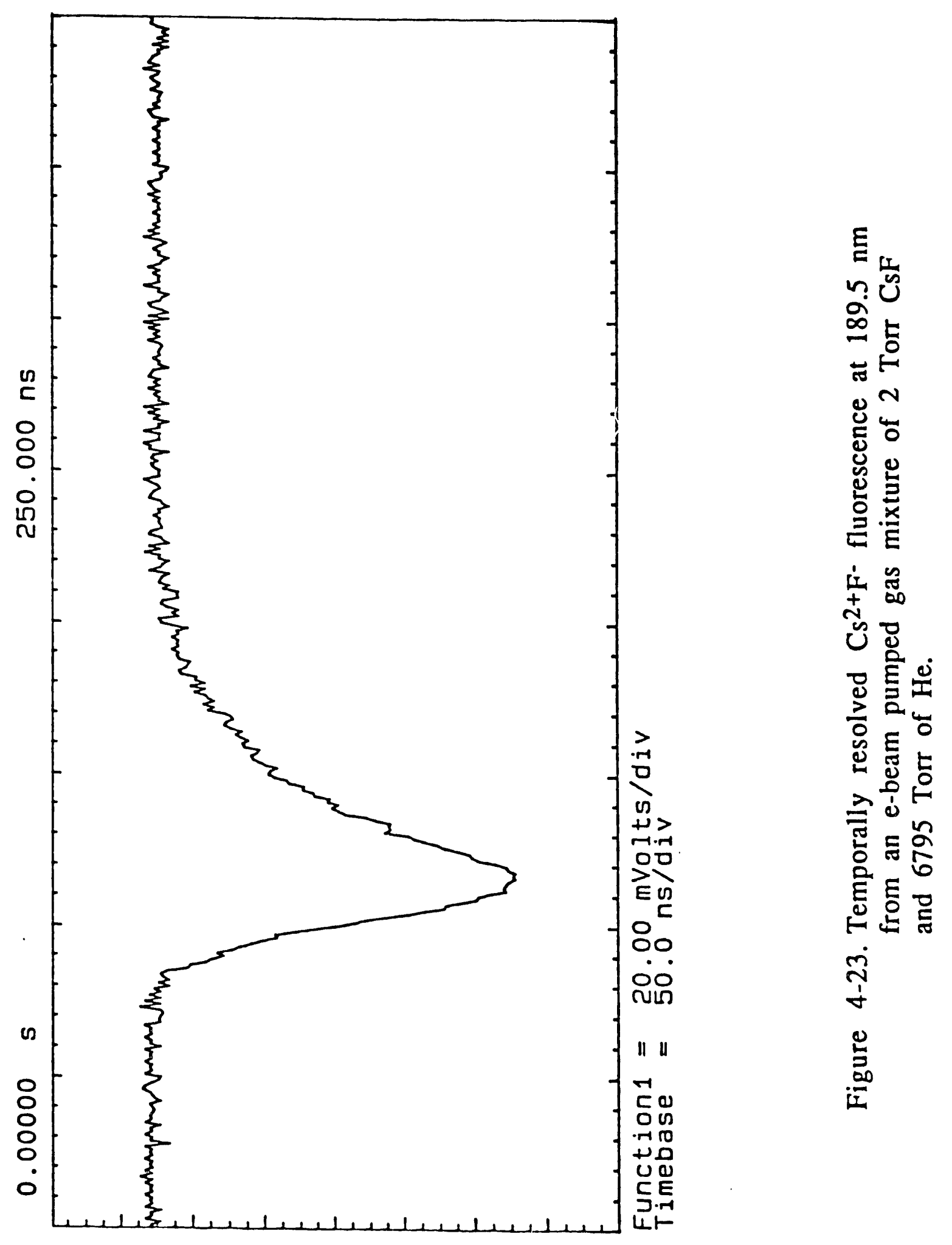




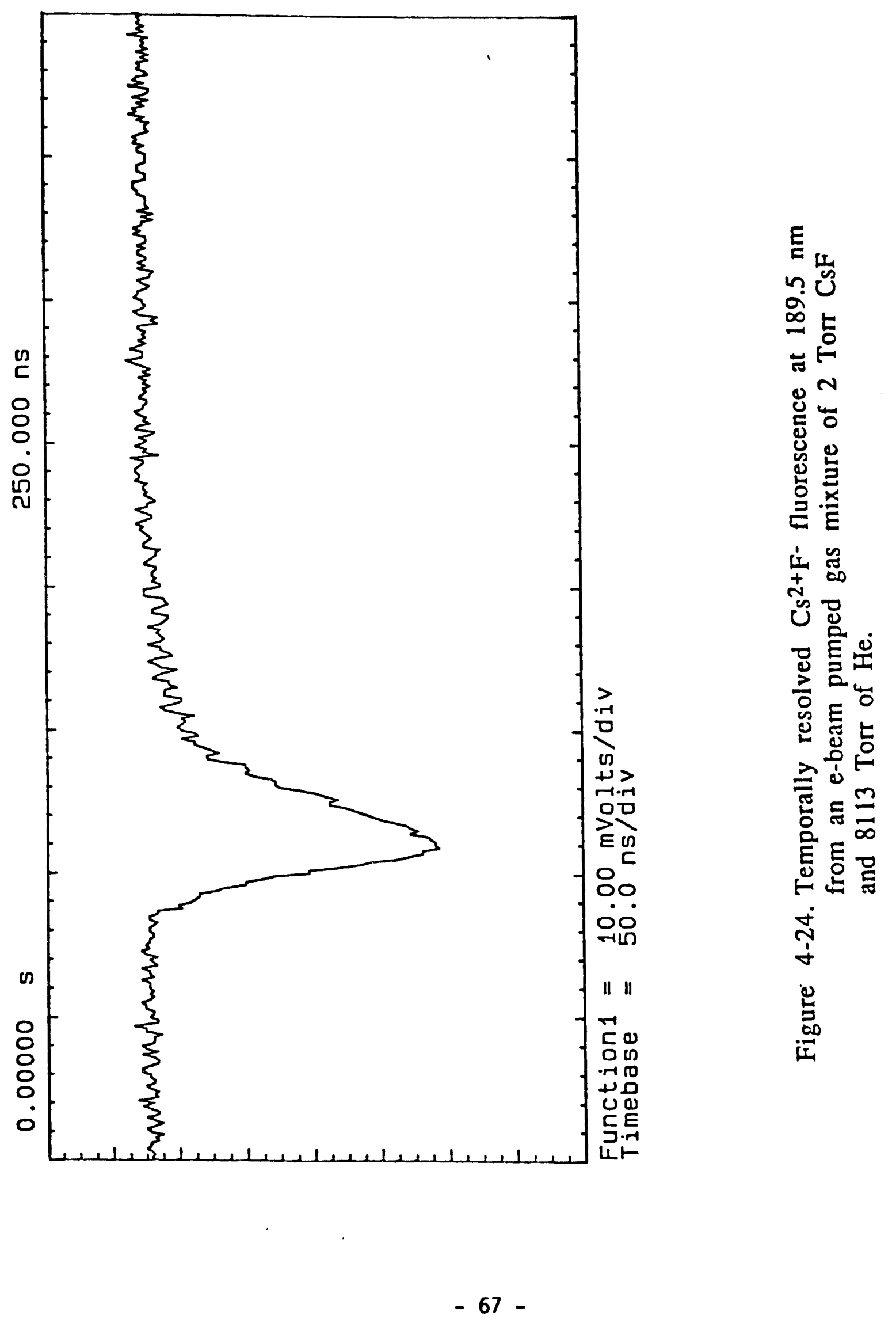




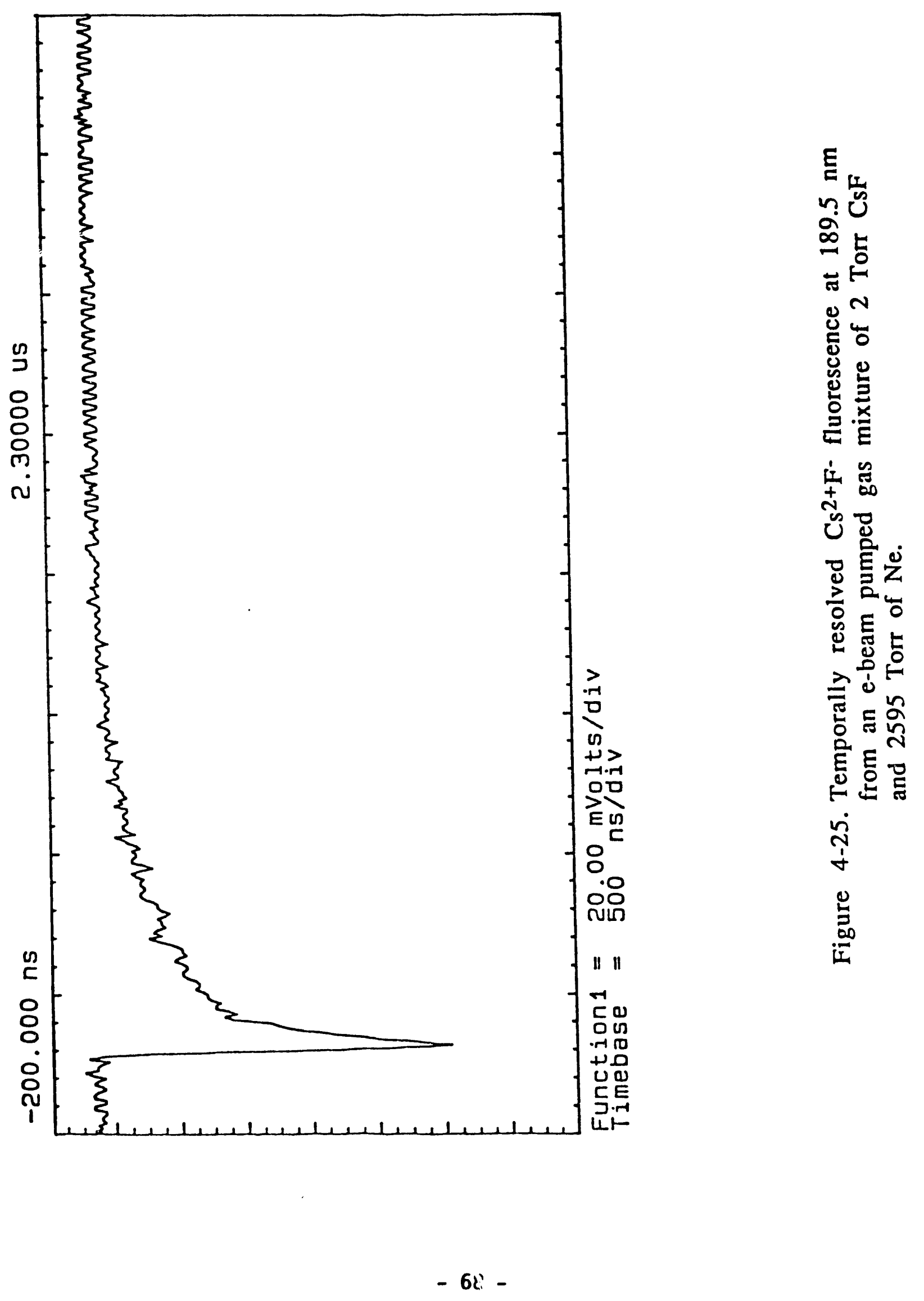




$$
\begin{aligned}
& \rightarrow \mathrm{Cs}+\mathrm{F}^{*} \\
& \rightarrow \mathrm{Cs}^{+} \mathrm{F}+\mathrm{e}^{-} \\
& \rightarrow \text { other } \\
\mathrm{Cs}^{2+\mathrm{F}^{-}}+\mathrm{F}^{-} & \rightarrow \mathrm{CsF}^{*}+\mathrm{F} \\
& \rightarrow \mathrm{CsF}+\mathrm{F}^{*} \\
& \rightarrow \mathrm{Cs}+\mathrm{F}_{2} \\
& \rightarrow \text { other } \\
\mathrm{Cs}^{2+\mathrm{F}^{-}}+\mathrm{M} & \rightarrow \mathrm{Cs}+\mathrm{F}+\mathrm{M} \\
& \rightarrow \mathrm{CsF}+\mathrm{M}^{+} \\
& \rightarrow \text { other } \\
\mathrm{Cs}^{2+\mathrm{F}^{-}} & \rightarrow \mathrm{Cs}^{+} \mathrm{F}+\mathrm{hv}
\end{aligned}
$$

Assuming rate constants for the recombination and collisions with electrons of $10^{-7} \mathrm{~cm}^{3} \mathrm{~s}^{-1}$, recombination with negative ions of $3 \times 10^{-}$ $6 \mathrm{~cm}^{3} \mathrm{~s}^{-1}$, collisions with molecules of $10^{-10} \mathrm{~cm}^{3} \mathrm{~s}^{-1}$, a radiative rate of $10^{9} \mathrm{~s}^{-1}$ and particle densities of $5 \times 10^{15} \mathrm{~cm}^{-3}$ for electrons, $3 \mathrm{x}$ $10^{14} \mathrm{~cm}^{-3}$ for negative ions and $10^{17} \mathrm{~cm}^{-3}$ for gas kinetic molecular quenchers, then the deactivation rates are $5 \times 10^{8} \mathrm{~s}^{-1}$ for recombination with negative ions, $10^{7} \mathrm{~s}^{-1}$ for collisions with molecules and $5 \times 10^{8} \mathrm{~s}^{-1}$ for collision with electrons. The total deactivation rate is approximately $3 \times 10^{9} \mathrm{~s}^{-1}$. Therefore about one third of the $\mathrm{Cs}^{2+} \mathrm{F}^{-}$ formed should radiate.

\subsubsection{Electron-Beam Excitation of $\mathrm{RbF}$}

According to the calculated potentials of Yang et al 15 , Steigerwald and Langhoff $44,21.5 \mathrm{eV}$ is needed for ionization and excitation of $\mathrm{RbF}$ to the $\mathrm{Rb}^{2+\mathrm{F}}-$ state. From the known ionization potential of $\mathrm{He}$ and the dissociation energy 45 of $\mathrm{He}_{2}{ }^{+}$this latter species has at most just sufficient energy for ionization and excitation of $R b F$ to $R^{2}+F^{-}$. Since fluorescence was not observed from e-beam excitation of $\mathrm{RbF}+\mathrm{He}$ gas mixtures, it is assumed that the change transfer reaction is slow.

$$
\mathrm{He}_{2}++\mathrm{RbF} \rightarrow 2 \mathrm{He}+\mathrm{Rb}^{2}+\mathrm{F}^{-}
$$


This may be because it is slightly endothermic. Another possibility is that the reaction is slightly exothermic for the production of $\mathrm{Rb}^{2}+\mathrm{F}^{-}$ $(v=0)$ but is endothermic for vibrationally excited $R b^{2}+F-$. The vibrational distribution of $\mathrm{Rb}^{2}+\mathrm{F}$ - should be determined by the Franck-Condon factors for the $R b F$ to $\mathrm{Rb}^{2}+\mathrm{F}^{-}$transition. Since the potential energy minimum for $\mathrm{RbF}$ and $\mathrm{Rb}^{2}+\mathrm{F}^{-}$occurs at different internuclear separations, the Franck-Condon factors should favor the production of vibrational excited $\mathrm{Rb}^{2}+\mathrm{F}-$. Therefore, the absence of $\mathrm{Rb}^{2+} \mathrm{F}^{-}$emission may be because the Franck-Condon factors for the charge transfer reaction favors production of vibrational excited $\mathrm{Rb}^{2+} \mathrm{F}^{-}$states for which $\mathrm{He}_{2}{ }^{+}$has insufficient energy to produce.

\subsubsection{Electron-Beam Excitation of Three Component Mixtures}

No $\mathrm{Cs}^{2}+\mathrm{F}^{-}$or $\mathrm{Rb}^{2}+\mathrm{F}-$ emission was observed from e-beam pumping a three component gas mixture; $\mathrm{He}$ or $\mathrm{Ne}$ buffer gas/Cs or $\mathrm{Rb} / \mathrm{F}$ atom donor $\left(\mathrm{BF}_{3}, \mathrm{SiF}_{4}\right.$ or $\left.\mathrm{CF}_{4}\right)$. Figure 4-26 shows the emission spectrum

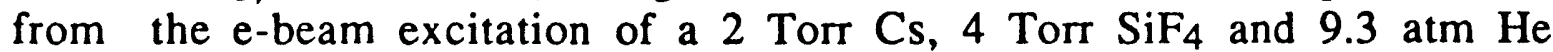
gas mixture. Figure $4-27$ is for a 2 Torr $\mathrm{Cs}, 3.6$ Torr $\mathrm{CF}_{4}$ and $9.2 \mathrm{~atm}$ He. There was no $\mathrm{Cs}^{2}+\mathrm{F}^{-}$emission observed. Since impurity atomic lines are observed with pure $\mathrm{He}$ gas, the absence at any emission including impurity lines in the $170-200 \mathrm{~nm}$ wavelength region for the $\mathrm{He} / \mathrm{Cs} / \mathrm{BF}_{3}$ mix suggest $\mathrm{s}$ that some molecule present is absorbing the radiation. The most likely candidate for this molecule would be the $F$ atom donor, $\mathrm{SiF}_{4}$ or $\mathrm{CF}_{4}$.

Figure 4-28 shows the emission spectrum from the e-beam excitation of 4 Torr $\mathrm{Rb}, 6$ Torr $\mathrm{BF}_{3}$ and $9.8 \mathrm{~atm}$. He gas mixture. The spectrum from a 10 Torr $\mathrm{Rb}, 513$ Torr $\mathrm{SiF}_{4}$ and 9.1 atm He gas mixture is shown in Figure 4-29. The peak near $121 \mathrm{~nm}$ is probably due to Lyman $\alpha$ and He II emission. Since the emission around $132 \mathrm{~nm}$ was present when the cell was cold, it is not $\mathrm{Rb}^{2}+\mathrm{F}^{-}$emission. Apparently the $\mathrm{BF}_{3}$ and $\mathrm{SiF}_{4}$ do not absorb strongly in this $120-140 \mathrm{~nm}$ wavelength region. Therefore, the absence at any strong $\mathrm{Rb}^{2}+\mathrm{F}^{-}$emission implies that $\mathrm{Rb}^{2}+\mathrm{F}^{-}$is not being formed. This may be because the fluorine bonds in $\mathrm{BF}_{3}$ and $\mathrm{SiF}_{4}$ are too strong. 


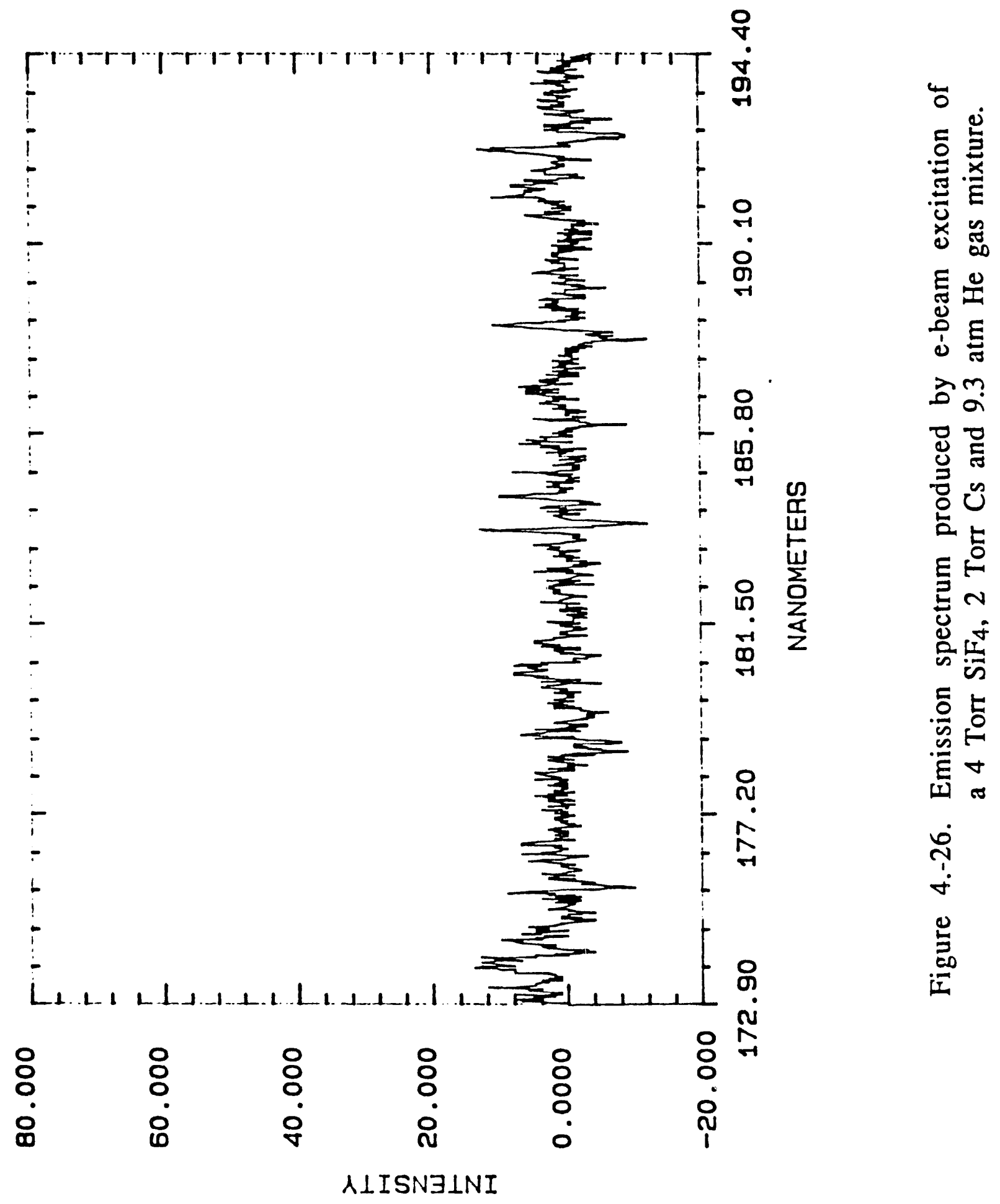




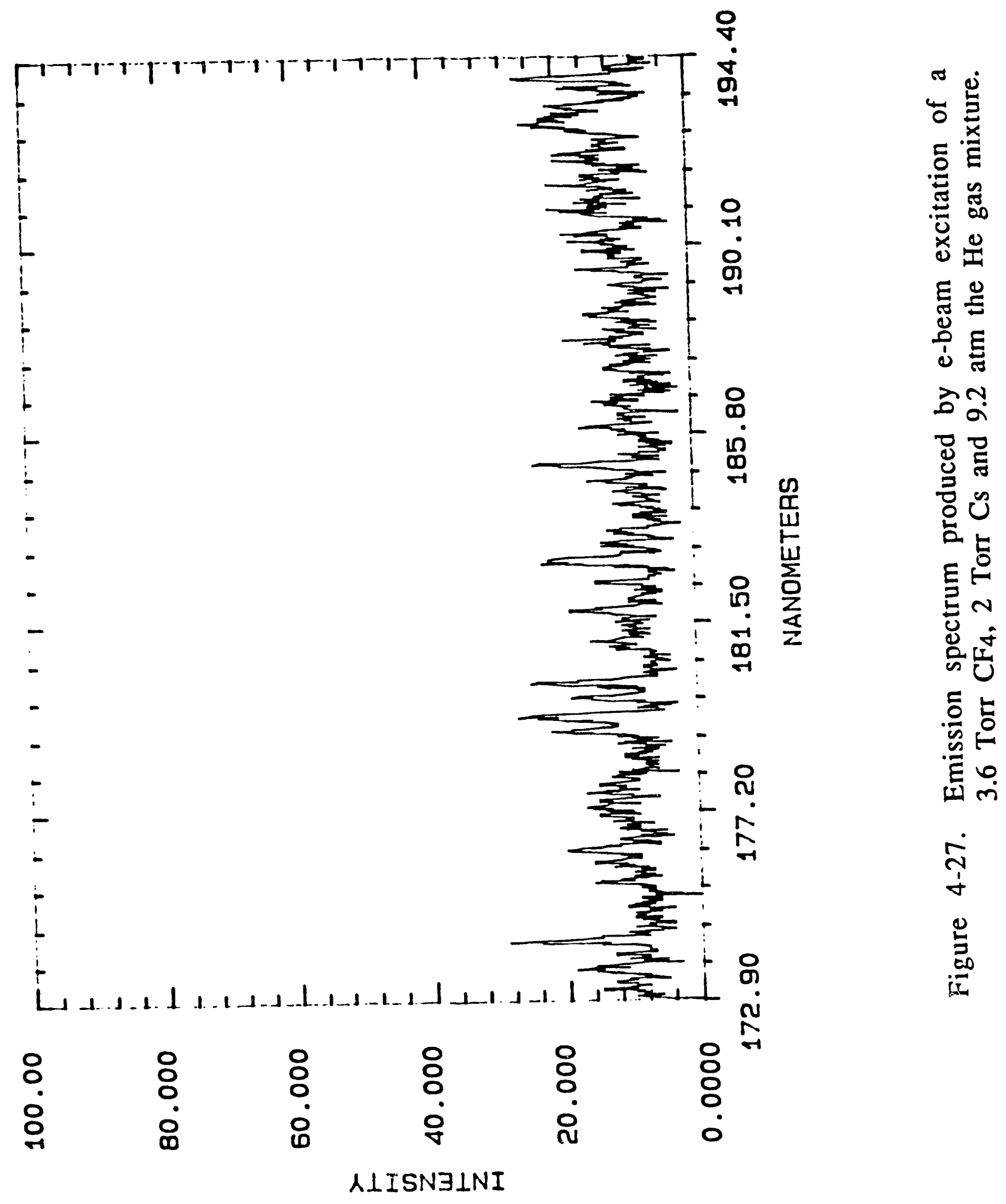




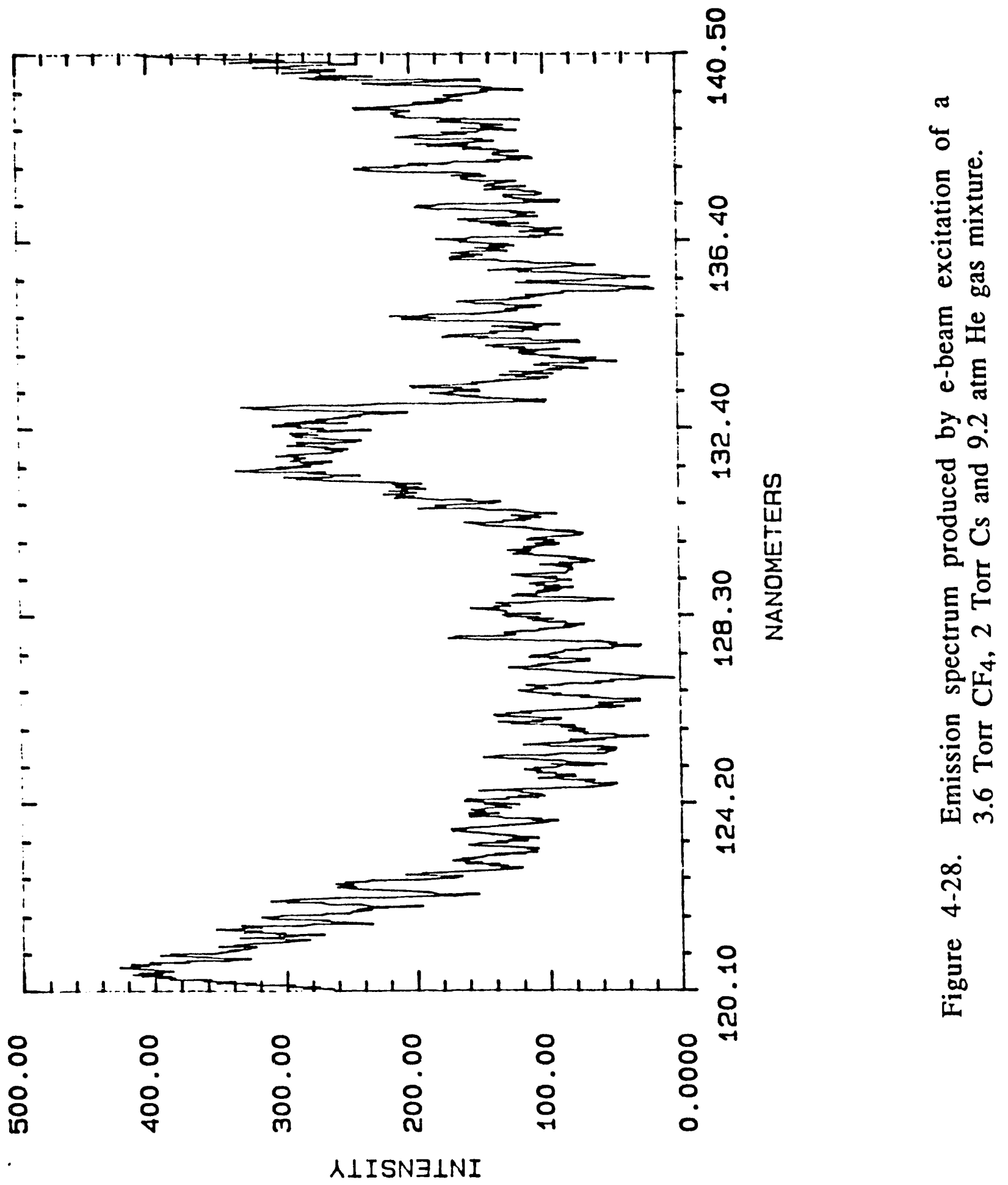




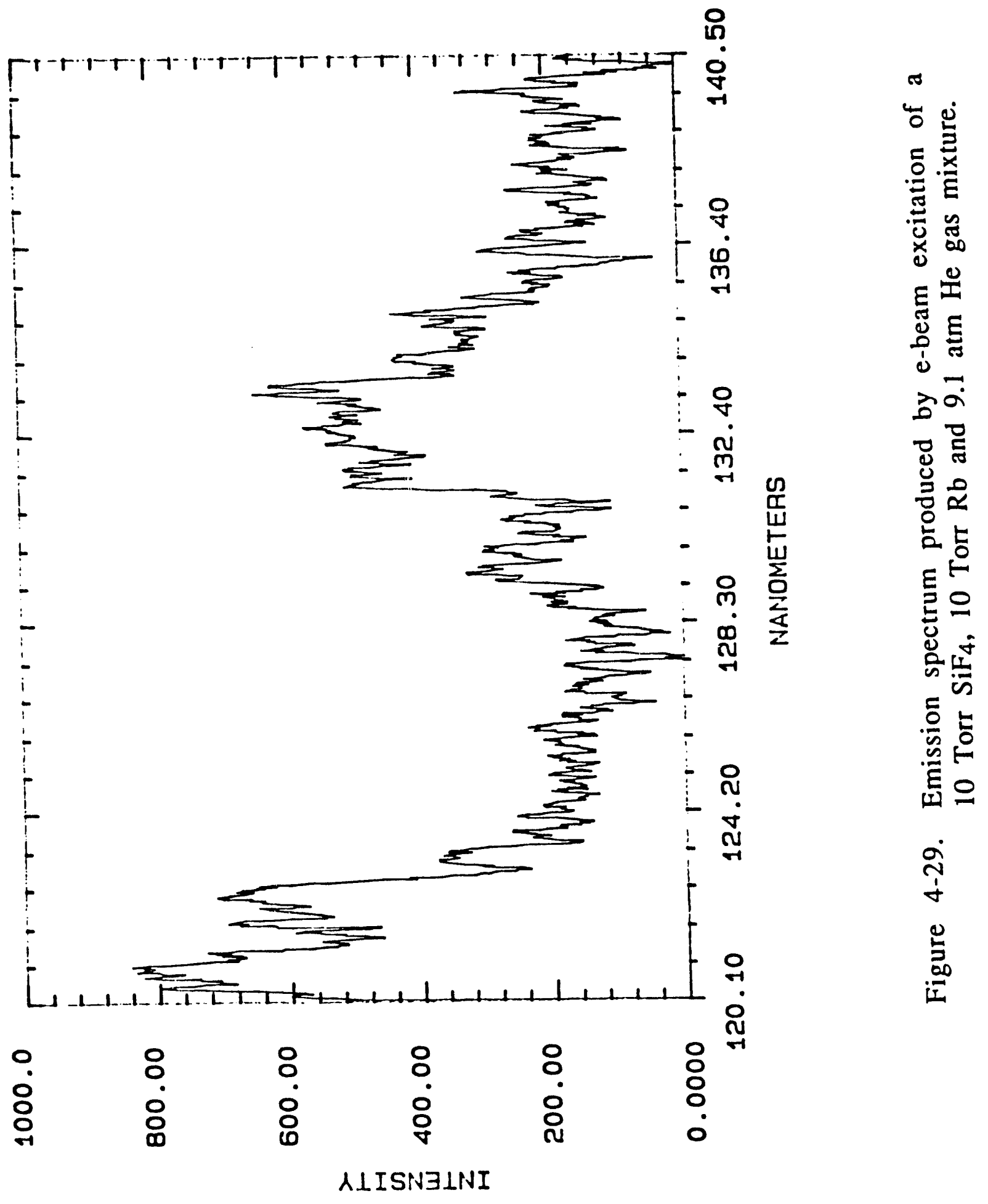


In summary the prospect at a CsF ionic laser appears unlikely due to CsF absorption and $\mathrm{F}$ atom donor absorption. However, $\mathrm{F}$ atom donor and alkali halide absorption does not appear to be as severe a problem for the $\mathrm{Rb}^{2}+\mathrm{F}^{-}$system. But a suitable $\mathrm{F}$ atom donor molecule must be found. 


\subsection{Future VUV/XUV Laser Research Recommendations}

Although the emphasis in this program has been to investigate ionic alkali halide excimers. We also recognize that several other potential candidate molecules are of interest in the development of XUV lasers.

\subsection{Ionic Rare-gas Alkaline Excimers}

It has been proposed in recent papers $8,46,47$ to investigate ionic molecules with the same electron configuration as the well proven neutral rare-gas halide excimers and ras-gas dimers. VUV and XUV transitions have already been observed for the excimers of the alkalihalide ions which are isoelectronic to the neutral rare-gas halides. ${ }^{13-15,36}$

VUV/XUV emissions can also be expected from ionic rare-gas alkali excimers which are isoelectronic to the rare-gas dimers. 46 The upper state is an ionic molecule formed by combining a rare-gas ion $\mathrm{Rg}$ with a ground state alkali atom A. Similar to the rare-gas dimers, the molecule is expected to radiatively decay to the lower state $\mathrm{RgA}^{+}$ correlating to $\mathrm{Rg}+\mathrm{A}^{+}$. Lue to the relatively small binding energies for both the upper and lower states 48,49 , the decay energy is expected to be on the order of the difference in ionization potentials for $\mathrm{Rg}$ and $\mathrm{A}$.

Radiation in the VUV and the XUV has been observed from the ionic states of $\mathrm{Xe}, \mathrm{Kr}$ and $\mathrm{Ar}$-alkali molecules with ion-beam excitation. 50 Using laser produced soft $x$-ray excitation, Millar et al ${ }^{51}$ also observed a distinct emission peak at $165 \mathrm{~nm}$ from an excited $\mathrm{Xe}-\mathrm{Rb}$ vapor mixture.

Recently in the Company sponsored XUV IR\&D Program we have studied the fluorescence from $\mathrm{KrRb}, \mathrm{XeRb}$ and $\mathrm{ArRb}$ ionic states. The emissions are derived from excitation of mixtures of rare-gas and rubidium vapor that are generated in a heat pipe by laser-produced soft $x$-rays. Both the emission wavelength and the corresponding 
emission intensity appear give and promise for the construction of a VUV/XUV laser.

Figures 5-1 and 5-2 show the emission spectra from $\mathrm{KrRb}$ and $\mathrm{XeRb}$ ionic states. Emission peaks at 164 and $134 \mathrm{~nm}$ were observed from $\mathrm{Xe}-\mathrm{Rb}$ and $\mathrm{Kr}-\mathrm{Rb}$ mixtures, respectively. By varying the rare-gas, the wavelengths of the observed emission shifts it appears that they originate from rare-gas rubidium compounds. As in the case of raregas halide excimers, the emission wavelength of rare-gas alkali molecules decreases with decreasing atomic weight of rare-gas. Since the emission only occurs in the presence of $\mathrm{Rb}, \mathrm{Rb}$ must be included in either the excitation process or the emitting compound must contain $\mathrm{Rb}$. The close agreement of the observed emission wavelengths to the wavelengths estimated based on the rare-gas dimer tyme transitions make it likely that $\mathrm{RgRb}$ is the emitter. The $\mathrm{RgRb}$ ionization potential should be nearly the alkali ionization potential. Since the ionization potential of $\mathrm{Rb}$ is $4.18 \mathrm{eV}, \mathrm{RgRb}$ states above $4.18 \mathrm{eV}$ would be expected to preionize. Thus, the fluorescence yield from highly excited neutral molecules is probably very small. Excited molecules emitting VUV radiation must be well above the ionization limit of $\mathrm{RgRb}$ and can preionize rapidly. Therefore, the most likely source of the VUV emission is rare-gas alkali ions.

The key process leading to the formation of the $(\mathrm{RgRb})^{+}$molecule was ascribed by Fielder et $\mathrm{al}^{50}$ and Millar et $\mathrm{al}^{51}$ to be the three body reaction

$$
\mathrm{Rg}^{+}+\mathrm{Rg}+\mathrm{A} \rightarrow \mathrm{Rg}^{+} \mathrm{A}+\mathrm{Rg}
$$

and the decay of the $\mathrm{Rg}^{+} \mathrm{A}$ is expected to proceed by

$$
\mathrm{Rg}^{+} \mathrm{A} \rightarrow \mathrm{Rg}+\mathrm{A}^{+}+\mathrm{hv}
$$

The rate constant $\mathbf{k}$ for the three body reaction is probably greater than $10^{-29} \mathrm{~cm}^{6} / \mathrm{sec}$ based on the $\mathrm{Kr}^{+} \mathrm{Na}$ formation rate estimated by Fielder et al 50 and the $\mathrm{Xe}+\mathrm{Cs}$ formation rate given by Basov et al 47 . Termolecular reaction rate constants ranging in value from $(1-4) \times$ $10^{-31} \mathrm{~cm}^{6} / \mathrm{s}$ for a number of rare-gas ion reactions

$$
\mathrm{Rg}^{+}+\mathrm{Rg}+\mathrm{Rg} \rightarrow \mathrm{Rg}_{2}^{+}+\mathrm{Rg}
$$




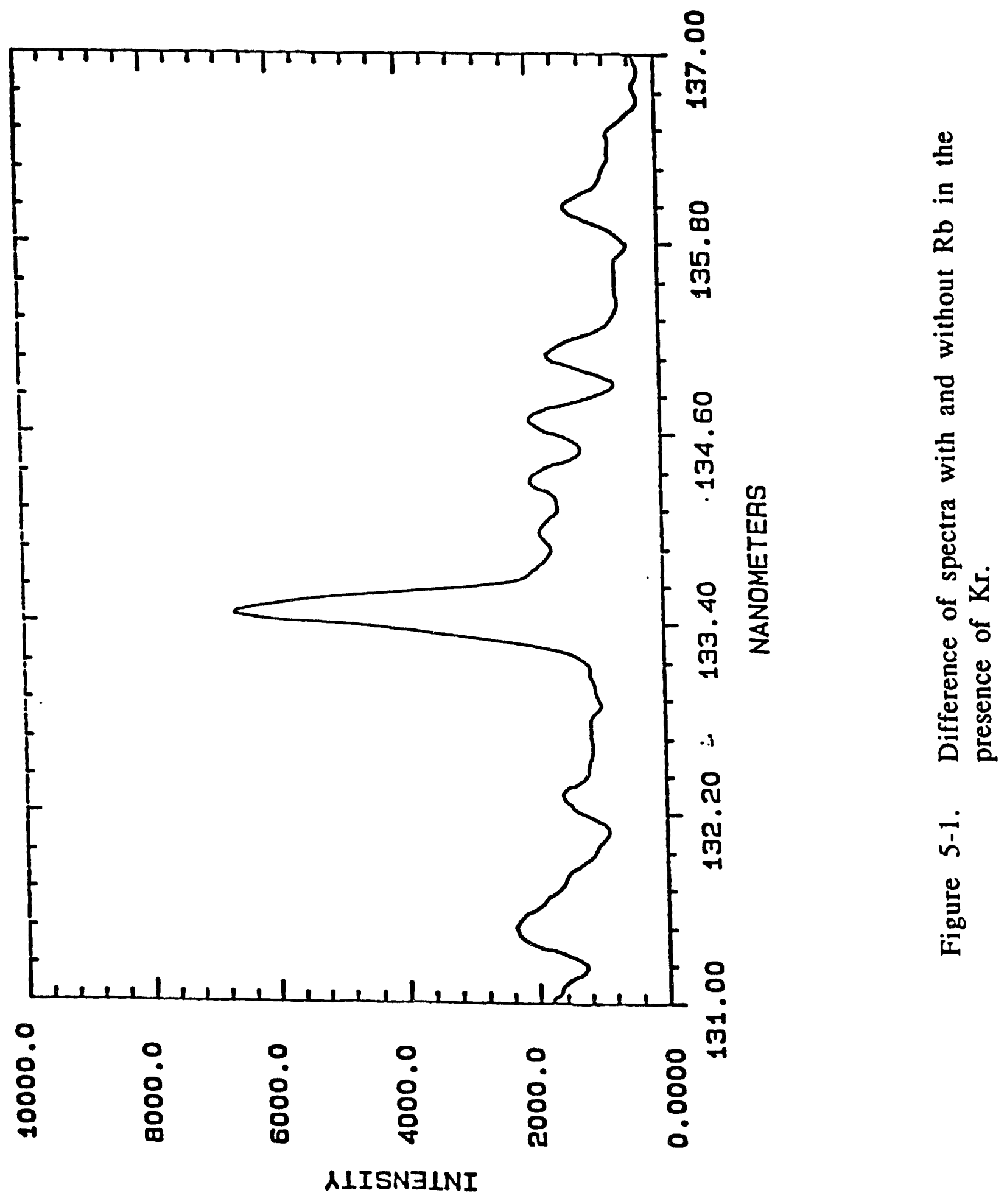




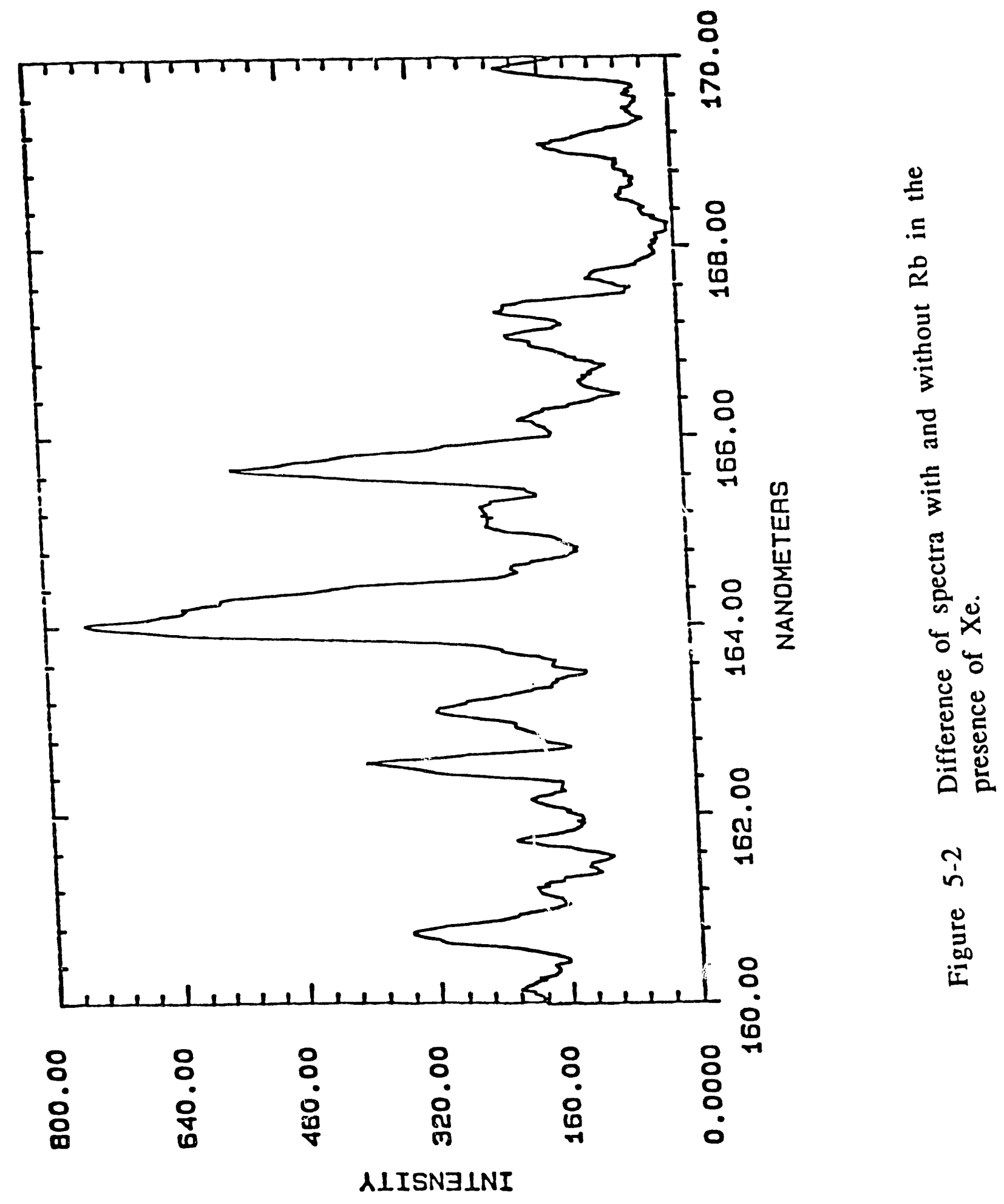


were measured for $\mathrm{Ar}, \mathrm{Kr}$, and $\mathrm{Xe}^{52}$. Therefore, the formation of the ionic rare-gas dimers, $\mathrm{Rg}_{2}{ }^{+}$and the conversion of the $\mathrm{Rg}_{2}{ }^{+}$molecules to the excited rare-gas dimer states, $\mathrm{Rg}_{2}+$ are expected to be insignificant at the pressures used in our study.

Basov et $\mathrm{al}^{47}$ have made a theoretical analysis of the expected lasing efficiency of rare-gas alkali ionic molecules in VUV/XUV in rare-gas alkali mixtures excited by an electron beam. Their calculations show an efficiency of several percent with an achievable gain of $0.01 \mathrm{~cm}^{-1}$ for these molecules. The main kinetic processes involved in the formation and dissociation of $\mathrm{Rg}^{+} \mathrm{A}$ molecules such as $\mathrm{Kr}+\mathrm{Rb}$ produced by electron-beam excitation are given in Table 5-1. The upper active level of $\mathrm{Kr}^{+} \mathrm{Rb}$ can be efficiently populated by processes 3 and 6 .

Reaction 6 is an is an analog of the "harpoon" reaction between alkali metals and halogens. The estimated stimulated emission cross sections for $\mathrm{Xe}+\mathrm{Rb}, \mathrm{Kr}+\mathrm{Rb}$ and $\mathrm{Ar}^{+} \mathrm{Rb}$ are in the range of $1 \times 10^{-16} \mathrm{~cm}^{2}$ and are included in Table 5-2.

The ionic rare-gas alkali molecules, are isoelectronic to the rare-gas dimers. While the lower states in the rare-gas dimers are repulsive, the corresponding $\mathrm{RgA}^{+}$is weakly bound due to the polarization interaction. Their binding energies have been established to be on the order of $0.1 \mathrm{eV}$ from scattering experiments of Radzig48 and Viehland 49 . Since the lower state is only weakly bound, the $R g R b$ ions appear to be promising candidates for XUV lasers. The narrow widths of the observed bands indicate that the radiative transitions terminate in bound state of the lower potentials.

\subsection{XUV Lasers by Quartet to Doublet Energy Transfer in Alkali Atoms}

Recently, Harris et al53,54 identified a subclass of quartet levels in alkali-like atoms or ions which retain metastability against autoionization and radiate quite strongly in the XUV. Because of their metastability against autoionization and their large doublet component, the core-excited quartet levels of alkali-metal atoms are of a great interest to the potential construction of XUV lasers. The unique property of the quasi-metastable levels is that they permit 
Table 5-1

The main processes involved in the formation and Dissociation of $\mathrm{Kr}+\mathrm{Rb}$ molecules

\begin{tabular}{|c|c|}
\hline $\begin{array}{l}\text { No. of } \\
\text { process }\end{array}$ & Process \\
\hline 1 & $\mathrm{Kr}+\mathrm{e}_{\mathrm{p}} \rightarrow \mathrm{Kr}^{+}+\mathrm{e}+\mathrm{e}_{\mathrm{p}}$ \\
\hline 2 & $\mathrm{Kr}+\mathrm{e}_{\mathrm{p}} \rightarrow \mathrm{Kr}^{*}+\mathrm{e}_{\mathrm{p}}$ \\
\hline 3 & $\mathrm{Kr}^{+}+\mathrm{Rb}+\mathrm{Kr} \rightarrow \mathrm{Kr}^{+} \mathrm{Rb}+\mathrm{Kr}$ \\
\hline 4 & $\mathrm{Kr}^{+}+\mathrm{Kr}+\mathrm{Kr} \rightarrow \mathrm{Kr}_{2}^{+}+\mathrm{Kr}$ \\
\hline 5 & $\mathrm{Rb}^{+}+\mathrm{Rb}+\mathrm{Kr} \rightarrow \mathrm{Rb}_{2}^{+}+\mathrm{Kr}$ \\
\hline 6 & - $\quad \mathrm{Kr}_{2}{ }^{+}+\mathrm{Rb} \rightarrow \mathrm{Kr}^{+} \mathrm{Rb}+\mathrm{Kr}$ \\
\hline 7 & $\mathrm{Kr}^{+} \mathrm{Rb}+\mathrm{e} \rightarrow \mathrm{Kr}^{*}+\mathrm{Rb}$ \\
\hline 8 & $\mathrm{Kr}^{+}+\mathrm{e} \rightarrow \mathrm{Kr}^{*}+\mathrm{Kr}$ \\
\hline 9 & $R b 2^{+}+e \rightarrow R b^{*}+R b \longrightarrow R b+R b$ \\
\hline 10 & $K r^{*}+R b \rightarrow R b^{+}+e+K r$ \\
\hline 11 & $\mathrm{Kr}_{2}^{*}+\mathrm{Rb} \longrightarrow \mathrm{Rb}^{+}+\mathrm{e}+\mathrm{Kr}+\mathrm{Kr}$ \\
\hline 12 & $\mathrm{Kr}^{*}+\mathrm{Kr}+\mathrm{Kr} \rightarrow \mathrm{Kr}_{2}^{*}+\mathrm{Kr}$ \\
\hline 13 & $\mathrm{Kr}^{+} \mathrm{Rb} \longrightarrow \mathrm{Kr}+\mathrm{Rb}^{+}+h v_{1}$ \\
\hline 14 & $\mathrm{KR}_{2}{ }^{*} \rightarrow \mathrm{Kr}+\mathrm{Kr}+h v_{2}$ \\
\hline
\end{tabular}




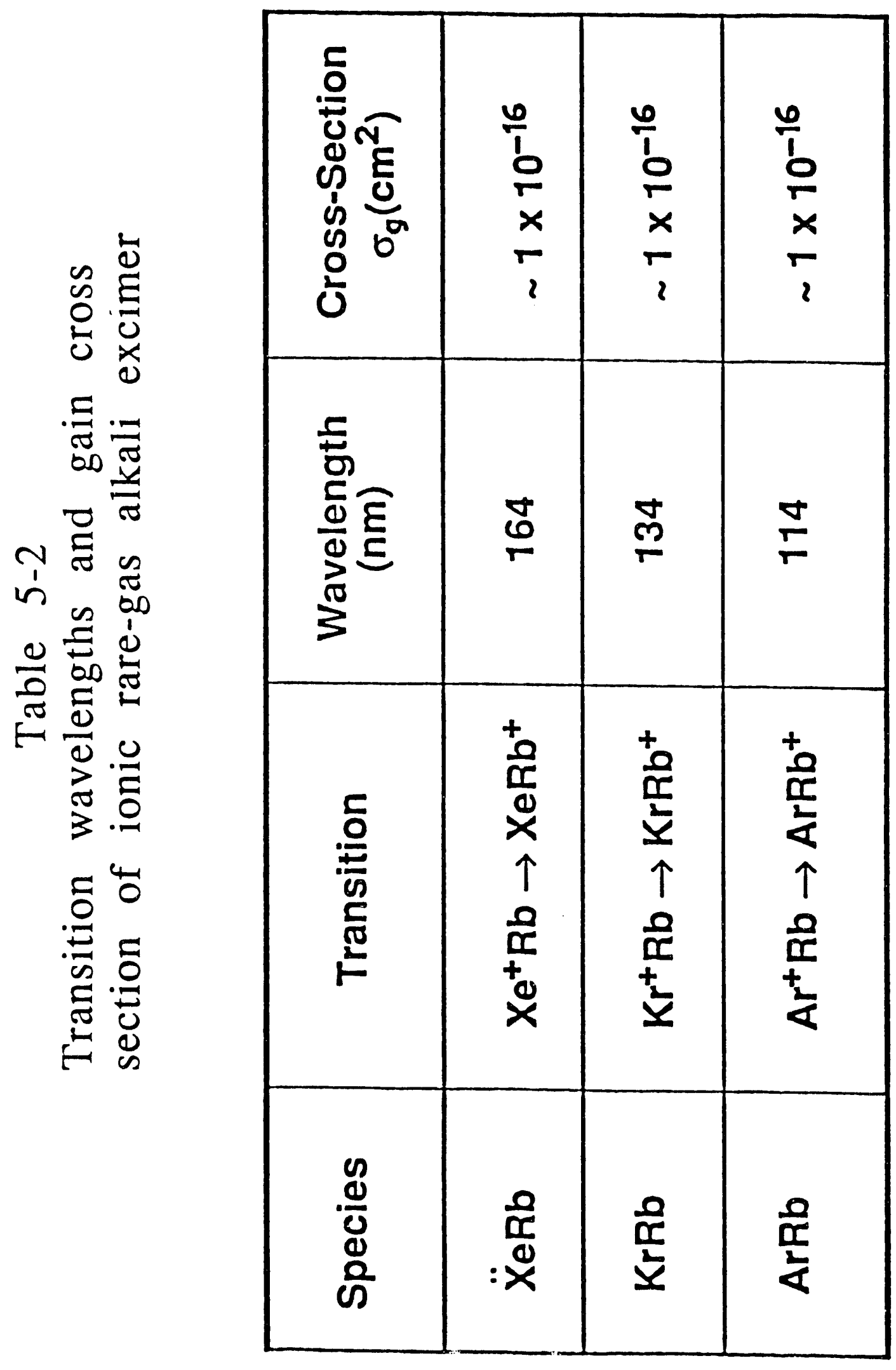


quartet-doublet transfer schemes at large intercombination oscillator strengths and allow efficient emission in the XUV.

Using laser produced soft $x$-ray excitation in the same IR\&D Program we have studied the quartet-doublet transition of potassium atoms. In this study, the heatpipe was operated between $350^{\circ} \mathrm{C}$ to $600^{\circ} \mathrm{C}$ to produced a $K$ vapor pressure of several Torr. Inside the pipe, soft $x$ rays ionize the $K$ vapor, producing inner shell ionized $K^{+}(3 p 3 d 4 s)$, the first by charge transfer and the second by direct electronic excitation. Additionally, collisional excitation with $\mathrm{He}^{+}$may also contribute to the $\mathrm{K}$ quartet population. The emission peak of $72 \mathrm{~nm}$ shown in Figure 53 is believed to correspond to the transition as it is in good agreement with that observed with microwave excitation.

The identification of energy levels and determination of autoionization probabilities and oscillator strengths for quartetdoublet transfers in alkali atoms have proven useful in selection of candidate media for XUV lasers and for calculating relevant laser parameters. The calculated dominant XUV radiation rates, autoionization rates, Doppler widths and stimulated emission cross sections for $\mathrm{K}, \mathrm{Rb}$ and $\mathrm{Cs}$ quartet levels are summarized in Tables 5-3 and 5-452-55. On using soft $x$-ray excitation, we observed an intense emission centered at $72 \mathrm{~nm}$ in potassium. This excitation technique can also be used to study rubidium quartet emission at $82.4 \mathrm{~nm}$. Because of the small energy defects between the $\mathrm{He}$ metastables and the R.b quartet levels, (Figure 5-4 and between the $\mathrm{Ne}$ metasiables and the $\mathrm{Rb}$ quartet states), Figure $5-5$ it is expected that this emission can be efficiently scaled-up using electron beam excitation of $\mathrm{He}-\mathrm{K}$ and $\mathrm{Ne}-\mathrm{Rb}$ mixtures. 


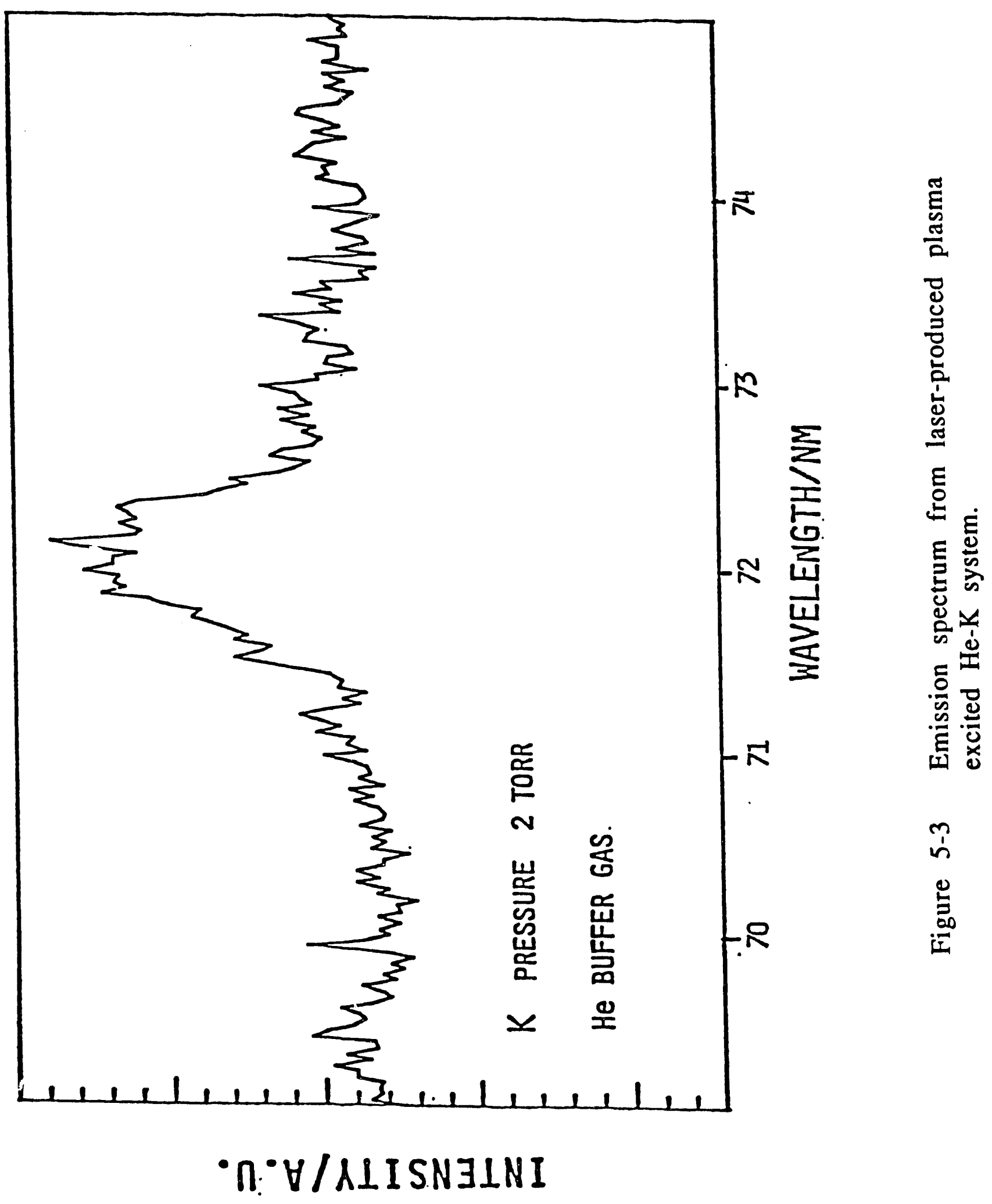




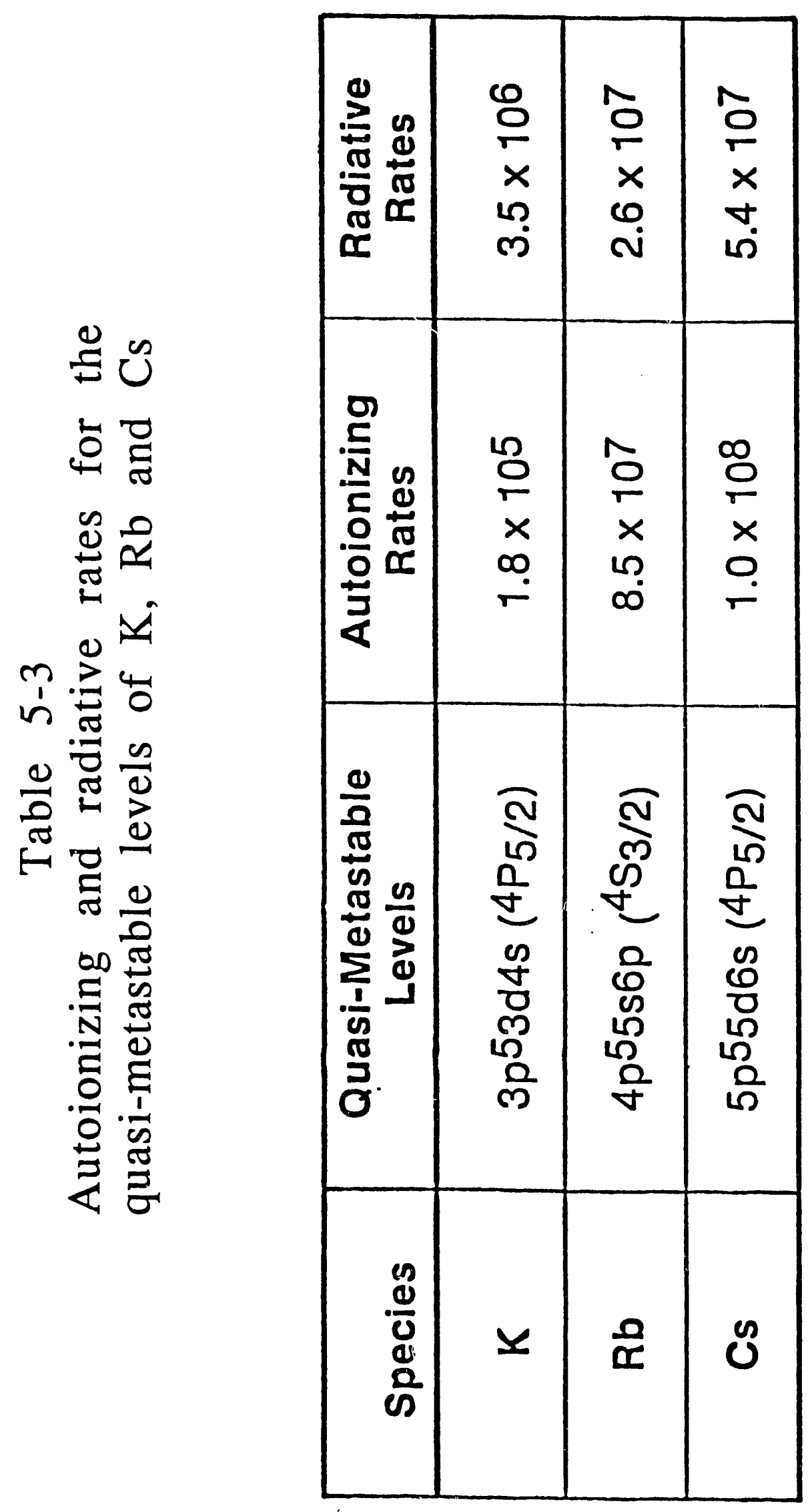




\begin{tabular}{|c|c|c|c|c|c|}
\hline \multirow{5}{*}{ 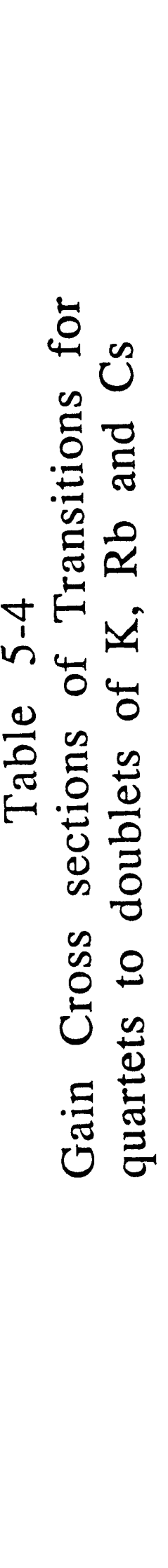 } & 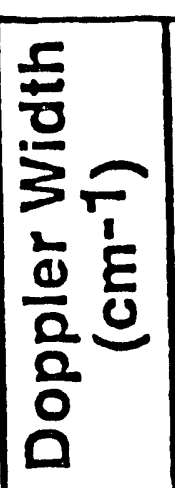 & \begin{tabular}{l}
$\stackrel{9}{+}$ \\
\hdashline
\end{tabular} & $\begin{array}{l}\stackrel{+}{N} \\
\stackrel{0}{ }\end{array}$ & $\frac{n}{0}$ & \\
\hline & 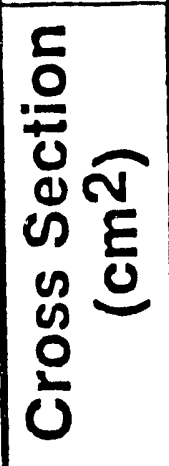 & $\begin{array}{l}0 \\
\frac{0}{b} \\
+ \\
x \\
o \\
\dot{\forall}\end{array}$ & $\begin{array}{l}\frac{2}{5} \\
\frac{1}{2} \\
\times \\
\frac{1}{6}\end{array}$ & $\begin{array}{l}\frac{8}{b} \\
\dot{0} \\
\dot{x} \\
\dot{\sigma} \\
\dot{\forall}\end{array}$ & \\
\hline & 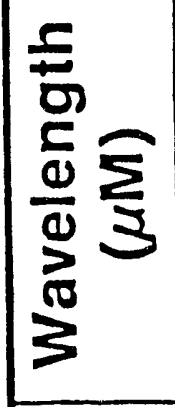 & $\overline{\mathfrak{N}}$ & 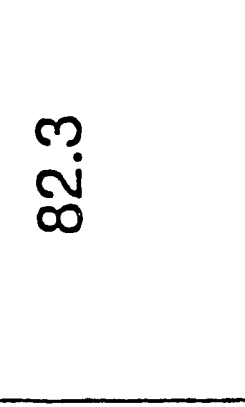 & 횽 & \\
\hline & 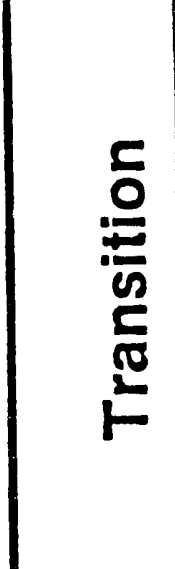 & 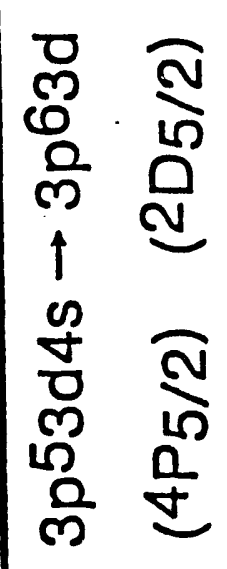 & 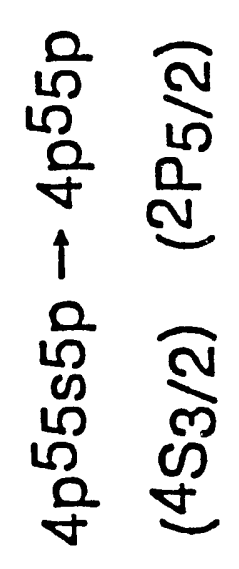 & 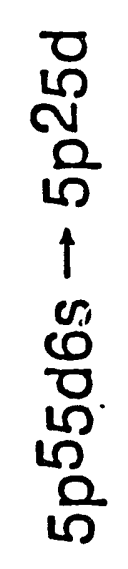 & 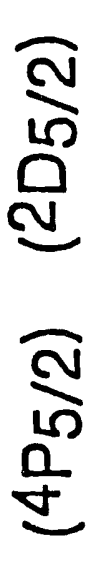 \\
\hline & 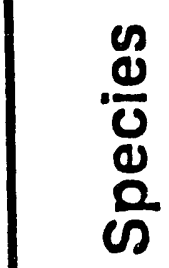 & $\overline{\mathbf{E}}$ & $\bigodot_{0}^{0}$ & $\sum_{\mathscr{U}}$ & \\
\hline
\end{tabular}




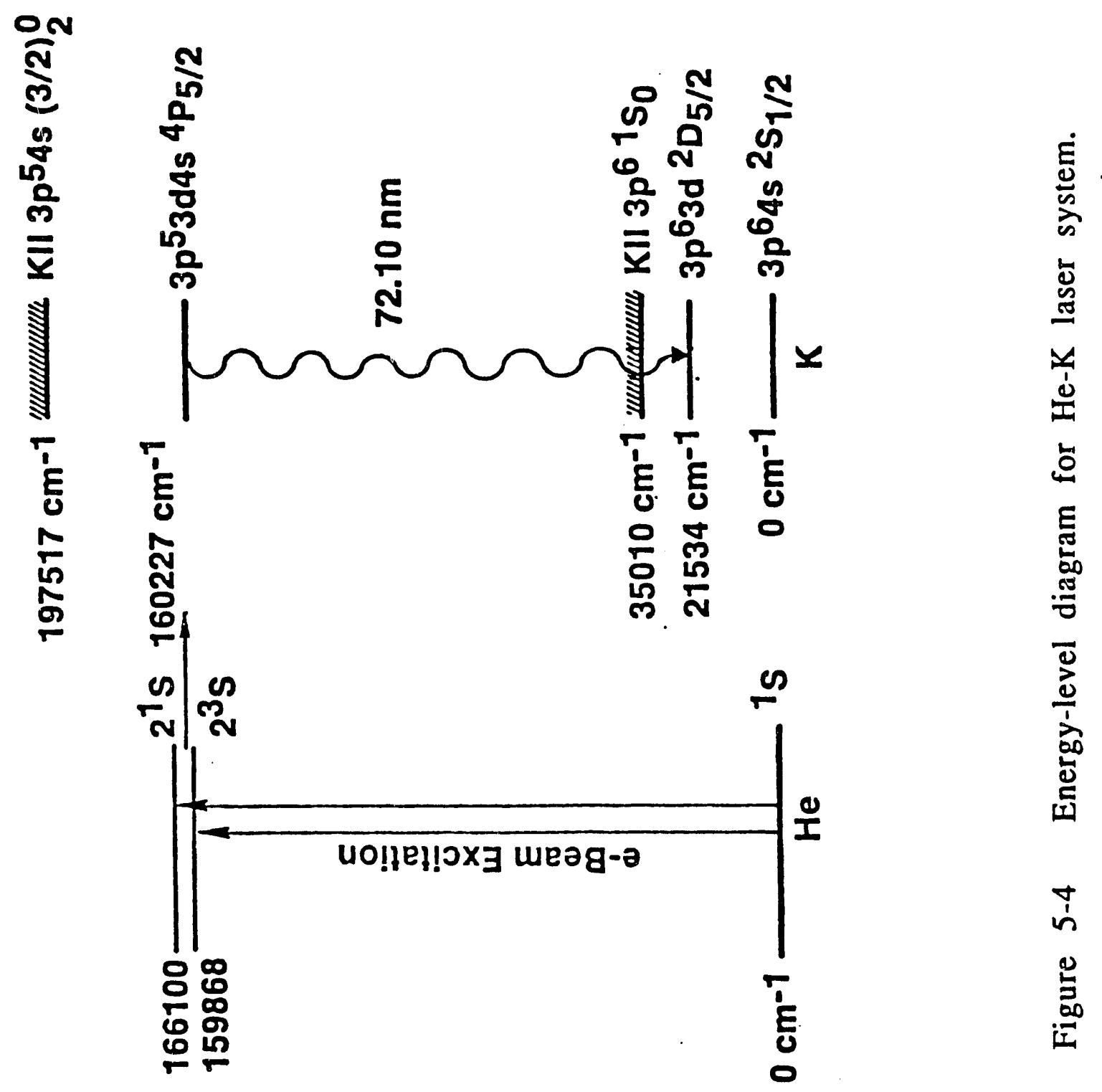



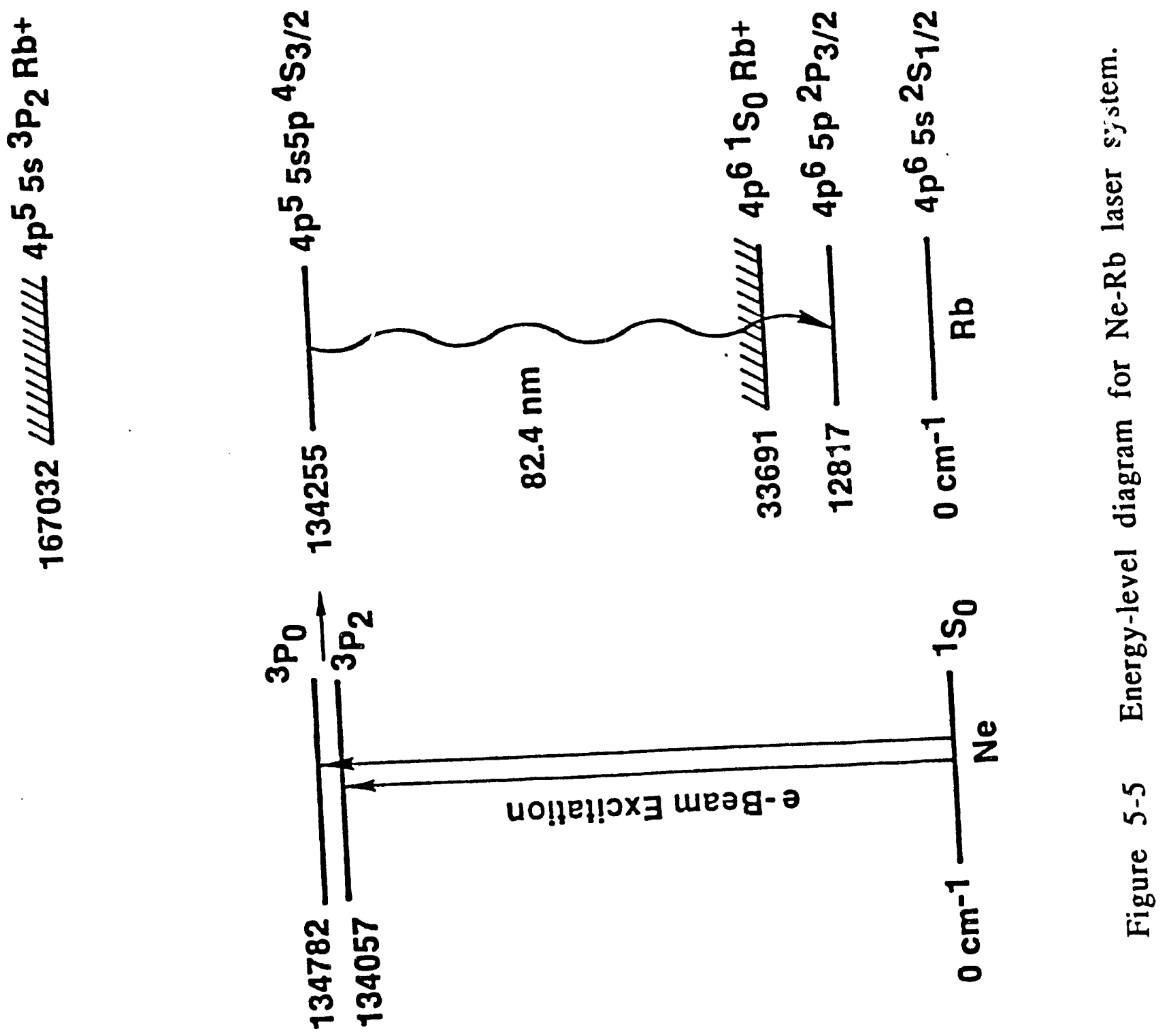


\subsection{References}

1. S. C. Wallace and G. Zdariuk, Appl. Phys. Letter 28, 449 (1976).

2. H. Egger, R. T. Hawkins, J. Boker, H. Plummer, M. Rothschild, and C. K. Rhodes, Opt. Letter 5, 282 (1980).

3. W. Jamarox, P. E. LaRocque, and B. P. Stoicheff, Opt. Lett. Z, 617 (1982).

4. K. D. Bonin and T. J. Mcllrath, J. Opt. Soc. Am. B2, 527 (1985).

5. K. Miyazaki, H. Sakai, and T. Sato, IEEE J. Quantum Electron. QE-22, 2266 (1983).

6. V. O. Papayan, A. E. Martorosyan, and K. Tittlel, IEEE J. Quantum Electron. QE-19, 1835 (1983).

7. G. H. Muller II, D. D. Lowenthal, M. A. DeFaccio, and A. V. Smith, Opt. Lett. 13, 651 (1938).

\&. R. Sauerbrey and H. Langhoff, IEEE J. Quantum Electron. QE-21, 178 (1985).

9. T. T. Yang, J. A. Blauer, C. E. Turne;, Jr., and D. A. Copeland, Proceedings of Lasers in Fluid Mechanics and Plasma Dynamics ÁIAA Journal, 23, No. 5, 741-748 (1985).

10. J. Blauer, T. T. Yang, C. E. Turner, Jr., and D. A. Copeland, Appl. Opt., 23, 4352 (1984).

11. E. S. Rittner, J. Chem. Phys. 19, 1030 (1930).

12. A. A. Abrahamson, Phys. Rev. 178, 76 (1969).

13. F. Steigerwald, F. Emmert, H. Langhoff, W. Hammer, and T. Griegel Opt. Commun. 56, 240 (1985).

14. F. Steigerwald and H. Langhoff, Chem. Phys. $\underline{88}$, 7376 (1988).

15. T. T. Yang, V. T. Gylys and D. G. Harris, J. Opt. Soc. Am. B 6 1536 (1989). 
16. C. K. Rhodes, ed., Excimer Lasers, 2nd ed. (Springer-Verlag, Berlin, (1984).

17. R. G. Caro, J. C. Wang, R. W. Falcone, J. F. Young, and S. E. Harris, Appl. Phys. Lett. 42, 9 (1983).

18. P. Marmier, and E. Sheldon, Physics of Nuclei and Particles. Academic Press, New York and London, 175 (1969).

19. R. D. Evans, The Atomic Nucleus. McGraw Hill, New York (1955).

20. H. Frauenfelder and E. M. Henley, "Subatomic Physics". Prentice-Hall, Inc., Englewood Cliffs, N. J. (1974).

21. E. Schatzlein, W. Walter, R. Sauerbrey, H. Laughoff: Applied Physics B. 27, 49 (1982).

22. J. R. Woodworth, J. K. Rice: J. Chem. Phys., 69, 2500 (1978).

23. C. B. Collins, A. J. Cunningham and B. W. Johnson, "Recombination Laser". Third Semi Annual Report Contract N00014-67-A-0320-0007.

24. H. C. Kapteyn, R. W. Lee and R. W. Falcone, Phys., Rev. Lett., 57, 2939 (1986).

25. H. C. Kapteyn and R. W. Falcone, Phys. Rev. A., 37, 2033, (1988).

26. R. Popil, P. D. Supta, R. Fedosejevs, and A. A. Offenberger, Phys. Rev. A $\underline{35}, 3874$ (1987).

27. J. K. Spong, J. D. Kmetec, S. C. Wallace, J. F. Young, and S. E. Harris, Phys. Rev. Letter. 58, 2631, (1987).

28. R. L. Kelly and L. J. Palumbo, NRL Rep. 7599 (Naval Research Laboratory, Washington, D.C., 1973).

29. J. R. Woodworth and J. Rice, J. Chem. Phys. 69, 2500 (1978).

30. T. H. Dunning, Jr., and P. J. Hay, J. Chem. Phys. $\underline{69,} 134$ (1978). 
31. A. W. Potts, T. A. Williams, and W. C. Price, Proc. R. Soc. London Ser. A 341, 147 (1974).

32. M. Kraus, J. Chem. Phys. 67, 1712 (1977).

33. Y. C. Yu, D. W. Setser, ar,d H. Horiguchi, J. Phys. Chem. 87, 2199 (1983).

34. P. S. Julienne and M. Krauss, Appl. Phys. Lett. 35, 55 (1979).

35. T. T. Yang, Rocketdyne Proposal to U.S. Department of Energy (Rocketdyne Division/Rockwell International, Canoga Park, California 1987).

36. S. Kubodera, L. Frey, P. J. Wisoff, and R. Sauerbrey, Opt. Lett. 13, 446 (1988).

37. F. E. Niles and W. W. Robinson, J. Chem. Phys. 42, 3277 (1965).

38. E. C. Beaty and P. L. Patterson, Phys. Rev., 137, A364 (1965).

39. Electron-Ion Recombination is Gas Lasers, M. A. Biondi, Vol. 3 Gas Lasers Applied Atomic Collision Physics, E. W. McDaniel and W. L. Nighan, Ed., Academic Press (1982).

40. A. V. Phelps, Phys. Rev., 99, 1307 (1955).

41. J. M. Pouvesle, A. Bouchoule, and J. Stevefelt, J. Chem. Phys. 77, 817 (1982).

42. J. M. Pouvesle, J. Stevefelt, and C. B. Collins, J. Chem. Phys. $\underline{82}, 2274$ (1985).

43. J. M. Pouvesle, J. Stevefelt, H. R. Jahani, V. T. Gylys and C. B. Collins, J. Chem. Phys., 83, 2836 (1985).

44. F. Steigerwald and H. Langhoff, J. Chem. Phys. $\underline{88,} 12$ (1988).

45. G. Herzberg, "Molecular Spectra and Molecular Structure Spectra of Diatomic Molecules", Van Nostrand Reinhold Comany. (1950). 
46. N. G. Basov, M. G. Voitik, V. S. Zuev, and V. P. Kutakhov, Sov. J. Quantum Electron, 15, 1455 (1985); Sov. J. Quantum Electron, 15, 1461 (1985).

47. N. G. Basov, M. G. Voitik, V. S. Zuev, A. D. Klementov, V. P. Kutakhov, and S. A. Pendyur, Sov. J. Quantum Electron, 17, 106 (1987).

48. A. A. Radzig and B. M. Smirnov, Chem. Phys. 31, 319 (1985).

49. L. A. Viehland, Chem. Phys., 85, 291 (1984).

50. J. Fiedler, L. Frey, F. Steigerwald, H. Langhoff, T. Griegel, K. Petkau and W. Hammer, Z. Phys. D. 11, 141, (1989).

51. P. Millar, T. Peterson, G. Warwar, P. J. Wisoff, and R. Sauerbrey, Opt. Lett. 14, 171 (1989).

52. High Pressure Ion Kinetics, W. J. Wiegand in Gas Lasers, Vol. 3 Applied Atomic Collision Physics, E. W. McDaniel and W. L. Nighan, Ed. Academic Press, (1982).

53. S. E. Harris, D. J. Walker, R. G. Caro, and A. J. Mendelsohn, Opt. Lett. 2, 168 (1984).

54. S. E. Harris and J. F. Young, J. Opt. Soc. Am., B. 4, 547 (1987).

55. T. T. Yang, D. G. Harris, and V. T. Gylys, Paper WDD31, QELS 1989, April 24-28, 1989, Baltimore, Maryland.

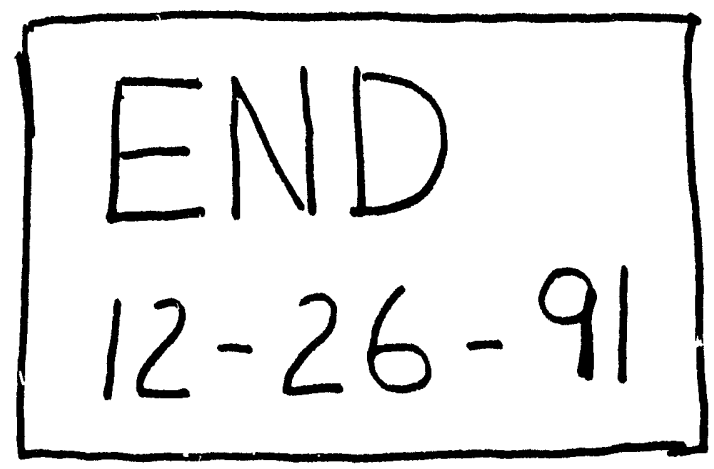

